Illinois State University

ISU ReD: Research and eData

Theses and Dissertations

3-24-2016

\title{
Librarians and Student Affairs Professionals as Collaborators for Student Learning and Success
}

Dallas Long

Illinois State University, dlong@ilstu.edu

Follow this and additional works at: https://ir.library.illinoisstate.edu/etd

Part of the Higher Education Administration Commons, and the Library and Information Science Commons

\section{Recommended Citation}

Long, Dallas, "Librarians and Student Affairs Professionals as Collaborators for Student Learning and Success" (2016). Theses and Dissertations. 519.

https://ir.library.illinoisstate.edu/etd/519

This Dissertation is brought to you for free and open access by ISU ReD: Research and eData. It has been accepted for inclusion in Theses and Dissertations by an authorized administrator of ISU ReD: Research and eData. For more information, please contact ISUReD@ilstu.edu. 


\title{
LIBRARIANS AND STUDENT AFFAIRS PROFESSIONALS AS COLLABORATORS FOR STUDENT \\ LEARNING AND SUCCESS
}

\author{
Dallas Long
}

293 Pages

Increased accountability in higher education is compelling librarians to demonstrate their impact on student learning and student success. To do so, they are encouraged to collaborate with student affairs professionals to improve students' experiences. However, the literature suggests librarians lack formal, structured partnerships with student affairs professionals, and that librarians and student affairs professionals are largely unfamiliar with each other's roles in student learning. They may have narrow or inaccurate perceptions of each other, and lack meaningful ways to collaborate. This study explored librarians' and student affairs professionals' perceptions of each other's roles in student learning and success. Additionally, this study identified opportunities for prospective collaborations and the conditions which impede or facilitate prospective collaboration. By using multiple focus groups in a phenomenological study design and the concept of third-space professionals as a framework, this study described 
the experiences and perceptions of librarians and student affairs professionals at several four-year, residential public universities in Illinois.

KEYWORDS: Collaboration, Focus groups, Librarians, Library, Student affairs 


\title{
LIBRARIANS AND STUDENT AFFAIRS PROFESSIONALS AS COLLABORATORS FOR STUDENT \\ LEARNING AND SUCCESS
}

\author{
DALLAS LONG
}

\author{
A Dissertation Submitted in Partial \\ Fulfillment of the Requirements \\ for the Degree of \\ DOCTOR OF PHILOSOPHY \\ Department of Educational Administration and Foundations \\ ILLINOIS STATE UNIVERSITY \\ 2016
}


Copyright 2016 Dallas Long 


\title{
LIBRARIANS AND STUDENT AFFAIRS PROFESSIONALS AS COLLABORATORS FOR STUDENT \\ LEARNING AND SUCCESS
}

\author{
DALLAS LONG
}

COMMITTEE MEMBERS:

James C. Palmer, Chair

Phyllis McCluskey-Titus

Mohammed Nur-Awaleh

Scott Walter 


\section{ACKNOWLEDGMENTS}

First, I wish to thank my family. Throughout my life - and in particular these past seven years - they supported me, encouraged me, helped me get through the difficult moments, and were there to celebrate my accomplishments. My parents, John and Karen Long, instilled me with the values, confidence, and strong sense of self that have enabled me to pursue my ambitions, nurture my writing, and explore my passions. In particular, I want to thank my mother for the many ways and hours she supported me during my study. I truly wish everyone could have a mother as committed to her child's success as my mother has been to mine.

My husband, Jason, and I kindled our relationship after I had already begun my doctoral studies. He has never known me as a partner not shut away in our home office, toiling away long hours on nights and weekends. Too many times, I put my studies and my dissertation first. He stood with me during all those lonely days and nights. He helped me, too, when I faced great adversity from which I am still physically and emotionally recovering. He encouraged me not to let my accident and subsequent health matters put an end to my years of work toward my doctoral degree, and I persevered. I could not imagine this journey without him. That journey is now coming to an end, and I look forward to this next part of our lives together.

Additionally, I thank my grandmother, Eveline Long, my mother-in-law and father-in-law, and my many friends, who all saw too little of me these past seven years. 
Not least, I thank Jim Palmer, Phyllis McCluskey-Titus, Mohammed NurAlaweh, and Scott Walter. I am grateful for their interest in me and my work and for their insights and the generosity of their time.

D. L. 


\section{CONTENTS}

\section{Page}

ACKNOWLEDGMENTS

CONTENTS

iii

TABLES

\section{CHAPTER}

I. INTRODUCTION 1

Statement of the Problem 4

Background Context for the Study $\quad 5$

Purpose of the Study and Research Questions 8

Overview of the Study Method $\quad 9$

The Conceptual Framework 11

Assumptions and Limitations of the Study $\quad 14$

$\begin{array}{ll}\text { Significance of the Study } & 15\end{array}$

$\begin{array}{ll}\text { Organization of the Study } & 17\end{array}$

II. REVIEW OF THE LITERATURE 19

$\begin{array}{lr}\text { Selection of Sources } & 20\end{array}$

Part I: Overlapping Values 21

Service to Students $\quad 22$

Community Development 23

Equality and Social Justice $\quad 26$

$\begin{array}{ll}\text { Citizenship } & 27\end{array}$

Part II: The Phenomenon of Collaboration in Higher Education 29

Part III: Student Affairs and Other Actors in Collaboration 38

Part IV: Librarians and Other Actors in Collaboration 46

Part V: Librarians and Student Affairs in Collaboration 52 
First-Year Experience $\quad 58$

On-Course 64

Career Preparation $\quad 66$

$\begin{array}{ll}\text { Gap Analysis } & 67\end{array}$

$\begin{array}{lll}\text { III. METHODOLOGY } & 73\end{array}$

Philosophical and Methodological Framework 74

Overview of Focus Groups $\quad 75$

Focus Group Theory $\quad 78$

Strengths and Limitations $\quad 80$

$\begin{array}{lr}\text { Sampling } & 83\end{array}$

$\begin{array}{ll}\text { Recruitment } & 85\end{array}$

Stage 1: Securing Permission from Chief Library and Student Affairs Officers 85

Stage 2: Recruiting Focus Group Participants 87

$\begin{array}{ll}\text { Participants } & 89\end{array}$

Focus Group Procedures $\quad 91$

Data Analysis 93

The Deixis Tool 94

The Vocabulary Tool $\quad 95$

The Intonation Tool 96

The "Why This Way and Not That Way" Tool 96

The Intertextuality Tool 97

$\begin{array}{ll}\text { Trustworthiness of the Study } & 97\end{array}$

Transferability $\quad 98$

Dependability 98

Confirmability 99

Credibility $\quad 99$

Researcher's Subjectivity and Positionality 100

$\begin{array}{ll}\text { Conclusion } & 107\end{array}$

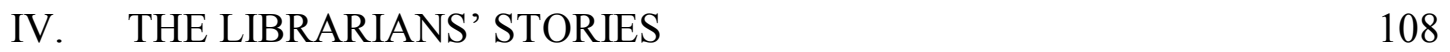

Librarians' Roles 112 
Information Purveyor

Teaching

Community Development

Interactions with Undergraduate Students

Managing Student Employees

Limited Presence in Students' Co-Curricular Activities

Transactional Interactions

The Student Affairs Professionals' Roles

Lack of Familiarity

The Shuffle

"Running a Different University"

Collaboration with Student Affairs Professionals

Mission Confusion

Perceived Lack of Interest from Student Affairs Professionals 153

"The Jenga Pile"

154

Reward Systems

Conclusion

V. THE STUDENT AFFAIRS PROFESSIONALS' STORIES

Student Affairs Professionals' Roles

Holistic Student Development

Institutional Differences in Participants' Interpretations of Roles

Interactions with Undergraduate Students

Student Affairs Professionals as Teachers

Librarians' Roles

Librarians as Educators

"The Invisible People"

Collaboration with Librarians 
VI. THE DIVERGING AND SOMETIMES INTERSECTING WORLDS OF LIBRARIANS AND STUDENT AFFAIRS PROFESSIONALS

Diverging Worlds

Differences in Predominant Roles

Lack of Familiarity, Structural Barriers, and Differing Perspectives on Expertise

Sometimes Intersecting Worlds

Teaching Students Transferable Skills

Descriptions of Student Learning and Success

Perceptions of Librarians' and Student Affairs Professionals' Roles

How Do Librarians and Student Affairs Professionals See Their Work Intersecting?

How Might Librarians and Student Affairs Professionals Approach Collaboration?

Clear Mission and Collaboration as Priorities from

Changed Roles and Identities for Librarians and Student Affairs Professionals

Librarians as Student Specialists

VII. REVISITING THE CONCEPT OF THIRD-SPACE PROFESSIONALS 237 
Knowledges $\quad 242$

Relationships $\quad 246$

Legitimacies $\quad 249$

Conclusion 252

$\begin{array}{lll}\text { VIII. DISCUSSION } & 256\end{array}$

Overview of the Study $\quad 257$

Reflection on the Genesis of the Study 261

Major Findings $\quad 264$

My New Thoughts $\quad 267$

Significance of the Findings 269

Implications for Practice in Higher Education $\quad 270$

Opportunities for Future Research $\quad 274$

$\begin{array}{ll}\text { Conclusion } & 276\end{array}$

$\begin{array}{lr}\text { REFERENCES } & 279\end{array}$ 


\section{TABLES}

$\begin{array}{lll}\text { Table Page } & \end{array}$

1. Characteristics of the Four Participating Higher Education Institutions 88

2. Focus Group Participants 91

3. Librarians at University A 110

4. Librarians at University B 111

5. Librarians at University C 111

6. Librarians at University D 112

7. Student Affairs Professionals at University A 161

8. Student Affairs Professionals at University B 161

9. Student Affairs Professionals at University C 162 


\section{CHAPTER I}

\section{INTRODUCTION}

I read about a project at some university recently where, um, the students that were identified as 'at risk' for failing, like, their first year were required to set up an appointment with their librarian, their advisor, and maybe the writing consultants. I thought that was something cool... like a team of personalized student support services. Is that what student affairs people do? I thought they did basic services. We could try, but I just don't know... [trails off] (Amy, librarian, University A)

We had somebody from the library come present to the career center two and a half years ago, maybe, on some great resources they had for students searching for careers. But we got busy and just dropped the ball on that. That could be a great way that we could be working with them. Until we had this conversation, I never thought that perhaps it would be good for the career advisors to reach out... But I'll be honest, I just never really think about the librarians as partners in helping students succeed. They've always seemed more like book-pushers literally - than really focused on helping students. (Jack, student affairs professional, University B)

The quotations above demonstrate academic librarians and student affairs professionals are not very familiar with each other's roles or work. In light of the many calls for academic affairs and student affairs to work together to create seamless learning environments for students, librarians and student affairs professionals are two groups that have yet to seriously explore collaborations that improve the student experience. Tinto (1987) theorized that student success - or persistence to graduation - is most favorable when students' intellectual endeavors and social experiences are tightly integrated. Additionally, Kuh (1996) proposed students learn best in "seamless" learning environments, in which the curricular goals of higher education institutions and students' 
experiences outside the classroom are interwoven and facilitate students' cognitive, psychosocial, and identity development. The Powerful Partnerships report contends that when the domains of student affairs and academic affairs work together, significant progress is made towards student learning and, as a result, student persistence (American Association for Higher Education, Task Force on Student Learning, 1998). Consequently, many faculty members and student affairs professionals and have heeded the call and engaged in collaborations that enrich the student experience.

However, relatively few librarians and student affairs professionals have partnered to find ways to advance student learning and success. At first, librarians and student affairs professionals may not appear to share common purposes and goals. Librarians collect, preserve, and disseminate knowledge while almost invariably working within the framework of a library. Student affairs professionals help students navigate and adjust to campus environments. They tend to students' advising, housing, recreation, and health needs, among other areas.

Yet both groups of professionals are integral to student success and are as focused on student learning as the English professor who strives to improve students' writing skills. Librarians and student affairs professionals shape student learning and development outside of the traditional classroom environment. Librarians teach information literacy and critical thinking skills that influence students' cognitive development. They influence the campus climate by designing libraries that are dynamic learning spaces and by crafting collections that support curricular needs and reflect students' interests and identities. Similarly, student affairs professionals guide students' cognitive, ethical, psychosocial, and identity development through their counseling of 
students in crises and through their instilment of citizenship, diversity, and leadership skills. Additionally, they contribute to how students experience the campus climate by interpreting student culture, advocating for students, facilitating discussions with student groups, and remedying conflicts.

While relatively few examples of collaboration between librarians and student affairs professionals are detailed in the scholarly and professional literature, both groups stand to improve student learning and student success by working together. For example, career services counselors are concerned that students lack knowledge of the industries and employers with whom they interact at career fairs (Ledwith, 2014). Their lack of preparation leaves employers with poor impressions of the students and missed opportunities for formal job interviews (Ledwith, 2014). Librarians teach students research skills and information literacy as part of higher education instititions' established curriculum, while career services counselors help students think about career paths and interviewing skills. By partnering together, librarians could teach students to apply their information-seeking skills to researching careers and prospective employers, providing the students with better-informed information prior to interviews, while the career services counselors could gain deeper familiarity with the resources librarians make available for students to research different careers and employment sectors. As a result of the collaboration, students may benefit by being better prepared at career fairs and making favorable impressions on employers. Opportunities for collaboration between student affairs professionals and librarians are potentially rich and offer the promise of improved student experiences. 
I propose that understanding librarians' and student affairs professionals' perceptions of their own and each other's roles in student learning and success is a key to identifying opportunities for prospective collaboration between the two groups and to identifying the conditions which impede or facilitate prospective collaboration. Using focus groups, I spoke with 23 librarians at four higher education institutions and 14 student affairs professionals about these perceptions. Their responses provided insight into the diverging and intersecting areas of librarians' and student affairs professionals' work and the feasibility of collaboration between these two professional groups.

\section{Statement of the Problem}

Although librarians and student affairs professionals have common ground on which to base potential collaborations and partnerships, relatively little collaboration seems to have taken place (Hinchliffe and Wong, 2012; Swartz, Carlisle, \& Uyeki, 2007). When librarians and student affairs professionals have undertaken attempts at collaboration, many of these collaborations are reportedly not successful and do not persist (Strothman \& Antell, 2010). In Arcelus' (2008) and Kezar and Lester's (2009) studies of successful collaboration between interdisciplinary groups, perceptions influence the willingness and ability of different professional groups to work together. In order for a collaboration focused on improving the student experience to be successful, actors must have a shared understanding of student learning and an appreciation for the expertise that each group brings to the collaboration (Kezar \& Lester, 2009). Therefore, an important concern for building successful collaborations between librarians and student affairs professionals is ensuring that both groups have insight into each other's 
expertise and then find value in the contributions each could make to improving student learning and student success.

However, the literature suggests librarians' and student affairs professionals' perceptions of each other are not well understood. Tenofsky (2007) and Walter (2007) claim librarians and student affairs professionals are largely unfamiliar with each other's work and do not understand how each contributes to student learning and to student success. In the relatively few case studies of collaborations, only the librarians' voices are heard (Aguilar \& Keating, 2009; Elguindi \& Sandler, 2013; Lampert, Dabbour, \& Solis, 2009). The student affairs professionals' contributions and perspectives are almost entirely unknown. This study addresses the question of how librarians and student affairs professionals view the other and what their perceptions might mean for potential collaborative ventures between the two groups. With this study's findings, librarians, student affairs professionals, and other educators will develop insights into whether and how successful collaborations to improve the student experience may be approached.

\section{Background Context for the Study}

Kuh (1996) proposed that students perceive their educational experiences as disjointed and unconnected. When students are able to bridge their curricular and extracurricular learning experiences, they are able to apply critical thinking skills to their social and personal lives and make better informed decisions and display greater autonomy and competence (Kuh, 1996). Similarly, students are able to apply lessons learned from their extracurricular experiences to complex problem-solving and collaborative work in their classroom experiences. Consequently, Kuh (1996) argued 
that student affairs and academic affairs must forge collaborations to bridge the divide between students' classroom and out-of-class experiences.

Pascarella and Terenzini (2005) proposed that students' development and learning are affected by the frequency, content, and quality of their interactions with faculty. Tinto (1987) claimed that students persist to graduation at greater rates when they integrate socially and intellectually with the culture of the campus. Accordingly, student affairs professionals have partnerships with faculty members to promote such learning environments. Many of these partnerships are highly structured and formal in design, ranging from faculty involvement in living-learning communities in residence halls, through faculty-in-residence programs, to first year experience programs (Streit, Dalton, \& Crosby, 2009).

However, librarians are largely absent from these structured, formal partnerships with student affairs professionals (Walter, 2009; Hinchliffe \& Wong, 2012). Moreover, the library profession is experiencing profound changes: Student behavior, modes of research, learning styles, and technology are rapidly transforming expectations of librarians and libraries. In 2010, the Association of College and Research Libraries issued The Value of Academic Libraries as a response to growing calls in higher education for libraries to demonstrate their importance to student learning. In the report, Oakleaf (2010), stated:

$[\mathrm{P}]$ arents and students expect [libraries] to propel students into successful careers with high earning potential, and the general public expects [libraries] to change lives...these constituents expect libraries to achieve these goals but to also demonstrate evidence of doing so. (p. 4) 
Oakleaf (2010) proposed the most effective ways librarians could demonstrate their success are by increasing their impact on student persistence, on academic performance, and on student learning inside and outside of the classroom. If librarians are now asking "How are students changed by the library and by librarians?" they must look towards other groups in higher education for guidance. Oakleaf offered no road map for librarians but encouraged librarians to move outside the confines of the library and to collaborate with those who are most deeply engaged in student persistence and student learning outside of the classroom - namely student affairs professionals.

Although collaborations between librarians and faculty members are plentiful in higher education literature, collaborations between librarians and student affairs professionals are relatively scarce and less explored (Hinchliffe \& Wong, 2012; Swartz, Carlisle, \& Uyeki, 2007). All of the literature is written by and for practitioners, and virtually all of it from librarians' perspectives. Why have librarians and student affairs professionals not yet embraced each other as partners in student learning and success?

Walter (2007) proposed student affairs professionals and librarians are generally not aware of each other's educational roles. However, librarians and faculty members are better acquainted with each other's respective roles because of librarians' close support of the curriculum and of faculty research endeavors. At higher education institutions where librarians hold faculty rank and status, librarians and faculty members also participate together in tenure and promotion deliberations and in campus governance (Walter, 2007). On the other hand, student affairs professionals and librarians are arguably less visible to each other. Moreover, student affairs professionals and librarians appear to have narrow understandings of each other's domains. Student affairs professionals view librarians as 
largely concerned with the custody of books and journals and rarely willing or able to engage with students outside the library, whereas librarians consider student affairs professionals to be "babysitters" concerned with student entertainment and discipline and also possibly lacking in the academic rigor necessary to shape students' cognitive development (Tenofsky, 2007).

Finally, studies on interdisciplinary collaboration suggest that perceptions matter greatly. For collaborations between different groups to be successful, both groups must have common philosophical ground and a deep appreciation for the knowledge, skills, and expertise that each brings to the collaboration (Arcelus, 2008; Kezar, 2006; Kezar \& Lester, 2009). Therefore, explorations of librarians' and student affairs' perceptions of each other are crucial so each group can develop keener insight into the common values and philosophies they share and to craft successful, long-lived collaborations that improve the student experience.

\section{Purpose of the Study and Research Questions}

Librarians and student affairs professionals do not appear to be deeply familiar with each other's educational roles. Therefore, the purpose of this study was to explore librarians' and student affairs professionals' perceptions of each other's roles in student learning and success, to identify opportunities for prospective collaborations, and to identify the conditions which impede or facilitate prospective collaboration. The following research questions guided the study:

- How do librarians and student affairs professionals describe student learning and student success? 
- How do librarians and student affairs perceive their own roles and each other's roles in student learning and student success?

- Where do they see the work of librarians intersect, if at all, with the work of student affairs professionals?

- How might they approach collaborations in these intersecting areas?

- How might the work and identities of librarians and student affairs professionals change because of these collaborations?

\section{Overview of the Study Method}

The study employed a qualitative, phenomenological research design, which is appropriate for probing the meaning that participants attach to certain situations and problems (Creswell, 2009). In this case, focus groups were utilized to provide rich descriptions of how librarians and student affairs professionals understand and explain their own and each other's roles in student learning and success, and how they might collaborate with each other in ways that benefit students. Focus groups are especially effective when the topic of the study concerns group interaction. This study was concerned with collaboration, which certainly requires one or more actors working together to create meaningful experiences for the benefit of students. Morgan (2002) suggested interviews in a group setting allow researchers to observe how and why individuals accept or reject others' ideas, which is critical when the explored topic concerns collaboration, partnerships, or other activities in which individuals must have a shared vision or sense of purpose. 
I drew the sample of focus group participants from four higher education institutions within the state of Illinois. The institutions selected for the study represented a range of institutional types in the state, including size of student enrollment and private or public in character, as denoted by Carnegie classification. Participants in the study were librarians and student affairs professionals employed full-time at those four higher education institutions and who had been employed in their respective field for three or more years. In all, I conducted seven focus groups, involving 23 librarians and 14 student affairs professionals. I held focus groups for the librarians and for the student affairs professionals separately. At each focus group meeting with librarians, I asked the following questions as my interview protocol:

- What do you perceive to be the role of librarians at this institution?

- Tell me about your interaction with undergraduate students. How do librarians here interact with students and for what purposes?

- Let's turn our discussion to student affairs professionals. What do you perceive to be the role of student affairs professionals at this institution?

- Do librarians at this institution interact with or collaborate with student affairs professionals? If so, tell me about those interactions or collaborations.

- What other observations or insights about our discussion today might you wish to share?

The interview protocol for student affairs professionals was the same but transposed student affairs professionals for librarians. Gee's (2011) theory of discourse analysis served as the framework for data analysis and interpretation. I coded the transcripts of the focus groups using Gee's (2011) deixis, vocabulary, intonation, “why 
this way and not that way," and intertexuality tools. A number of different provisions aided the study's trustworthiness, including testing the interview protocol, triangulation of sites, member checking and confirming my findings with the participants in two webinars, and a description of the researcher's background and positionality.

\section{The Conceptual Framework}

Because the study ultimately explored perceptions of professional identity, Whitchurch's (2010) concept of third-space professionals was employed as the underpinning framework. Whitchurch (2008) argued that three categories of people are typically employed at higher education institutions: faculty or instructional staff who engage in teaching, research, and service; support staff who perform largely clerical duties or manual labor; and professional staff who attend to the institutions' needs for professional services. Whitchurch (2010) proposed professional staff are increasingly responsible for student learning and postulated that a "third space" has emerged between the professional and the academic domains:

[T]he blurring of boundaries between functional areas, professional and academic activity, and internal and external constituencies have contributed to the creation of a third space between the professional and the academic. In this space, the concept of non-instructional staff has become reoriented towards one of partnership with academic colleagues and the multiple constituencies with whom institutions interact (p. 378).

Whitchurch (2008) developed her concept based on a qualitative study of 54 professionals employed at $12 \mathrm{UK}$ and US higher education institutions. The institutions varied in missions, size, history, and teaching and research orientations. Her participants 
included accountants, human resources officers, student services staff, and public relations officers. Whitchurch determined that some participants were bounded professionals; their professional activities were limited to the scope of their position descriptions and, in essence, practiced their craft within the context of higher education. These bounded professionals were predominantly in roles such as human resources officers, accountants, and public relations officers and rarely interacted with students in the course of their duties.

Other participants were cross-boundary: They assumed some responsibility for teaching and student learning outside the classroom. This assumption of responsibility appeared to be the participants' individual choice and was largely circumstantial, such as volunteering to facilitate first-year experiential courses for supplementary stipends (Whitchurch, 2008). Blended professionals saw teaching and student learning as distinctly within their purview, and the practice of their profession was largely shaped by this belief. Student services staff and librarians were among the blended professionals, regardless of institution or institutional type (Whitchurch, 2013). They occupied the "third-space," in which professional identity coalesced with those of their faculty colleagues (Whitchurch, 2008).

Whitchurch's (2008) findings suggested that professional staff are differentiated in their professional identity according to their function, and "blended professionals" perform roles that marry professional services with teaching or student development components. Blended professionals have a sense of simultaneously "belonging and not belonging entirely to either professional domains or academic domains" and "working in 
ambiguous conditions with a multi-layered reality of the academic enterprise" (Whitchurch, 2009, p. 408).

Within her conceptual framework of third-space professionals, Whitchurch (2013) expanded her prior study on blended professionals to a much larger phenomenological study in order to understand how blended professionals make sense of their identity and work lives. Whitchurch (2013) employed four research questions (paraphrased): How do they understand their work? What is the "space" they fill in their institutions? How do they perceive themselves? How do faculty and administrators perceive third space professionals?

Applying social capital and actor-network theories as frameworks to interpret participants' stories, Whitchurch (2013) proposed four dimensions of third-space professional identity. In the spaces dimension, blended professional staff recognize the multiple realities of their institution, the ambiguity of their working conditions, and redefine physical, virtual, and cognitive spaces that are "safe" and accommodate the duality of the professional and academic identities (p. 11). In the knowledges dimension, blended professional staff integrate their professional and academic knowledge into theory-to-practice. In the relationships dimension, they experience weakening ties to the professional bodies that exist outside of higher education and fashion strong alliances to new networks that support their work. Their ability to achieve credibility with faculty members and to challenge the status quo concerns the legitimacies dimension.

Whitchurch's (2010) concept of third-space professionals is an appropriate lens with which to explore the research problem. At its heart, third-space professionals emphasize the themes of professional identity and identity tension. Becher and Trowler's 
(2001) study of the cultures of academic disciplines serves as a framework for many investigations of academic identities. Indeed, their study has proven helpful for understanding the barriers that impede interdisciplinary collaboration among faculty members (Arcelus, 2008; Kezar \& Lester, 2009). However, Whitchurch’s (2010) concept of third-space professionals may prove more helpful because it specifically explores the professional identities of staff who do not belong to the professoriate and are not encumbered by the barriers to collaboration that Becher and Trowler (2001) identified, such as inflexible reward systems that prize peer-reviewed publications, among others. Rather, Whitchurch's (2010) concept of third-space professionals explores how blended professionals navigate spaces, relationships, and territories that bring them out of their traditional roles and allow them to forge new alliances that integrate the institutions' needs for services with an educational component oriented toward student growth and learning. This emphasis on identity tension is crucial to the study, as the definition of collaboration pursued here relies upon the creation of something new that changes the way collaborators work and view themselves and their roles rather than merely a collaboration that relies on a co-location of services.

\section{Assumptions and Limitations of the Study}

I assumed that librarians and student affairs professionals both have reason and desire to collaborate in order to enhance student learning and success. This assumption guided my interest in this topic and my exploration of the study. However, this assumption could prove false or weak. I also assumed the librarians and student affairs professionals included as study participants have sufficient prior knowledge and 
experience of traditional-aged, residential undergraduate students in order to have formed opinions about student learning and success.

In addition, readers should be aware of several study limitations. First, this study focused on small groups of librarians and student affairs professionals at several higher education institutions in Illinois. It was intended to be an initial exploration of the topic and not a comprehensive study. A second limitation of the study is that participants were recruited via purposeful sampling, which could have lead to the sample not being representative of their respective populations. The study relied upon data reported by participants directly, and participants' stated experiences and perceptions may not accurately reflect the reality of their situations. Participants tend to overstate their own comprehension and overestimate their skills and abilities, so the participants' beliefs about their impact on student learning and success or on collaboration generally may not be accurate (Suskie, 2009). Lastly, the study's trustworthiness depended partly upon the opportunity to confirm my interpretations of the focus group discussions and my conclusions with participants in at least one of two webinars I held several months following the focus group meetings. Only a few of the participants took part in the webinars, thereby limiting the confirmability.

\section{Significance of the Study}

As librarians respond to the profession's call to demonstrate their impact on student learning and success by partnering with student affairs professionals, they must develop greater awareness of the expertise of student affairs professionals and envision new ways of working together. However, the literature suggest librarians have little awareness of student affairs professionals and vice versa. When librarians and student 
affairs professionals are aware of each other, the literature indicates they may hold unfavorable or inaccurate perceptions of each other's roles in students' lives and may not fully appreciate their own capabilities in enriching students' experiences outside of their traditional settings and responsibilities. Additionally, student affairs professionals' voices are almost entirely lacking in librarians' depictions of the few collaborations treated in library literature, and often librarians concede these collaborations have uncertain futures. It is difficult to discern what roles student affairs professionals have played in such collaborations, aside from guarantors of space and access to students.

This study is significant because it is the first study that explored librarians' and student affairs professionals' perceptions of each other's roles in student learning and may have provided each other with a stronger, more accurate understanding of the complexity of each other's roles and strengths that they could bring to prospective collaborations. Additionally, the study helped identify possible ways librarians and student affairs professionals could collaborate to advance student learning and success in ways that are deeper than co-location of services. In practical contexts, readers of this study are likely to be scholars and practitioners of librarianship and student affairs, and these groups will benefit from greater understandings of each other's work.

Collaborative experiences will benefit the librarians and student affairs professionals as individuals as well as ultimately the students. Although student affairs professionals are certainly educators, Moore and Marsh (2007) describe student affairs as teaching from "afar" by creating environments and experiences for students (p. 7). Moore and Marsh (2007) advocated for student affairs professionals to adopt a stronger teacher identity rather than an educator identity and to design individual interactions with 
students to develop students' cognitive and psychosocial skills. Librarians have expertise in curriculum design and teaching activities, which they could transfer to student affairs professionals so that student affairs might create more intentional teaching moments. At most higher education institutions, librarians belong to academic affairs; perhaps by working more closely together, student affairs professionals will forge stronger connections with other faculty as well. Finally, student affairs professionals might benefit from the information sources that librarians manage. Librarians could help them remain current in professional and scholarly literature.

Student affairs professionals have much to offer to librarians. Although librarians have a strong teaching identity, they must find new ways of connecting with students outside of the library. Librarians could benefit from student affairs professionals' knowledge of student development theories. They could apply this knowledge to help students locate and evaluate information that in turn helps students navigate college or make better informed decisions about their extracurricular experiences. Finally, student affairs professionals can teach librarians advising skills that help librarians more appropriately diagnose and understand students' information needs.

\section{Organization of the Study}

Eight chapters comprise this study. In this first chapter, I have introduced the study, provided an overview to the work of librarians and student affairs professionals, described the purpose of the study and explored the study's conceptual framework, significance, method, and limitations. Next, the second chapter consists of a review of the literature that begins with an exploration of the intersecting roles and values of the two professions. Collaboration within the context of higher education is addressed and 
narrows to discuss collaboration between librarians and other actors in higher education and between student affairs professionals and other actors in higher education. Finally, the review presents case studies of collaborations between librarians and student affairs professionals and analyzes the gaps in the literature to illuminate the problem addressed by this study.

In the third chapter, I review the methods I employed to select and recruit my participants and to explore, interpret, and present the data for the study. The fourth and fifth chapters organize the stories the librarians and the student affairs professionals shared in their respective focused discussions. I discuss the diverging and sometimes intersecting work of librarians and student affairs professionals in the sixth chapter, and I revisit the conceptual framework in the seventh chapter. Finally, the concluding chapter discusses the implications for professional practice and suggests avenues for future research. 


\section{CHAPTER II}

\section{REVIEW OF THE LITERATURE}

The purpose of the study was to explore librarians' and student affairs professionals' perceptions of each other's roles in student learning and success, to identify opportunities for prospective collaborations, and to identify the conditions which impede or facilitate prospective collaboration. This review organizes and examines the literature that demonstrates areas where the work of librarians and student affairs professionals intersect and explores collaboration in higher education as a phenomenon. Additionally, this review details collaborations between librarians and other actors in higher education, between student affairs professionals and other actors, and between librarians and student affairs professionals.

The literature review consists of five sections and begins with an exploration of the intersecting roles and values of the library and student affairs professions. In the second section, the review discusses collaboration within the context of higher education generally, while the third and fourth sections discuss collaborations between academic librarians and student affairs professionals, respectively, with other actors in higher education institutions. In the final section of the literature review, collaborations specifically between academic librarians and student affairs professionals are addressed. A critical analysis of the literature as a whole concludes the literature review. Gaps in the literature are identified and discussed, warranting a study of the phenomena explored in 
the dissertation. Lastly, implications are drawn for research questions that guided the study.

\section{Selection of Sources}

Searches for sources included in this literature review were performed on the bibliographic databases most relevant to library and student affairs literature, including Library Literature and Information Science; Library, Information Science, and Technology Abstracts; Social Sciences Citation Index; and the Education Resource Information Center (ERIC). These bibliographic databases were searched via the database aggregator EBSCO. Additionally, searches were performed on ProQuest Dissertations and Theses to identify relevant doctoral dissertations and on OCLC WorldCat to identify monographs not included in the aforementioned bibliographic databases. Terms and phrases employed in the literature searches included librar\$ (library, libraries, librarian, librarianship) and ("student affairs," or "student services," or “student development" or "student support”); librar\$ and (collaboration or partnership); ("student affairs" or "student services") and (collaboration or partnership); and (collaboration or partnership) and "higher education."

Sources published in languages other than English or whose topics focused on non-academic types of libraries were excluded from the literature search. Additionally, sources published prior to 2008 were also excluded from the search to ensure currency and relevance to the rapidly evolving context of libraries and librarianship and to the increasing emphasis on collaboration in higher education generally. A publication date of no more than five to six years from the time of the literature search seemed an appropriate limit for currency. However, some sources published prior to 2008 are 
included in this review; citation analyses of the search results revealed these older sources to be cited five or more times by recent sources and are thus deemed seminal or otherwise noteworthy. Sources whose topics concerned institutions outside of the US, Canada, UK, and Australia were also discarded because the philosophical, training and organizational differences between Anglo-American and other international libraries and student support services are too marked for the purposes of this review. Finally, studies that chiefly concerned collaborations for the benefit of graduate students, adult learners, and others enrolled in continuing education or certification programs were discarded because these collaborations were not designed to improve the learning experiences of the traditional-aged, residential undergraduate student. Studies that chiefly involved 2year institutions of higher education were also excluded for similar reasons.

\section{Part I: Overlapping Values}

Young (1993) purported, "Values are the essences of philosophy that guide our actions in important ways"(p. 23). It is arguably easiest to identify where librarians and student affairs professionals intersect in their work by examining the core values shared by both professions. Gorman (2000), Maxwell (2006), Cossette (2009), and Rubin (2010) examined the values that guide librarianship, and Reason and Broido (2011), Hamrick, Evans, and Schuh (2002), Rentz, (1994) and Young (1993) discussed the core values of the student affairs profession. Taken together, the following core values overlap clearly in the writings of each scholar: service to students, community development, equity and social justice, and citizenship. Certainly, these are not the only core values of each profession. Indeed, the library scholars discuss other core values in librarianship such as the stewardship of human knowledge, and the student affairs 
scholars discuss values such as counseling and assessment (Gorman, 2000; Hamrick, Evans, \& Schuh, 2002). However these values are either not shared by both professions or are not well explored in their respective scholarly and professional literatures.

\section{Service to Students}

If the fundamental purpose of librarianship is to communicate information to people, then service to others is an essential value. Davies (1974) claimed the service orientation of librarianship arose partly because public libraries in $19^{\text {th }}$ century America were intended to socialize the "unruly masses of immigrants" (p. 54). Librarians sponsored programs on US history and culture and on the English language; additionally, they helped immigrants navigate cities' available social services (Davies, 1974). Gorman (2000) and Cossette (2009) contended that librarians see themselves as distinctly infused with an educational purpose because of the profession's early goals. For academic librarians, service to students is their predominant ethic since students comprise academic librarians' largest clientele (Alire \& Evans, 2010). In order to serve students capably, librarians select collections based on students' curricular needs and career interests. They catalog and organize resources using students' natural language and sense-making. Lastly, they design library spaces, hours of operation, and technologies based on the student community's particular needs (Cossette, 2009).

Reason and Broido (2011) claimed student affairs' underlying fundamental mission is to serve students: All services, programs, and learning outcomes are designed to engage students in their own learning processes. Student affairs professionals design and manage services that have student maintenance functions, such as housing; financial aid; and health services, so students might experience fewer distractions from their 
learning experiences. Other student affairs professionals design and manage programs that engage students in extracurricular experiences that teach students citizenship, leadership, and other soft skills that serve students when they enter the professional world (Hamrick et al, 2002).

Young (2003) suggests student affairs professionals' service value extends not only to students but to faculty as well. Student affairs professionals "provide teachers of subject matters with information about their students - when, where and how they find significant experiences inside and outside the classroom" (Young, 2003, p. 92). Service to students may seem an obvious value of the profession, given the name of the field. Nonetheless student affairs represents such a wide and diverse range of functions that many student affairs professionals may not be in direct contact with students frequently. Many student affairs professionals - those concerned with assessment, for example may serve primarily administrative functions, but their overall work is still centered around services for students (Hamrick et al, 2002).

\section{Community Development}

Roberts (2003) described community as "the binding together of individuals toward a common cause or experience" (p. 539). Building a sense of community between students has many educational benefits. It provides students opportunities to develop leadership skills, to develop interpersonal skills through communication and conflict resolution. Community development creates a sense of belonging for students who might otherwise be marginalized and enhances students' sense of responsibility for maintaining community standards (Roberts, 2003). Other benefits of community are not strictly educationally meaningful but contribute to a safe and healthy environment 
(Hamrick et al, 2002). Incidents of vandalism, property theft, and assaults decrease when students perceive a relationship with and responsibility for each other and their surroundings (Roberts, 2003). Students are also more likely to persist to graduation if others value their involvement (Hamrick et al, 2002). A sense of community can also unite a campus during a time of crisis and create an enduring loyalty to the institution long after students have graduated (Hamrick et al, 2002).

Building a sense of community between people is a core value that guides the work of librarians. Gorman (2000) noted the library is often a focus point of neighborhoods, where people come together to participate in programs, lectures, and cultural events. Leckie and Buschman (2007) described academic libraries as the "intellectual heart" (p. 12) of colleges and universities, and often the geographic heart of the campus as well. Librarians design libraries as communities intentionally, enriching the social fabric of the students they serve by hosting lectures, traveling exhibits, and musical performances and by sponsoring game and trivia nights. Librarians make deliberate decisions in their use of library space and relationships with students. Spaces are designed to balance active and collaborative learning styles with quiet, reflective areas (Leckie \& Buschman, 2007). Recently, librarians are connecting with student communities by organizing raves and dance parties in libraries during final examination periods ("Flashmobs in Libraries", 2010).

Student affairs professionals shape communities between students as well. However, their role in community development appears more complex; they must decide what the "community" is that they are shaping - students residing on a floor of a residence halls; the entire population of first-year students; adult learners in an online 
environment; or all the students, faculty, and staff on the campus? Student affairs professionals must also decide what a healthy community resembles - is it one that follows rules and experiences few disciplinary measures, or is it one that encourages and respects diverse viewpoints and perspectives? What does a healthy community look like that encourages both?

Therefore, community building is a very intentional process for student affairs professionals. Many models of community development emphasize the students' building of the community through their involvement - with each other and with the planning of activities that bring members of the community into direct contact (Blimling \& Whitt, 1999). Student affairs professionals must identify students who are potential leaders in the community; help students with envisioning programs that appeal to the larger student body; plan, manage, and market programs; and holding students responsible for their contributions. Those "involved" students begin to see themselves as responsible for the programs they create, and the participants in the programs begin to see that they themselves can effect change by initiating change (Roberts, 2003). If student affairs professionals marshal the community's development carefully, they can ensure that the community reflects the values and learning outcomes that are desired. As Roberts (2003) said, "people support what they create" (p. 553).

Although both librarians and student affairs professionals strive to develop communities, librarians are passive in their creation of that community (i.e., "build it and they will come") whereas student affairs professionals appear to actively recruit students and put responsibility for the development of community at least partially into students' hands. Additionally, librarians tend to view the library as the community's focal point, 
while student affairs professionals consider community development from the microlevel, such as floors of a residence hall, to the macro-level, such as the entire campus and surrounding community.

\section{Equality and Social Justice}

Student affairs professionals are concerned with students' fair access to resources and treatment in higher education. Blimling and Whitt (1999) claimed students are typically most concerned about fairness in the distribution of opportunities and services, particularly in regards to admissions, financial aid, student discipline, and health services. However, Rentz (1994) proposed social justice is a more sophisticated value that builds from equality. Rentz (1994) defined social justice as "fairness and equity in the distribution of opportunity, in the treatment of individuals, in the assurance of personal and economic security, and in the protection of civil and human rights" (p. 21). Reason and Broido (2011) emphasized ways in which student affairs professionals promote social justice in higher education. Student affairs professionals ensure the campus is committed to remedying policies or procedures that have historically disadvantaged groups of people. They work towards policies and procedures that are fair and inclusive for all people and strive to ensure that students recognize and are prepared to remedy inequality within the campus and the surrounding community (Reason \& Broido, 2011).

Librarians are committed to equality and social justice too. However, the scope of their work is more limited to equality in information access. Librarians recognize the power of information to transform society and uplift people. They actively reach out to those who could benefit from library services, recognizing that access to information is unevenly distributed among groups of people (Rudin, 2010). A number of studies in the 
library literature propose that student persistence in higher education is linked to library usage, and, in turn, greater sophistication in information literacy and research skills (Emmons \& Wilkinson, 2011). Students who use the library frequently, seek assistance from librarians, and demonstrate higher competency levels of information literacy are more likely to earn baccalaureate degrees in four to six years than their counterparts who do not use the library (Mezick, 2011).

Librarians recognize students do not benefit from librarians' expertise equally (Alire \& Evans, 2010). Solis and Dabbour's (2006) and Whitmire's (2004) studies indicate that students of color, first-generation students, students whose first language is not English, and low socio-economic status students do not fully understand the purpose of libraries. All of these groups use the library less frequently, ask for assistance from librarians less often, and demonstrate lower levels of information literacy than other counterparts (Solis \& Dabbour, 2006; Whitmire, 2004). Consequently, librarians create programs and information services targeted especially for special groups, such as brochures in other languages and library orientation sessions in first-year courses (Alire \& Evans, 2011).

\section{Citizenship}

Hamrick, Evans, and Schuh (2002) defined citizenship as "actively attending to the well-being, continuity, and improvement of society through individual action" (p. 183). Reason and Broido (2011) claimed that citizenship must be taught and is therefore both a skill and a learning outcome. Student affairs professionals create avenues for students to practice citizenship, such as coordinating service-learning activities in the community at large and facilitating discussions with students regarding social ills and 
unjust laws and regulations (Dungy, 2003). Additionally, student affairs professionals advocate for students to have a voice in campus governance (Crume, 2004). Student government associations provide voices to students and create opportunities for students to express concerns and opinions on issues ranging from "grading policies, food quality, college affordability, and even the selection of college or university presidents" (Laosebikan-Buggs, 2006, p. 5). Student affairs professionals recognize such participation in governance has strong implications for student involvement and leadership development, as well as instilling social responsibility and respect for democracy (Laosebikan-Buggs, 2006).

Similarly, librarians seek to facilitate students' citizenship and sense of social responsibility. Librarians remove barriers that inhibit students' abilities to participate in democracy, such as organizing voter registration drives on campuses and directly registering students to vote. Librarians also struggle to protect students' right to privacy. Federal and state investigators have challenged a number of academic librarians to turn over records of students' reading habits or browsing histories associated with computer workstations since the passage of the Patriot Act (Rubin, 2010). Finally, librarians help students become educated citizens by teaching information literacy skills, including the recognition of political biases in writing, the credibility of authors' credentials, the effects of the marketplace on information production and control, and laws and regulations such as those concerning copyright, that both inhibit and protect students' creative expressions (Alire \& Evans, 2010). 
Librarians and student affairs professionals shape student learning and development outside of the traditional classroom environment. Librarians teach information literacy and critical thinking skills that influence students' cognitive development. They influence the campus climate by designing libraries that are dynamic learning spaces and by crafting collections that support curricular needs and reflect students' interests and identities. Similarly, student affairs professionals guide students' cognitive, ethical, psychosocial, and identity development through their counseling of students in crises and through their instilment of citizenship, diversity, and leadership skills. Additionally, they influence how students experience the campus climate by interpreting student culture, serving as advocates for students, facilitating discussions with student groups, and remedying conflicts.

In short, librarians and student affairs professionals have much common ground philosophically, including a deep commitment to service to students, advocacy for equity and social justice, and the practice and teaching of citizenship. However, few examples of collaboration between librarians and student affairs professionals are detailed in the scholarly and professional literature, but each stands to gain from collaborative ventures. Opportunities for collaboration between student affairs professionals and librarians are potentially abundant and offer the promise of improved student experiences.

\section{Part II: The Phenomenon of Collaboration in Higher Education}

What does collaboration mean within the context of higher education? Schrage (1990) described collaboration as the process of shared creation, in which two or more people with complementary skills interact together to create a shared meaning that neither could have come to on their own. Montiel-Overall (2010) provided an excellent 
definition within the educational context: "collaboration is a process by which two or more individuals work together to integrate information in order to enhance student learning" (p. 8). John-Steiner (1998) suggested that true collaborators not only plan, decide, and act jointly, but they also think together and combine independent conceptual schemes to create an original framework. They share resources, talent, and power, and their resulting work products reflect the blending of all participants' contributions (JohnSteiner, 1998).

Schrage (1990) claimed that collaborations in higher education are most ingrained in an institution's culture when those collaborations are formal and highly-structured essentially crafting a road map for successors to follow. Schrage (1990) said collaborations that are interdisciplinary must have at least two "passionate leaders," who are focused on solving a problem that each party sees as "real" and whose academic homes provide early support for collaboration (p. 11). However, even formal, highlystructured collaborations between people from different academic disciplines can fail when they do not recognize the "road blocks" of interdisciplinary work: the boundaries and norms that transcend participants and are systemic to their respective disciplines (Schrage, 1990).

The focus of this proposed study is on collaborations between librarians and student affairs professionals that will ground a long-lived partnership. By "long-lived," I mean structures are in place to keep a program or relationship meaningful and productive even if the original people have moved on to other opportunities. John-Steiner's (1998) emphasis on collaborators' sharing of resources, talent, and power is intriguing because scholarship on educational organizations suggests that each of those elements is highly 
contested and likely the root of potential barriers. Indeed, Schrage (1990) warned that interdisciplinary work is "fraught with difficulties" (p. 17).

Kuh (1996) and Pascarella and Terenzini (2005) purported that student success is associated with seamless learning environments, in which comprehensive policies and practices are designed to complement cohesive educational missions and priorities. Pascarella and Terezini (2005) argued engagement - the amount of time and effort students dedicate to their programs of study and other educational activities - is the primary vehicle by which students learn, develop, and persist to graduation. Pascarella and Terenzini (2005) claimed,

The greatest impact appears to stem students' total level of campus engagement, particularly when academic, interpersonal, and extracurricular involvements are mutually reinforcing. Therefore, the holistic nature of learning suggests a clear need to rethink and restructure highly segmented departmental program configurations (p. 647).

Whitt (2010) called the benefits of research on seamless learning environments "unequivocal" (p. 518) and noted higher education literature has extolled for years the benefits of collaborations between student affairs and academic affairs that reduce the fragmentation between curriculum and campus environments. Indeed, Blimling and Whitt (1999); Hamrick, Evans, and Schuh (2002); and Manning, Kinzie, and Schuh (2006) professed nearly identical arguments, although their works were largely exhortative rather than empirical. In the library literature, Bennett (2007); Raspa and Ward (2000); Gilchrist (2009); and Walter (2009) were similarly exhortative regarding 
the capacity of collaborations between libraries and academic affairs to enhance student success.

Despite the rather large body of literature devoted to the value of such collaborations, relatively little research has examined such collaborations and the conditions that make them fruitful or ineffectual. Kezar (2006) and Kezar and Lester (2009) examined collaborations in higher education broadly. Employing a multiple case study design, Kezar explored collaboration as a phenomenon and specifically the developmental process of collaboration. Among her research questions, Kezar asked how the context for collaboration emerges, grows, and becomes implemented; what the relative importance of learning is in the development of collaboration; and what, if any, initial conditions are necessary for collaboration to develop; and if collaboration develops in stages? Kezar interviewed faculty and staff to discern their perceptions, analyzed documents related to the collaboration and to the institutional missions, and observed various activities related to collaboration, such as meetings; activities; and interdisciplinary research symposia. Kezar collected and interpreted her data at four nonelite higher education institutions that were geographically dispersed across regions of the US that serve large numbers of commuting students, and that had an overall population of approximately 30,000 undergraduate students.

Using her findings, Kezar (2006) identified eight core elements that are necessary to create a context that enables collaboration: mission, integrating structures, campus networks, rewards, a sense of priority from senior administrators, external pressure, values, and learning. Additionally, Kezar constructed a 3-stage developmental model for collaboration. In the first stage of building commitment, Kezar described the institutions' 
senior administrators synthesizing ideas and information from a variety of sources to persuade faculty and staff of the need to conduct collaborative work. Senior administrators crafted their arguments using the institution's underlying values to make a case while also relying on external pressure from funding agencies and disciplinary professional associations to require faculty to seek out interdisciplinary partners for practical applications of their work (Kezar, 2006). In commitment, the second stage of the model, Kezar claimed that senior administrators revised the institutional mission to better support collaboration and demonstrated through leadership that collaborative efforts were high institutional priorities. In sustaining, the third stage of the model, Kezar noted that collaborations are formalized by integrating networks to support collaboration, such as opening meetings to more individuals or using non-academic spaces for meetings, and modifying reward systems - such as tenure standards - to recognize interdisciplinary work.

Kezar (2006) emphasized the importance of formal processes to enable collaboration, such as discussions within the context of academic senates and taskforces to study and revise mission statements. Kezar did acknowledge informal processes, such as faculty members inviting like-minded colleagues to coffee to discuss collaborative ideas, as important to the success of collaboration, but she did not probe these informal moments deeply. Kezar speculated these moments might be as powerful or more powerful in reorienting a campus culture toward collaboration but she simultaneously downplayed these as "micro-changes" (p. 858) that fell outside the focus of her study. Although Kezar's (2006) 3-stage developmental model for collaboration in higher education is compelling because it considers the phenomenon on an institutional scale, 
there is scant attention to the people as actors in collaboration. Montiel-Overall (2010) claimed that successful collaboration requires interpersonal skills as much as it does synergy between functional areas. John-Steiner (1998) studied collaborations between artists and scientists inside and outside of higher education. Her observations and interviews suggested that individuals must possess a set of relational dynamics, such as intellectual ownership, trust, autonomy, and creativity. These dynamics must be present in order for participants to express both the desire and the capacity to engage in collaborative works with people outside their discipline (John-Steiner, 1998).

In a subsequent study, Kezar and Lester (2009) investigated the work lives of Harvard University faculty who participated in collaborative efforts, such as teamteaching with student affairs professionals in learning communities or working on curricular reform issues. In multiple interviews with participants and analyses of documents, Kezar and Lester (2009) found that faculty who participated in collaborative work with student affairs professionals or with faculty outside of their respective disciplines were highly discouraged and reported that the institution penalized their collaborative work while explicitly encouraging their work.

Kezar and Lester (2009) blamed responsibility-based budgeting, the "fiscal system in which various units or schools are responsible for their own revenue developments and covering costs" (p. 33) as a primary barrier to collaboration. A common application of responsibility-based budgeting in units with heavy teaching loads is the expectation for significant production of credit-bearing courses. One of the disadvantages of responsibility-based budgeting is that units compete for the same students to enroll in their courses and increase the revenue stream (Kezar \& Lester, 
2009). Similarly, team or interdisciplinary teaching is unintentionally discouraged because the instructors' salaries are paid out of their home unit's budget, while the revenue generated by the credit-bearing course will go to the unit associated with the course (Kezar \& Lester, 2009). Additionally, Kezar and Lester found that faculty are often not awarded course releases, and collaborative efforts are then often above and beyond normal work expectations. Additionally, merit salary increases for student affairs professionals are typically allocated based on individual performance, as are evaluations for institutional service awards (Kezar \& Lester, 2009).

Interestingly, the participants in Kezar and Lester's (2009) study often described their collaborative work with student affairs professionals as interdisciplinary whereas the student affairs professionals referred to their work simply as collaborations or partnerships. Given the paucity of research on the persons involved in collaboration, as well as Schrage's (1990) warning that interdisciplinary work is "fraught with difficulties" regarding disciplinary boundaries and norms (p. 21), it is worth examining collaborations between student affairs and academic affairs in the context of disciplinary cultures. Becher and Trowler (2001) suggested that faculty and other academic professionals are socialized into cultural patterns of behavior, which they called "academic tribes."

Disciplinary identity, according to Becher and Trowler (2001), is preserved through the distinction between "us" and "them," which often takes shape in the need to speak the same language, to participate in the social life of the discipline, and to share the same beliefs about teaching, research, and service. Distinctive cultural features of the discipline make it easy for the "in" group to identify outsiders and make it difficult for 
outsiders to join the group. Becher and Trowler suggested that outsiders are often treated with suspicion, which makes interdisciplinary work difficult, if not impossible:

Men of the sociological tribe rarely visit the lands of the physicists and have little idea of what they do over there. If the sociologists were to step into the building occupied by the English department, they would encounter the cold stares if not the slingshots of the hostile natives. (p. 45)

Becher and Trowler (2001) asserted that academic tribes develop to protect knowledge. If knowledge were easily understandable and available, specialists would lose their authority and influence. Applying Becher and Trowler's definition of an academic discipline, student affairs and librarianship are academic disciplines in their own right. They have distinct objects of research (i.e., the information-seeking process and organization of information for librarians and student development for student affairs professionals). Each has a body of accumulated knowledge organized by specific theories and principles. Each applies specific research methods and epistemologies to validate their knowledge, uses specific language adjusted to their knowledge, and reproduces its ways of knowing, working, and communicating through a process of institutionalization, which includes scholarly literature, professional bodies, and preprofessional training.

Becher and Trowler (2001) explained that academic tribalism does not make relationships between academic tribes impossible: Tribes with comparable values and technical language are more likely to reach a consensus. Collaboration between academic disciplines is most successful when each discipline shares a common vision of learning, a common language, a common perspective on students, and the ability to foster 
mutually satisfying dialogue. Becher and Trowler acknowledged interdisciplinary work is less challenging between disciplines when the respective disciplines are malleable, at least partially, by their institutional mission.

Walter's (2009) perspective reinforces Becher and Trowler's (2001) argument. Walter (2009) claimed the library and student affairs professions are each "valuerelational" disciplines, in which the members are "committed to, and find meaning in, specific ideologies" (p. 8). In other words, they must be attentive to their campus culture. If their institution values student development and learning outside of the classroom, then so too should the librarians and student affairs professionals employed at the institution.

Becher and Trowler's (2001) work illustrated that disciplinary differences can be a barrier to collaboration because librarians and student affairs professionals each have distinctive languages and ways of knowing that impede interdisciplinary work. Nonetheless, Becher and Trowler cautioned that their study was limited to interdisciplinary work between faculty of different disciplines. Their work omits higher education's professional staff entirely. Becher and Trowler (2001) confessed, "There is an almost total neglect of the professions in terms of documentation of their cultures. This may be connected with the fact that their academic embodiment is far from easy to demarcate" (p. 53). Trowler (2012) reviewed the literature on disciplinary differences and academic identity more recently; he suggested that in the intervening decade few studies had examined whether interdisciplinary work involving professional staff would be stymied by disciplinary differences comparable to those of faculty. Cownie (2012) argued that an ethnography of professional staff, such as student affairs professionals, is 
needed for "disciplines torn between the academic and the vocational" which "sit uncomfortably on the sidelines of the academy" (p. 60).

\section{Part III: Student Affairs and Other Actors in Collaboration}

Collaboration between student affairs and academic affairs has received at least some attention in the higher education literature in recent years. Similar to collaborations between librarians and faculty members, many of these collaboration between student affairs and academic affairs seek to improve student learning and student experiences with the close involvement of faculty. These case studies focus on a variety of collaborations, including the design of living-learning communities in residence halls, diversity initiatives, and study abroad programs. Other studies examined the nature of the collaborations themselves rather than the intended outcomes of the collaborations.

Arguably one of the best known and widely emulated collaborations between student affairs professionals and faculty are living-learning communities (LLCs) established for the purpose of creating seamless learning environments between students' classroom and residence hall experiences (Borst, 2011). Laufgraben and Shapiro (2004) suggested that LLCs "represent a scholarly community, emphasize deep learning for an engaged and diverse community with a high level of faculty participation, and integrate the academic and social experiences of college life" (p. 156). Borst (2011) investigated the effect of faculty interaction on first-year students' cognitive development when those faculty and students participated in the LLCs at 19 institutions with the 2006, 2007, and 2008 cohorts in the Wabash National Study of Liberal Arts Education. Among the LLCs included in the study, student affairs professionals tended to the students' living conditions, social and recreational programs, and met with faculty regularly to discuss the 
LLCs' intended learning outcomes and student progress. The faculty members drove the LLCs' educational goals, selected curriculum, and created learning experiences. The student affairs professionals were responsible for the LLCs' continuity, recruiting both faculty and students when these groups moved on.

Borst (2011) did not specifically examine the partnerships between faculty and student affairs professionals themselves but instead evaluated the quality of these collaborations. In a longitudinal investigation of pre-test and post-test scores of the students, Borst (2011) determined that the correlation between students' cognitive development and academic performance was lower for LLC students than for students who did not participate in LLCs. Borst did question why the collaborative efforts were not more effective and noted that in the subset of participants who did have a more powerful correlation between academic performance and cognitive development, the faculty and student affairs professionals reported an equitable share of responsibility for program administration and frequent, high quality communication.

Barr (2013) explored partnerships between student affairs professionals and faculty in faculty-lead study abroad programs. Barr interviewed participants at three higher education institutions where faculty created and coordinated study abroad programs and subsequently reached out to student affairs professionals for help with solving student problems, such as strategies for combating homesickness or counseling in the event of student death. Although student affairs professionals played a consultative role initially, faculty coordinators found that problems could be mitigated early by involving student affairs professionals more closely in the conception of new study abroad programs, in site selection, and in orientation and acculturation processes. 
Student affairs professionals enhanced student experiences by counseling students prior to departure, reached out to students at various points during their time abroad, and aided students with reflective thinking once they returned to their home institutions. Faculty members themselves reported less stress and burn-out associated with the study abroad programs and indicated student affairs professionals aided students with "sense-making" and applying the lessons learned during their experiences abroad to enriching their domestic experiences (p. 145.)

LePeau (2012) examined faculty and student affairs collaborations in the context of the American Commitments Project, a national project launched by the Association of American Colleges and Universities in the 1990s to integrate diversity initiatives within the curriculum and co-curricular activities. LePeau interviewed 18 faculty and student affairs professionals at four higher education institutions to identify how collaborators created partnerships built around diversity and inclusion. The findings suggest that three types of collaborations existed between faculty and student affairs professionals: complementary, coordinated, and pervasive (LePeau, 2012). Complementary partnerships were rigid and compartmentalized, but the most common type of collaboration and particularly amongst those who were new participants to working together. LePeau explained complementary partnerships as the student affairs professionals taught about those areas over which they had most authority, such as civic engagement or service-learning, whereas the faculty members taught about those areas on which they were the most knowledgeable, such as the history of civil rights movements and the theoretical foundations of civic engagement. 
Coordinated partnerships were defined by a blurring of the lines between student affairs and the faculty. The collaborators enjoyed productive, frequent collaboration and discussed wide-ranging topics. They felt entirely comfortable with either student affairs or faculty collaborators able to step in and teach any component of the activity. These collaborators tended to have relationships that were deep, personal, many years in the making, and often built on mutual respect (LePeau, 2012). The pervasive partnerships tended to be the most rare, and the participants perceived the blurring of student affairs and academic affairs to be the "standard operation of the entire campus" (p. 222). These participants saw seamless learning as the ideal to which the institution should aspire to align all curricular and co-curricular programs, and they were comfortable challenging the barriers and contradictions that existed, especially in governance bodies. These participants rethought pedagogy inside and outside the classroom and were more likely to be campus leaders or faculty and student affairs professionals with highly established reputations at their respective institutions (LePeau, 2012). However, LePeau offered little guidance on how student affairs professionals and faculty might cultivate collaborations that yield coordinated or pervasive partnerships. Rather, these collaborations appeared to result because of the serendipitous meeting of like-minded individuals.

Stolz (2010) explored ways collaborations between student affairs professionals and faculty developed at a Midwestern university to promote seamless learning for students with disabilities. Stolz interviewed two campus leaders, three student affairs professionals, and nine faculty members to identify how, why, and when collaborations take place. The context of disability presented unique characteristics in collaborative 
efforts, but themes emerged from the participant interviews that described barriers to collaboration in regards to position, identity, and space. Stolz found that collaborators who created seamless learning for students with disabilities navigated these boundaries best by persistently demonstrating how the collaborations met the institution's stated values for inclusivity, success, and independence.

In addition to the case studies that recount best practices, a number of original research studies have emerged in recent years that investigate the perceptions, experiences, or conditions of collaborations between academic affairs and student affairs professionals. Most of these studies examine collaborations from an organizational or structural perspective. In a phenomenological study, O'Connor (2012) explored the factors that support or inhibit academic affairs and student affairs from working collaboratively to support holistic student experiences. O’Connor held focus groups consisting of faculty members and student affairs professionals who had participated in collaborations for at least three years at several public universities in the Mid-Atlantic region. O'Connor found the factors that support collaboration include a common mission and values, support from senior administrators, and a shared understanding of students. However, participants noted the silo-ing effect between academic affairs and student affairs played an incredibly powerfully role in the inhibition of collaboration - as a lack of a common understanding of student learning and success was heightened, then the greater the apparent silo-ing effect (O'Connor, 2012). Interestingly, the study suggested the silo-ing effect was blamed for disconnects in communication between collaborators, the lack of resources to support collaboration such as marketing and flyers to stimulate 
student interest, and diminished student support in the collaborative ventures (O'Connor, 2012).

O'Connor's (2012) findings support Arcelus' (2008) study on the cultures of academic affairs and student affairs. In an ethnographic survey of a residential liberal arts college, Arcelus (2008) probed in nearly 100 interviews and in observation of over 250 meetings how faculty and student affairs professionals perceived their own and each other's roles as educators and how these perceptions influenced the potential for collaboration between the academic affairs and student affairs divisions to optimally benefit students. Arcelus concluded that the ethos for crafting a campus culture that emphasizes educating the whole student is often stymied by the "widening gap" (p. 124) between academic affairs and student affairs divisions. The gap includes structural differences but is also the result of disciplinary and professional cultures that define the role of educators quite differently (Arcelus, 2008). Indeed, Arcelus found that student affairs professionals perceived faculty as self-centered and little concerned with students' experiences outside of those students' performances in the faculty members' own courses - a strong indication that faculty were solely concerned with "the life of the mind" (p. 144) and not the whole student. Similarly, faculty members were skeptical of student affairs professionals' attempts to collaborate, often perceiving overtures as attempts to diminish the "academic primacy" (p. 167) held by the faculty. However it is difficult to generalize Arcelus' findings since the study took place at a single institution.

Rodem's (2011) study appears to be one of the few that have examined interpersonal relationships between student affairs professionals and faculty in the context of collaborative activities. Rodem conducted multiple interviews with faculty 
and student affairs professionals who co-taught a first-year seminar course at Bowling Green State University. Most participants found collaborations beneficial for students, and they believed they were able to achieve more in partnership than they would have been able to accomplish individually (Rodem, 2011). While participants rated trust, comfort, and effective communication as essential factors in successful collaborations, they reported too that roles were far more complex and situational than they expected. Participants' satisfaction with the collaboration and the measurable effects on student learning increased with the passage of time, during which participants saw each other increasingly as friends, mentors, and confidantes. Rodem concluded that informal personal connections are vital for collaborations between faculty and student affairs professionals, and those responsible for fostering collaborations should intentionally develop and support opportunities for personal connection.

Lastly, Peltier (2014) examined the perceptions of student affairs professionals held by faculty who participated in collaborative work at a private, four-year liberal arts college located in the southeastern US with a student enrollment of approximately 2,000 undergraduates. The college's mission statement indicated that it created a "studentcentered culture built upon openness and collaboration between faculty, staff, students, and alumni," and the college had been recognized for its excellence in integrative learning by the Commission on Colleges of the Southern Association of Colleges and Schools (p. 40). Peltier conducted interviews, analyzed documents, and observed people and places associated with the college. The purpose of the study was to probe the relationship between faculty and student affairs professionals from the perspective of the faculty with a particular focus on the issues and challenges to collaboration. The 
participants included faculty from the disciplines of history, biology, English, public affairs, art history, Spanish, and business administration; all of the participants had collaboration with student affairs professionals in service-learning programs, LLCs, or new student orientation.

Largely, the faculty identified lack of time as the most profound barrier to collaborations with student affairs professionals. Time spent on course preparation, teaching, research, and service to disciplinary associations left the faculty with what they perceived to be little time for being more committed to working with student affairs professionals. Although most of the faculty saw the benefits of working with student affairs professionals and recognized the difference seamless learning environments could make on students' success and academic performance, many faculty were less certain of the roles of student affairs professionals. One participant remarked:

Even after several years at [the college] and understanding that student affairs staff work long hours, hold advanced degrees... I only vaguely know what they do beyond the briefest description of managing student issues outside the classroom - and that's after I've collaborated with several staff on new student orientation for three years in a row! (Peltier, 2014, p. 80)

Other faculty observed that they had difficulty bonding with student affairs professionals because many tended to be young, not far removed from the students in terms of age and life experiences, and prone to leaving after only a few years at the college. Others perceived collaborations with student affairs professionals as unable to accomplish what the faculty members had hoped to achieve by collaborating - markedly advancing students' cognitive skills. One faculty member claimed: 
The student affairs staff only talked of social dimensions, whereas I was most concerned with helping students think. I understand how cognitive, psychosocial, and ethical development are interconnected - but I didn't see how I could contribute to those other areas as much as I could in shaping students' thinking. (Peltier, 2014, p. 90)

Although Peltier's (2014) study is constrained in its generalizability as a singlesite case study, it is nonetheless informative. While the argument for seamless learning is persuasive to many faculty, faculty may still perceive their influence on cognitive development as their primary contribution to student learning. Student affairs professionals may need to revise their message to emphasize the import and efficacy of cognitive development on co-curricular activities in order to forge successful and lasting partnerships with faculty. Additionally, student affairs professionals' roles and responsibilities may be poorly understood by faculty, despite past interactions that suggest successful relationships. Student affairs professionals may need to find ways to explain the myriad roles they fulfill, especially those at liberal arts college where they might wear many hats.

\section{Part IV: Librarians and Other Actors in Collaboration}

Library literature is abundant with case studies exemplifying librarians who are working closely with teaching faculty to improve students' information literacy skills or to ensure the relevant of library collections to research endeavors. Arguably, collaboration between librarians and faculty is essential for librarians to teach information literacy skills effectively to students. Yousef (2010) claimed, "[faculty] are 
the key to influencing student acceptance of information literacy. Therefore, librarians need to concentrate on academic partnerships and interest in information literacy" (p. 4).

Raspa, a professor of interdisciplinary studies, and Ward, a librarian, wrote one of the recent seminal works on librarian and faculty collaboration to promote students' information literacy. Raspa and Ward (2000) shared mutual interests in the ways students learn the research process. Together, Raspa and Ward tossed out the conventional methods of library instruction: faculty bringing students to the library as part of a course and assuming a non-participatory role while the librarian orients the students to the library and demonstrates how to find and search databases for topics pertinent to the course's assignments. Instead, Raspa and Ward created a new curriculum for UGE 1000, Wayne State University's freshman orientation course, by making students responsible for crafting their own strategies for finding and analyzing information. Raspa and Ward consulted with each student to revise and refine the strategies and interjected challenges to students' critical thinking in efforts to develop their information literacy skills.

As another example, the librarians at the University of Nevada-Las Vegas collaborated with faculty on student learning on a grand scale: They created the Faculty Institutes, a series of workshops in which librarians work with new faculty to investigate research-based learning activities that integrate library resources and course learning outcomes (Bowles-Terry, 2014). To this end, the participants discuss how research-based learning supports student learning, and they articulate goals and learning outcomes for research assignments. The librarians help faculty discover technology options that support research-based learning, such as data clearinghouses and cloud-based storage; the 
faculty help the librarians communicate the expectations of assignments to students and identify resources that best support the intended learning outcomes.

Faculty members are not the only actors within higher education with whom librarians collaborate to advance research and student learning. Gibson, Morris, and Cleeve (2008) explored collaborations between academic librarians and university galleries and museum curators. Participants were interviewed at 12 higher education institutions whose campus leaders responded affirmatively to a survey that collaborations had taken place between the institution's library and its gallery or museum. Three themes to collaboration emerged: shared programming, in which librarians and curators jointly recruited and hosted visiting artists or exhibits; shared space, in which gallery and museum artifacts were exhibited temporarily at the library; and shared educational programs, in which curators taught workshop participants about the historic purpose and aesthetic values of artifacts, such as daguerreotypes, and librarians demonstrated conservation practices that restored the daguerreotypes (Gibson, Morris, \& Cleve, 2008).

Librarians have often collaborated with information technology professionals in order to provide robust technologies that advance research and learning or improve workplace efficiencies. Melling (2013) described the "super-convergence" of libraries and information technology at higher education institutions in the 1990s and 2000s, in which libraries and information infrastructures were jointly administered by chief information officers. In Melling's (2013) study, librarians and technologists collaborated on the teaching of technology skills to adult students returning to UK higher education institutions; the technologists provided training during specialized new student orientation for adult students, while the librarians provided training during individualized 
consultations at the students' request. Melling noted that librarians and information technologists collaborated on the design and delivery of learning management systems, with librarians often responsible for the creation of new course modules and training for faculty while the information technologist supported and coded the back-end systems. Interestingly, Melling (2013) found collaborations between librarians and information technologists to be "difficult" and "uneasy" (p. 152), particularly from the librarians' perspective. The librarian participants claimed information technologists often lacked effective communication and interpersonal skills and were skeptical of the information technologists' commitment to supporting student learning or faculty research. Information technologists reported similar frustrations with the librarians, noting librarians sometimes lacked mastery of the technology they supported and seemed resistant or hostile to working alongside the technologists. Ward and Raspa (2000) found "similar beliefs about the importance of engaging students, meaningful discussion, humor, and a passion for [personal growth]" were essential elements to successful collaborations between librarians and faculty (p. 13). In contrast, Melling found these qualities to be distinctly lacking in librarian and information technologist collaborations and speculated that higher education institutions that converged libraries and information technology would one day split these entities as "too dissimilar" to achieve the desired outcomes (p. 153). This speculation suggests that collaborations may not work or may not be long-lived unless the actors share common values and belief systems.

Perhaps surprisingly, few recent studies have examined faculty perceptions of their collaborations with librarians. Noting that qualitative descriptions of facultylibrarian collaborations in the library literature are largely positive portrayals but that 
none explores what collaboration with librarians means to the faculty, Schulte and Sherwill-Navarro (2009) surveyed 112 nursing faculty at 74 nursing schools in the Midwest and Southeast. Schulte and Sherwill-Navarro's study operated on the assumption that nursing faculty and librarians should have much common ground, as both groups belong to helping professions and as the rise of evidence-based nursing practice demands nurses become "information literate and appreciate the role of research in daily practice” (p. 57). Respondents defined their perspective of collaboration and described their perceptions of librarians, their experiences working with librarians, and their thoughts on how the work of librarians might or might not intersect with their roles as nursing educators.

Schulte and Sherwill-Navarro (2009) found nursing educators strongly perceived librarians to be experts at searching for information but little else. While many of the respondents replied that collaboration was the creation of something new that neither party could achieve alone - and offered examples of such collaboration - their ideas of collaboration with librarians was strictly limited to dedicating a portion of an instructional session to the demonstration of library resources. Moreover, the respondents believed that such collaboration was essential for student learning but did not feel that this collaboration should extend to their own classroom teaching. Schulte and Sherwill-Navarro concluded that librarians' skills are poorly understood by nursing faculty, and overcoming the traditional notions of librarians are a significant barrier to collaboration. 
Nilsen (2012) explored teaching faculty members' perceptions of librarians generally and of their role in curriculum development and instruction at post-secondary institutions in Canada. Of the 106 respondents to Nilsen's survey, more than half rated information literacy as very important to undergraduate students' critical thinking skills and to their academic performance. Many of those respondents also reported that they do not regularly work with librarians and attempt instead to teach information literacy skills to students themselves. When asked why they did not collaborate with librarians, many respondents said the role of librarians is simply too different from what faculty members do and that librarians could not be taken seriously as educators. Instead, many respondents reported librarians were more like administrators and chiefly concerned with the business of running a library rather than with teaching or venturing outside the library, while others said they doubted librarians' effectiveness at teaching due to librarians' lack of doctoral degrees. A few respondents remarked surprise that librarians should instruct students in any way at all, as faculty members were perfectly capable of doing so.

Although Nilsen's (2012) findings were similar to Schulte and Sherwill-Navarro's (2009) findings, Nilsen's study probed more deeply into faculty members' perceptions of librarians in an instructional role. The results were more varied, and Nilsen articulated that faculty ambivalence toward librarians is complex and multi-layered. Nilsen's findings indicate that faculty create their perceptions of librarians against the lens of their own roles and credentials as educators. The generalizability of the findings of both studies are questionable. Schulte and Sherwill-Navarro recruited their participants by asking librarians at different institutions to forward their recruitment message to nursing 
faculty. It seems likely that nursing faculty who respond to surveys brought to their attention by librarian colleagues might have different perceptions of collaboration with librarians than those who do not have a relationship with their institutions' librarians. While Nilsen's survey did not involve librarians as intermediaries and reached participants from a variety of academic disciplines, Nilsen herself noted a surprisingly high number of responses came from institutions in her province of British Columbia and progressively fewer the farther the members of the sample population were from British Columbia. This casts some doubt on the generalizability of her findings to regions outside western Canada.

Nonetheless, Nilsen's (2012) findings suggest that librarians might find greater acceptance by student affairs professionals as collaborators in student learning than by faculty. Student affairs professionals share some similarities with librarians - namely their teaching is not tied to academic coursework, they typically do not hold doctoral degrees, and they hold similar dual administrative and educational roles. There is a significant gap in the library and higher education literature regarding librarians and student affairs professionals' perceptions of each other and of their collaborative prospects.

\section{Part V: Librarians and Student Affairs in Collaboration}

Although descriptions or studies of collaborations between librarians and teaching faculty are plentiful in scholarly literature, few articles address collaborations between librarians and student affairs professionals (Hinchliffe \& Wong, 2012; Swartz, Carlisle, and Uyeki, 2007). In perhaps the earliest argument for collaboration, Forrest (2005), a librarian, recognized that student affairs professionals support students by providing 
critical information for building plans of study, persisting with or departing higher education, and exploring careers. Despite the advocacy for librarians to cultivate relationships with student affairs professionals, Forrest was short-sighted in not recognizing the potential of these collaborations to enrich student learning. Instead, Forrest questioned student affairs professionals' technology skills and familiarity with electronic information and argued librarians should teach their colleagues how to find electronic information and how to use technology more effectively.

Forrest (2005) postulated that if librarians teach student affairs professionals the skills librarians also teach students, then student affairs professionals would increase their productivity and pass higher quality information along to students. Certainly, Forrest's call for collaboration smacks of hubris and casts student affairs professionals in a poor light - even referring to educating student affairs professionals on technology use as librarians' "ethical responsibility to higher education" (p. 11). Nonetheless, Forrest asked an important question regarding collaborations between librarians and student affairs professionals: "Do they even exist?" (p. 12).

Gatten's (2005) perception of student affairs professionals was far more positive; he acknowledged student affairs professionals are experts in student development theories and suggested they have much to teach librarians about students. Gatten argued librarians should explore theories of students' psychosocial and cognitive development to better understand the context for students' information-seeking behavior. If bibliographic instruction and information literacy programs were adapted within the framework of these theories, the practice of librarianship would be improved (Gatten, 2005). 
Regrettably, Gatten's claims appear to have largely fallen on deaf ears in academic librarianship, with only a few subsequent studies on information literacy citing his work.

A few years later, Walter and Eodice (2007) noted that library instruction had evolved from merely demonstrating library resources to teaching information literacy, a critical analysis of information that emphasizes a student-centered, problem-solving approach. Walter and Eodice said:

If we are to realize the potential, the establishment of strategic relationships with campus partners is essential. Although instructional collaboration with members of the classroom faculty has been a subject of study for over a decade....collaboration with student services and other co-curricular programs remains largely unexplored. (p. 219)

In the intervening years, a few case studies have emerged exploring librarians and student affairs professionals in collaboration, mostly thanks to Hinchliffe and Wong's (2012) edited collection. The subsequent studies discuss librarian and student affairs professionals' collaborations concerning students' pre-entry to higher education, the firstyear experience, on-course study, and career preparation. These studies are organized differently from the preceding sections of the literature review. Perhaps the farthest ranging in the nature of collaborative work, the studies included showcase the intersections of librarianship and student affairs despite the breadth of their respective functions in higher education and diversity of roles. Consequently, Weaver's (2013) student journey lifecycle is employed in this section as a conceptual framework for organizing the studies into a coherent flow. Weaver argued: 
[Higher education professionals] need to understand a lot more about the entirety of the student experience, from a student's pre-entry into university, during their subsequent induction and first year experience, while on course, and beyond the [degree] into employment... or further study. Each stage of the journey places differing demands on academic and administrative processes. (p. 104)

Weaver (2013) developed the student journey lifecycle as a four-stage model spanning the stages of studentship. Weaver (2013) recommended that planning for services and programs, especially in libraries, commence from a student perspective with the four stages of studentship in mind. Consequently, services and educational experiences would be holistic, student-centered, and target the critical junctures of students' journeys through higher education. This framework is appropriate, given that many of the studies concern student-facing activities, such as marketing the library or teaching information literacy skills, in contexts that largely fall outside the students' formal courses of study.

\section{Pre-Entry}

Marines and Venegas (2012) examined a distinctive collaboration between instruction librarians and the Office of Educational Opportunities Programs (EOP), a student affairs unit, at the University of California-Santa Cruz. The EOP "ensures the recruitment, retention, and academic success of first-generation college students from low-income, educationally disadvantaged backgrounds" (Marines \& Venegas, 2012, p. 221). The purpose of the collaboration was to specifically prepare racially and ethnically under-represented high school juniors and seniors for study in the arts, humanities, and social sciences. The EOP recruited cohorts of 15-20 academically talented high school 
students to work on a research project for a semester under the mentorship of a faculty member. An instruction librarian met with students for one-on-one sessions during the research proposal, annotated bibliography, and writing stages of the projects. During the sessions, librarians taught students the "secret secrets" (Marines \& Venegas, 2012, p. 222) of research, including familiarity with library resources and physical layout, understanding peer-reviewed journals, reading the discourse of the discipline, and writing logic statements for why students included specific sources in their bibliographies.

The collaboration between the librarians and the student affairs professionals associated with the EOP appeared strong. Although the student affairs professionals left responsibility for instruction with faculty members from the arts, social sciences, and humanities, they were ultimately responsible for developing the curricula. Marines and Venegas (2012) noted the program had been in place since the 1980s, with the librarians' roles growing over time from consultative roles to developing elements of the program together with the student affairs professionals. However, Marines and Venegas observed that librarians and student affairs professionals had considerably different expectations of students' academic performance, with student affairs professionals encouraging librarians to expect higher standards from students' writing.

Hamrick, Evans, and Schuh (2002) echo the student affairs professionals' insistence that students are capable of meeting higher academic standards than the librarians anticipated. Student affairs professionals shape students' cognitive development by helping students think through complex situations, and they observe students rise successfully to extramural challenges that require project management, financial, and consensus building skills (Hamrick, Evans, \& Schuh, 2002). Hamrick, 
Evans, and Schuh speculated that faculty have a narrow understanding of students' cognitive ability and too often create assignments that emphasize content acquisition and writing over complex problem-solving. The librarians in Marines and Venegas' case study appear to share with the teaching faculty the lack of deeper understanding of students' learning capability. Unfortunately, Marines and Venegas did not explain if or how the librarians responded to the student affairs professionals' concern; rather they noted only the long-standing program was in danger of losing the librarians' participation due to the increasing need to provide the core services of reference desk coverage, bibliographic instruction, and collection development with declining numbers of librarians.

In direct response to Oakfleaf's (2010) entreaty for librarians to demonstrate greater value to higher education institutions, Miller (2012) sought a partnership with the office of admissions to enhance prospective students and parents' tours of the campus at Miami University. Miller (2012) recognized university administrators were assessing the "golden walk," (p. 586) or the student-led campus tour, which is one of the strongest influences on prospective students' decisions to apply and to enroll. Miller (2012) viewed this assessment as an opportunity for the librarians to build awareness of the library before students engaged in coursework.

With the guidance of the admissions director, several librarians created web pages featuring library services embedded on the Office of Admissions' website and corresponded via e-mail with prospective students and parents to welcome them and answer questions. Miller (2012) herself researched information conveyed by student tour guides, revised the tour script, and participated in the guides' training. The admissions 
director also influenced the library by recommending "a few cosmetic changes" (p. 588) to the library's facilities prior to campus tours. However, Miller did not clearly describe what sorts of interactions emerged between librarians and prospective students and parents or if the library or the Office of Admissions changed the nature of tours in a meaningful way; she noted merely the office of admissions staff were grateful for librarians' assistance.

\section{First-Year Experience}

While librarian/student affairs collaborations focused on students prior to their entry to higher education are rare, those focused on the students' first-year experience have received greater attention in the literature. The "first-year experience" is sometimes associated with solely a seminar course or a "University 101" course, in which students are aided in the transition to higher education. In her student journey lifecycle framework, Weaver (2013) adopted a much broader perspective. The first-year experience is a constellation of student-centered programs, services, and activities that together create a cohesive learning environment, increase student persistence, ease student transition to higher education, facilitate a sense of community and institutional loyalty, and spark personal growth.

Weaver (2013) postulated that much, if not the majority, of student learning during the first year of higher education takes place outside of the classroom; therefore collaborations between librarians and student affairs professionals designed to support the first-year experience should engage students largely outside of the established curriculum. Specifically, Weaver claimed student housing, counseling and tutoring programs, student unions, learning and media commons were the most promising 
grounds for collaborations. It is important to note that Weaver wrote with European systems of higher education, principally British, in mind.

Cummings' (2007) article does not concern the first-year experience per se but is the most appropriate study to preface this stage of the student journey lifecycle because she emphasized that student affairs professionals offer the most promise in helping librarians connect with students outside of the library, especially very early in students' experiences on campus. Cummings was focused on marketing Washington State University's library to students and recounted librarians' efforts at staffing tables with pamphlets advertising the library at transfer student orientations and at events coordinated by the Office of New Student Programs. When these activities attracted little interest from students, the residence life staff suggested librarians create door hangers advertising the library that the residence life staff would then post on freshmen's doors in the residence halls. The librarians ceased publishing the door hangers after two years due to fiscal restraints and uncertainty about their effectiveness, but Cummings noted the residence life staff taught the librarians more about student culture and the importance of timing when marketing the right message to first-year students. Despite this, Cummings did not imply that a new program or service developed together would subsequently commence.

Crowe, Hummel, Dale, and Bajirzian (2012), Long (2011), Riehle and Whitt (2009), and Strothman and Antell (2010) provided case studies of librarians entering traditional student spaces - the undergraduate residence halls - to market the library or to directly provide research and information support. In response to the chancellor's vision of seamless learning at the University of North Carolina at Greensboro, librarians were 
assigned to the residential colleges and made "house calls," in which they visited every first-year student during their first week on campus and provided reference services and information literacy workshops during other times of the year. The librarians found their experiences inconsistent; one librarian was warmly embraced by one of the residential college directors and integrated into college activities and programs, whereas many of the other librarians found the varied success was ultimately "not a good fit" for their time and expertise (Crowe, Hummel, Dale, and Bazirjian, 2012, p. 121).

Long (2011) described his role as a librarian who worked entirely outside of the university library and was embedded fully into the residence halls, managing several small branch libraries whose collections supported the living-learning communities at the University of Illinois at Urbana-Champaign. Long (2011) shared some responsibilities with residential life staff, such as training resident assistants, mediating student conflicts, and creating hall programming that integrated research skills and library resources. This unique position itself was borne out of a collaboration between the university library and the university housing division to bridge students' information needs not met by the research focus of the library (Long, 2011). The library initially funded the salary and provided a book budget to support first-year curricula and the housing division provided space and infrastructure support. However, Long acknowledged his role was difficult to navigate, often marginalized by librarians at the university library and poorly understood by residential life staff.

Strothman and Antell (2010) were inspired to bring library services into residence halls after participating in the University of Oklahoma's Faculty-in-Residence program and living among undergraduate students for three years. Based on their observations of 
students studying together in hall lounges and consulting each other for information guidance, Strothman and Antell concluded librarians could use these opportunities to teach students about research skills and information literacy at students' point-of-need. They established a program called Research Rescue, for which they provided refreshments at a set time in the lounges and made themselves available for research assistance. Additionally, they founded a book discussion group and held educational programs jointly with residential life staff, such as a popular program on censorship. Ultimately, student participation in these activities were low, leading Strothman and Antell to observe that "students guard their free time closely and are unwilling to give them up unless that an event is worth their while" (p. 53). Nonetheless, they found their involvement affirming because they believed they were able to reduce students' library anxiety and reach students who might not have otherwise benefitted from librarians' expertise (Strothman \& Antell, 2010).

Riehle and Whitt (2009) attempted to teach information literacy sessions in the lounges of residence halls at Purdue University. Their sessions were not tailored to individual students or to educational programs devised by residential life staff. Instead, they partnered with residential life to sponsor a traditional library instruction session as a regular hall program because the housing division's mission called for a specific number of academic programs in the halls. Residential life marketed the program and encouraged students to attend through food incentives, and the librarians oriented students to the library's website and services through laptop computers. Riehle and Whitt believed their sessions would have proven successful with more time to become established as a regular 
program, but the librarians were unable to continue the programs due to a more urgent need to cover service points and activities at the library.

Like residence hall staff, librarians have brought library services to students associated with cultural centers. Love and Edwards (2009) described their experiences approaching the student affairs professionals who managed the Latino/a and Asian American cultural centers at the University of Illinois at Urbana-Champaign. Much like Strothman and Antell (2010), Love and Edwards hosted programs at the cultural centers that oriented students to the library and held personal research consultations for students. The staff at the cultural centers provided space, introductions to students, and assistance with food incentives for the programs. Although Love and Edwards speculated they would be unable to forge long-lasting relationships with many students because of their commitments at the library, they noted the purpose of their outreach was partly to demystify the university library to under-represented students, whose persistence was lower than their Caucasian counterparts. Consequently, Love and Edwards found their time and efforts to be well spent and beneficial.

Aguilar and Keating (2009) created a similar opportunity at the University of New Mexico after Native American students reported in a survey that the university's libraries were overwhelming and intimidating, and that the students therefore felt discouraged from them. Supported by a grant from the Indigenous Nations Library Program, Aguilar and Keating provided wireless access networks and mobile equipment for the Native American cultural house and for the Women's Resource Center. Subsequently, three librarians spent an average of 12-20 hours per week at the cultural house and resource center. Aguilar and Keating reported significant success, suggesting the librarians 
answering primarily directional questions or referrals to student services offices at first but held numerous research consultations as the academic year unfolded. Aguilar and Keating attributed their success to establishing personal relationships with students that segued into professional mentoring, but the librarians noted they shared Native American identities with the students they served and observed that some of their Caucasian colleagues were unable to establish rapports and became frustrated with the students' lack of interest in their presence.

Librarians at California State University Northridge partnered with student affairs professionals to meet the information literacy needs of students in fraternities and sororities (Lampert, Dabbour, \& Solis, 2007). Inspired to reach out to the Office of Greek Life by the character Elle's speech extolling the virtues of sorority life in the film Legally Blonde, the librarians learned fraternity and sorority chapters held members to certain academic standards, and that some members struggled to maintain their grade point average (Lampert et al., 2007). Through the Office of Greek Life, Lampert et al. reached out to individual Greek chapters and offered library orientation and information literacy sessions for chapter members in their houses. Interestingly, Lampert et al. observed that the sessions were effective at reaching students, despite students appearing disinterested and bored at the sessions. Instead, Lampert et al. reported many of the same students visited them later at the library for consultations, explaining that they were too embarrassed to ask questions in front of their Greek brothers or sisters.

Love and Edwards (2009), Aguilar and Keating (2009), and Lampert et al. (2007) demonstrated that librarians can reach new audiences when they enter student spaces. The students associated with the cultural houses and the women's resource center felt 
comfortable, protected, and at ease in those spaces. Consequently, Love and Edwards and Aguilar and Keating were reportedly successful at helping the students navigate the library, arrange research consultations, and improve their information literacy skills.

Lozano (2010) described the importance of spaces that support students' sense of identity and belonging and noted that promoting spaces that enable students to feel psychologically secure will often positively influence students' academic performance. Long (2011), Strothman and Antell (2012), and Riehle and Whitt (2011) appeared to have less success reaching students in undergraduate residence halls, perhaps because these spaces are not principally designed to support students' identities but to provide safe living spaces.

Lastly, Maloney, Royce-David, and Griego (2012) partnered with the Office of New Student Programs and Family Programs at the University of the Pacific to bring a library presence to the first-year experience activities. Librarians participated in the “Mountains, Oceans, Valley Experience," a service project experience in which all firstyear students participate and attempted to increase students' early awareness of library resources. For example, students read John Muir's diaries, held by the library's special collections, before a trip to Yosemite National Park. However, the librarians had difficulty assessing the impact of their work and had yet to conclude whether students' early awareness of library resources translated to earlier use (Maloney, Royce-David, \& Griego, 2012).

\section{On-Course}

Accardi, Garvey-Nix, and Meyer (2012) created a plagiarism prevention program as a partnership between instruction librarians, writing center staff, and the student 
conduct and judicial officers. The program was borne from a noted increase in plagiarism cases referred to the student conduct and judicial officers by faculty at Indiana University Southeast. The vice chancellor of student affairs approached the librarians and the writing center staff for assistance, and together the collaborators developed the curricula for a program designed for different stages of student development (Accardi, Garvey-Nix, \& Meyer, 2012). A staff member from each area is responsible for teaching a different element of the program: The librarians teach citing sources correctly, the writing center staff teach time management skills for writing assignments and developing original statements, and the student conduct and judicial affairs staff teach the consequences stemming from plagiarism. Accardi, Garvey-Nix, and Meyer planned to expand their program to include transfer student orientation and the living-learning programs in the residence halls so students did not associate the program purely with punitive measures. The plagiarism education program appears to be one of the few examples of a collaboration between librarians and student affairs professionals in which each party brought expertise and energy to create a new program or service that served the students in a way that neither party could achieve separately.

Librarians partnered with student affairs to offer programs for students within the library to complement their studies. Kahl, a librarian, and Paterson, the dean of students, (2012) promoted civic engagement to students at Illinois State University by installing Thoughts on Democracy, an exhibit of eighty graphic works and recruiting speakers for an organized programs of lectures held at the library; they did not target any particular group of students as the exhibit's audience but believed many students would interact with the exhibit due to the library's popularity with students (Kahl \& Paterson, 2012). 
The case study is one of the few where the role of the student affairs professional is documented; in this case, Paterson negotiated vendor contracts and coordinated programs. However, Kahl and Paterson (2012) noted the Thoughts on Democracy exhibit was borne out of their particular passion for teaching citizenship and was not the result of the library's or student affairs division's priorities. The collaboration was never intended to be long-lived and did not result in continued joint passive programming after the Thoughts on Democracy exhibit ended (Kahl \& Paterson, 2012).

\section{Career Preparation}

Much of the literature emphasizes collaborations between student affairs professionals and a subset of librarians - those whose responsibilities provide direct service to patrons, such as reference, instruction, and outreach librarians. However, approximately half of academic librarians are principally engaged in other responsibilities related to library operations, such as acquiring and cataloging collections, preserving fragile or damaged materials, and administering electronic resource systems (Griffiths \& King, 2009). Elguindi and Sandler (2013) described a collaboration between several of these librarians and the staff at the career center and the Gay, Lesbian, Bisexual, and Transgender (GLBT) Resource Center at American University.

Elguindi and Sandler (2013) recognized that the career center and the GLBT Resource Center managed sizable book collections related to both career exploration and GLBT fiction. The student affairs professionals desired to circulate the materials to students but found managing their inventory and loans to be too cumbersome to continue without better organization and technology. The catalog librarians and a technology services librarian helped the student affairs professionals determine that an automated 
catalog and circulation system would best suit their purposes. Consequently, they adopted a technological solution and taught the student affairs professionals staff how to organize and manage their collections. Elguindi and Sandler explained all librarians are capable of outreach and collaboration and should consider what skills they have to offer that resolve unmet needs on campus; librarians should not look toward developing students' cognitive or information literary skills as the sole way they could contribute to student success.

The career services staff at the University at Buffalo maintained a book collection on job seeking strategies and interview tips for students (Hollister, 2005). After meeting the career services staff by teaching a University 101 course together, Hollister, a librarian at the University at Buffalo's undergraduate library, assessed the career center's book collection and found it "unwieldy, unattractive, and access-prohibitive" (p. 108). Hollister helped the student affairs professionals replace some materials with electronic counterparts, identify obsolete media, and craft a book donation policy. After Hollister helped the student affairs professionals curate their book collection, they found the opportunity to discuss the career center's goals and the ways they help students prepare for the job market. Hollister was then able to teach the career center staff about resources the undergraduate library held that helped the career center staff remain current on trends in career counseling in higher education.

\section{Gap Analysis}

For nearly 20 years, studies have shown that student persistence, development, and academic performance are greatly enhanced when faculty and student affairs professionals adopt a collaborative approach to learning (Kuh, 1996; Pascarella and 
Terenzini, 2005). For higher education institutions to support a seamless or holistic approach to student learning, academic affairs and student affairs divisions must reconceptualize their roles in learning and in their relationships with each other. Librarians and student affairs professionals would appear to be successful prospective partners in such collaborations. However, relatively few case studies of collaborations between the two disciplines exist.

Librarians and student affairs professionals shape student learning and development outside of the traditional classroom environment. The core values of both disciplines suggest areas in which librarians and student affairs professionals might overlap in their work, such as developing students' citizenship skills, advocating for equity and social justice in the educational process, and simply serving students' needs so they are able to successfully navigate their educational experience. Some examples of possible collaborations could include librarians and academic advisors participating together in intrusive advising to help exploratory students remain engaged in their studies. Librarians could also be embedded in career centers and TRIO programs in order to help students attain post-college employment aligned with their value systems and orient at-risk students more deeply into the academic environment.

Forrest (2005) asked of collaborations between librarians and student affairs professionals, "Do they even exist?" (p. 12). A few notable case studies on collaborations between librarians and student affairs professionals are available in the scholarly literature, but these case studies present significant shortcomings. All of the case studies are written by and for librarians and intended to provide best practices or showcase a set of circumstances that "worked." However, I question whether these case 
studies truly embody collaboration. John-Steiner (1998) suggested that true collaborators not only plan, decide, and act jointly, but they also think together and combine independent conceptual schemes to create an original framework. They share resources, talent, and power, and their resulting work products reflect the blending of all participants' contributions and endure long after the original collaborators have departed (John-Steiner, 1998).

Each of the collaborations appeared somewhat ephemeral: Lampert, Dabbour, and Solis (2007), Riehle and Whitt (2009), Strothman and Antell (2010), and Marines and Venegas (2012) offered no evidence that their collaborations will survive long after the individual actors have moved into different roles. Rather, their collaborations appeared to take shape because of common interests and unique, temporary circumstances. For example, Strothman and Antell taught information literacy to students through programs offered in residence hall lounges because those collaborators resided within the residence halls. Because her spouse's participation in the faculty-in-residence program was for only a year, the librarian collaborator noted that her residency was only temporary. Riehle and Whitt concluded their case study on research workshops in residence halls was successful in regards to student interest and attendance, but constrained too significantly by budgets, staffing, and diverse institutional priorities to continue. Rather, they intended to move their content to self-directed online tutorials and to train resident directors and resident assistants in research expertise as much as possible (Riehle \& Whitt, 2009).

Perhaps more troubling is the lack of perspectives shared by the student affairs professionals in these collaborations. None of the case studies explained the stakes, 
benefits, or desired outcomes from the student affairs professionals' perspectives. In most of the case studies, they were invisible collaborators and were barely mentioned at all. Their contributions to the collaborations appeared relegated merely to the provision of space, supplies, or permission. Their roles were largely those of gate-keeping, helping the librarians gain access to students in spaces where librarians did not typically venture such as residence halls and cultural houses. Where were the voices of the student affairs professionals?

If librarians and student affairs professionals have yet to collaborate extensively, what are the reasons for their lack of involvement? Becher and Trowler (2001) suggested collaboration between academic disciplines is most successful when each discipline shares a common vision of learning, a common language, a common perspective on students, and the ability to foster mutually satisfying dialogue. Yet higher education literature on collaborations between student affairs and academic affairs has focused primarily on the structural, cultural, human resource, and political barriers that exist to impede collaborations (Kezar, 2006; Kezar \& Lester, 2009; Becher and Trowler, 2001). More research is needed to enable successful collaborations between librarians and student affairs professionals, including exploring their perceptions of each other's roles in student learning.

Swartz, Carlisle, and Uyeki (2006) acknowledged librarians and student affairs professionals have very different ideas regarding effective student learning. Kezar (2006) claimed competing ideas as to what constitutes learning is one of the major impediments to collaboration generally, indicating epistemological differences create conflict. Although librarians value citizenship and other forms of student development, librarians 
are most interested in developing students cognitively. Student affairs professionals have broader assumptions about student learning and might grow frustrated with librarians' rather limited view of the scope of their work. Consequently, librarians' and student affairs professionals' ideas about what constitutes student learning and success and the way they see themselves able to make contributions are crucial to developing successful collaborations.

Schulte and Sherwill-Navarro's (2009), Nilsen's (2012), and Peltier's (2014) studies conveyed the importance of perceptions to collaborations. If one actor has unfavorable or inaccurate ideas about the other actor, collaborations will not develop easily; personality differences, interpersonal skills, and broad perspectives of campus environments matter (Peltier, 2014). The extant literature provides little to no indication what student affairs collaborators might have thought about their librarian collaborators. Similarly, the librarians' portrayals of the student affairs collaborators were fleeting, marginal, or outright absent.

Accordingly, this study attempted to address the gaps in the literature regarding how librarians and student affairs professionals perceive their own and each other's roles in student learning and success. Additionally, the study identified how librarians perceive student affairs professionals and vice versa. The following research questions were explored: How do librarians and student affairs professionals describe student learning and student success? How do librarians and student affairs professionals perceive their own roles and each other's roles in student learning and student success? Where do they see the work of librarians intersect, if at all, with the work of student affairs professionals? How might they approach collaborations in these intersecting 
areas? How might the work and identities of librarians and student affairs professionals change because of these collaborations? To think more deeply about the potential disciplinary similarities or differences between student affairs and librarianship, each profession's relationships to students and the language they use to talk about their work was examined. The findings provide an understanding of the values and philosophies they might have in common or which might place them far apart. 


\section{CHAPTER III METHODOLOGY}

The purpose of this study was to explore librarians' and student affairs professionals' perceptions of each other's roles in student learning and success, identify opportunities for prospective collaborations, and identify the conditions that impede or facilitate prospective collaboration. The study employed focus group interviews with librarians and student affairs professionals at four universities in Illinois. The study was guided by the following research questions:

1. How do librarians and student affairs professionals describe student learning and student success?

2. How do librarians and student affairs perceive their own roles and each other's roles in student learning and student success?

3. Where do they see the work of librarians intersect, if at all, with the work of student affairs professionals?

4. How might they approach collaborations in these intersecting areas?

5. How might the work and identities of librarians and student affairs professionals change because of these collaborations?

This study was conducted in two phases. First, I moderated seven focus groups at four higher education institutions in Illinois. Of the seven focus groups I held, four consisted of librarians and three consisted of student affairs professionals. All the focus 
groups had between four and seven participants. After I conducted the focus groups and analyzed my data, I held two webinars for all of the participants. In the webinars, I explained my findings and asked the participants if the findings made sense.

Subsequently, my participants and I engaged in a discussion of the findings' implications.

Following a discussion of the underlining rationale for employing the focus group technique to the study, this chapter describe the methods and procedures as well as the steps taken to assure trustworthiness and credibility of the collected data.

\section{Philosophical and Methodological Framework}

If the purpose of a study is to explore and understand participants' experiences and perspectives, a qualitative methodology is the most appropriate framework because it probes the meaning that participants attach to certain situations and problems (Creswell, 2009). This study aimed to provide rich descriptions of participants' understandings with the goal of generating new understanding of how the work of librarians and student affairs professionals intersect and what this understanding means for collaboration that furthers student learning and student success. Reddick (2014) noted, "researchers can clarify the why and the how behind participants' responses when conducting qualitative studies" (p. 38). Surveys with open-ended questions might collect short responses, but there is no opportunity for the researcher to better understand why a participant believes or thinks a certain way. A more in-depth qualitative methodology provides the researcher an opportunity to explore why. Because the study examined how participants understood and explained their own and each other's roles in student learning and student success, as well as how those roles might be changed by collaborating with each other, a phenomenological approach was appropriate. Phenomenological methodologies seek 
participants' voices in order to plumb their stories and perspectives for an understanding of how participants experience their lives and create meaning (Creswell, 2009).

Although individual interviews might yield such useful data, group interviews (e.g., focus groups) are appropriate when the topic of the study concerns group interaction. This study is concerned with collaboration, which certainly requires one or more actors working together to create meaningful experiences for the benefit of students. Reddick (2014) claims phenomenological group interviews pose two advantages over individual interviews: Data are expanded and enriched as participants reflect on and share their perspectives, and confirmation and clarification of understanding are immediately possible both among participants and between participants and researcher. The interaction between participants enhances the participants' sharing by stimulating discussion and enriching their stories (Reddick, 2014). Group interviews facilitate a more collaborative and rewarding atmosphere for the participants than do individual interviews.

\section{Overview of Focus Groups}

Focus groups were the most appropriate tool for collecting data in this study. Focus groups are a form of in-depth interviewing in a group setting (Krueger, 1998; Morgan, 2002; Stewart and Shamdasani, 2015). The purpose of focus groups is to collect rich, detailed data and to explore topics about which little is known from a group of people simultaneously. Morgan (2002) defined focus groups as a "research technique that collects data through group interaction on a topic determined by the researcher" ( $p$. 141). Stewart and Shamdasani (2015) differentiated group depth interviews from other techniques by examining the meaning of the three words: a group is a "number of 
interacting individuals having a community of interest," depth involves "seeking information that is more profound than is usually accessible at the level of interpersonal relationships" and interview implies the presence of a moderator who "uses the group as a device for facilitating discussion and information" (p. 39).

Focus group interviews typically involve five to eight participants who discuss a particular topic under the direction of a moderator who promotes group interaction and will generally last between 1-2 hours (Morgan, 2002). Although focus groups can vary in size, smaller groups tend to provide discussion that is less robust, and larger groups are difficult to manage and inhibit participation by all members of the group (Stewart \& Shamdasani, 2015). Although focus groups can be conducted in a variety of settings, it is most common for focus groups to be held in facilities designed for groups, such as conference rooms (Stewart \& Shamdasani, 2015). Audio- or video-taping the group interview is typical, although Krueger (1998) noted that video-taping participants tends to make participants uncomfortable and might stilt productive discussion, while audiotaping is less visible and less intrusive from the participants' perspective and therefore less inhibiting of discussion.

The moderator serves as the interviewer and is nondirective, thus enabling the discussion to flow naturally as long as it remains more or less on topic. Krueger (1998) recounted three types of moderators: professional, occasional, and researcher. Professional moderators are experts in interpersonal group dynamics and nonverbal communication; they probe at crucial moments without leading participants, make participants feel at ease, and refocus questions to keep discussions on track. Krueger (1998) claimed professional moderators are "worth their weight in gold and cost 
accordingly" (p. 38). While market research companies tend to employ professional moderators, most social science research involves occasional moderators (Krueger, 1998).

Occasional moderators are typically internal staff members of the organization associated with the research study and are experienced in leading staff meetings or other group discussions under normal work conditions. They can be valuable because they are intimately familiar with the discussion topics, the organization, or the history and culture of the participants (Krueger, 1998). While they might not be trained as expertly in group dynamics as professional moderators, social science researchers may choose to employ occasional moderators for two reasons: If the researcher does not share the racial, ethnic, gender, or occupational identities of the participants in the focus group or if the researcher is concerned his or her presence will bias the participants' responses (Krueger, 1998).

The researcher might also serve as the moderator. Krueger (1998) explained researchers are the most risky type of moderator, as they often lack experience with group facilitation and intergroup dynamics. There is also a risk the researcher will unintentionally bias the group interview with nonverbal behavior or chill discussion by not sharing the gender, racial/ethnic, or occupational identity of the participants (if the majority of participants will belong to the same gender, race/ethnicity, or occupation). However, advantages of researcher-moderators include deep familiarity with the subject matter being explored and fewer complexities in obtaining institutional review board approval and in focus group planning and administration (Krueger, 1998). For this study, I served as the moderator for the focus groups for the reasons Krueger (1998) identified. 


\section{Focus Group Theory}

Stewart and Shamdasani (2015) proposed four criteria that constitute focus group theory: focused research, group interactions, in-depth data, and humanistic interviews. The purpose of focused research is to gather qualitative data from individuals regarding their perceptions, reflections, or experiences in order to understand how these individuals create meaning. The objective of an interview, whether individual or group, will be relatively narrow in focus since the researcher is exploring a particular phenomenon or issue. This objective contrasts with survey research, which often gathers data on numerous topics and variables (Stewart \& Shamdasani, 2015). Indeed, Barbour and Kitzinger (1999) claimed focus groups are the most commonly prescribed methodology for research that is "exploratory, clinical, and/or phenomenological" (p. 9).

Reddick (2014) claimed what sets focus groups apart from other qualitative forms of inquiry and from interviewing is the interaction between groups members. Reddick (2014) noted, "Synergy in the group interaction usually prompts greater breadth and depth of information, and comparison of views within a group leads to greater insight into experiences” (p. 40). Stewart and Shamdasani (2015) reported “...stimulating interactions among group participants are hypothesized to generate more information than individual interviews would provide..” (p. 10). Morgan (2002) suggested interviews in a group setting allow researchers to observe how and why individuals accept or reject others' ideas, which is critical when the explored topic concerns collaboration, partnerships, or other activities in which individuals must have a shared vision or sense of purpose. 
Stewart and Shamdasani (2015) purported in-depth data is a bedrock for focus group research: "The prototypical focus group was characterized by a relatively small number of loosely structured questions that revolved around a focal topic or stimulus and encouraged extensive discussions and probing" (p. 12.) Krueger (1998) cautioned researchers that direct questions elicit direct answers, and 30 or more questions can reduce individuals' response times to 13 seconds or less. Krueger (1998) wrote, "Recent research concludes the vast majority of human thought is visual, metaphorical, and emotional and resides deeply in neurological substrata; access to these mental zones typically requires more subtle, indirect approaches to asking questions..." (p. 13) Morgan (2002) suggested less structured approaches to moderating focus groups result in participants talking to each other rather than addressing the moderator, and participants' interests are dominant rather than the researcher's interests. Morgan (2002) noted, "The goal is to understand participants' thinking rather than to collect answers to the researcher's questions" (p. 147).

Lastly, Stewart and Shamdasani (2015) identified humanistic interviews as the fourth criteria that girds focus group theory. Because focus groups require some degree of immersion into participants' lives, the researcher must demonstrate qualities that respect and enable the participants' voices. These qualities include active listening, empathy, openness, and honesty about oneself and the purpose of the research (Stewart \& Shamdasani, 2015). The data collected should be used for developmental rather than for evaluative purposes. Moderators should not seek to achieve group consensus and should not feel compelled to ask every question in the discussion guide if doing so would 
"destroy the elements of freedom and variability within the interview" (Stewart \& Shamdasani, 2015, p. 13).

\section{Strengths and Limitations}

Focus groups provide a number of advantages relative to other types of qualitative research. They collect data from a group of participants more quickly than would be the case for individual interviews. The open response format of the discussion provides opportunity to obtain large, rich amounts of data in the participants' own words, enabling the researcher to make important connections and identify nuances in meaning (Stewart \& Shamdasani, 2015). Researchers are able to interact directly with participants, allowing for the probing of responses and the clarifying of questions. It is also possible for the researcher to observe nonverbal responses (Stewart \& Shamdasani, 2015).

Additionally, focus groups can be catalytic, in that the group members may become motivated to take action regarding the topic they have discussed (Stewart \& Shamdasani, 2015).

There are nonetheless several potential limitations to consider in employing focus groups as a research method. Researchers may never truly know if the participants are sharing their true beliefs and perspectives, or if they are altering their responses in light of what they anticipate others in the group might want to hear. Piercy and Hertlein (2005) acknowledged bias is an inherent risk in focus groups as "strong group members, unfamiliar surroundings, or the moderator may have somehow biased the results" (p. 94). Reddick (2014) observed: 
Even though the potential for group interaction is perhaps its greatest strength, it could also be a barrier for participants to share, as they could feel as though they must reach a consensus with the group and limit their responses that would be dissimilar or contrary to the overall opinion. (p. 41)

Reddick (2014) and Stewart and Shamdasani (2015) suggested group cohesiveness is a critical element in ensuring group interaction and reducing barriers to sharing. The more cohesive the group, the more likely the moderator will be able to facilitate open and honest discussion of even the most sensitive of topics (Stewart \& Shamdasani, 2015). The more homogenous the group is, the more cohesive the group will be (Stewart \& Shamdasani, 2015). Although gender, age, socio-economic status, etc. will influence the homogeneity, and thus the cohesiveness, of the groups, Krueger (1998), Morgan (2002), Stewart and Shamdasani (2015) claimed personality traits are the greatest controlling factor. Stewart and Shamdasani (2015) noted extroversion is likely to have the most common and greatest effect on group interaction:

In a mixed group of extroverts and introverts, a moderator will need to work very hard indeed to keep the extroverts from dominating the discussion while drawing out the introverts. The bottom line with respect to personality factors in focus group research is that it is important to recognize them and in [some] cases make them the basis for selecting participants in specific groups. (p. 22-23) This is an especially important point in light of the two professional groups involved in this study. Cutler (2003) described the professional identity development of student affairs professionals and emphasized the great numbers of extroverted personalities in the student affairs profession. She speculated the student affairs 
profession strongly desires extroversion as a personality trait because student affairs professionals spend so much time working with students directly (often in informal environments, such as residential life). Student affairs professionals must build relationships with peers and students and be fully engaged during traditional work hours for meetings and nontraditional hours for face-time with students. Extroverted personalities are typically able to meet these demands more easily than introverted personalities (Cutler, 2003). Although introverted personalities are present and necessary in student affairs, the profession has a tendency to screen out introverted applicants during the hiring process (Cutler, 2003).

In librarianship, the socialization process tends the other direction. Historically, the nature of librarianship has favored solitary work. Arguably, it is not strictly necessary for librarians to build relationships with peers and students in order to be successful at acquiring the right resources for a strong collection, demonstrating databases, or answering reference questions accurately - although this may be changing in light of librarian's increasing emphasis on working more closely with faculty and students (Maxwell, 2006). Maxwell (2006) claimed that librarians adopt passive student outreach practices, too, such as investing time and effort into exhibits and guest speakers rather than engaging students directly, and that librarians wait at service points for students to initiate contact rather than seeking out students for reference consultations. Maxwell (2006) speculated that libraries' traditional quiet atmospheres tend to attract introverted personalities who desire to work alone. 
Although the high numbers of extroverted personalities in student affairs and introverted personalities in librarianship do not preclude collaboration with each other, the differences in personalities must be acknowledged as a possible barrier to the way each group manages its work and relates to others. Accordingly, this study employed separate focus groups for librarians and for student affairs professionals.

\section{Sampling}

I sampled librarians and student affairs professionals from a specific set of higher education institutions. Because I selected the institutions before I sampled the librarians and student affairs professionals employed there, I will describe my selection method of the institutions before addressing my selection of the participants. The study concerns collaborations designed to benefit traditional-aged, residential undergraduate students. Consequently, I recruited participants from higher education institutions with an undergraduate profile defined by the National Center for Education Statistics as predominately four-year and residential in character with an enrollment of at least 5,000 undergraduates.

Higher education institutions with enrollments of at least 5,000 undergraduate students were more likely to employ library and student affairs staff of sufficient size to enable me to recruit at least six to eight persons from each profession for focus groups. I wanted to include at least three higher education institutions in the study to enable a sufficient total number of participants and for site triangulation. Because my ability to travel was limited due to the constraints of my employment, I wanted these higher education institutions to be no more than 200 miles, or approximately a half day's drive, from my home city. 
Using the National Center for Education Statistics' College Navigator (https://nces.ed.gov/collegenavigator/), I identified 43 higher education institutions that met these criteria. Of these colleges and universities, I targeted 23 that represented a cross-section of institutions in terms of control (public and private), enrollment size, and focus (liberal arts and comprehensive curricula.) The diversity of the higher education institutions strengthened the study's trustworthiness.

I anticipated group interviewing between 36-48 participants in total by holding six focus groups that comprised six to eight participants per focus group. Because this study concerns collaboration between librarians and student affairs, I wanted approximately half of the recruited participants to be employed as academic librarians and approximately half to be employed as student affairs professionals. I did not target participants of a particular age or length of employment, but I used the following criteria to determine eligibility for participation in the study:

1) The participant was at least 18 years of age.

2) The participant possessed a degree in either library and information science or in a field that commonly places persons into student affairs positions, such as higher education administration, college student personnel administration, educational leadership, college student affairs, etc.

3) The participant was employed at the time of recruitment as either a librarian or as a student affairs professional and had been so employed - at either the participant's current higher education institution or elsewhere - for at least three years. Those with less than three years of professional experience might not have had sufficient time to formulate perspectives on their roles in student 
learning and success and on the collaborative efforts that might be undertaken between librarians and student affairs professionals.

4) The participant was engaged in activities that brought the participant into significant or daily contact with undergraduate students; such as teaching, advising, counseling, providing library reference or instructional services, etc.

\section{Recruitment}

Participant recruitment occurred in two stages. First, I sought permission from chief library officers and chief student affairs officers at the 23 higher education institutions to undertake my study with the librarians and student affairs professionals in their respective employ. I pursued the second stage of my recruitment only if both the chief library officer and the chief student affairs officer at the same institution consented. After both chief officers provided their consent, I pursued the second stage of recruitment by seeking librarians and student affairs professionals to participate in the focus groups.

\section{Stage 1: Securing Permission from Chief Library and Student Affairs Officers}

Morgan (1998) cautioned that focus groups that occur in the workplace must, by necessity, involve approved time off from participants' normal duties. Therefore, participants' supervisors must provide permission in order to gain access to participants. Morgan (1998) recommended seeking permission from the highest possible person in the hierarchy, who could then assure lower level supervisors that prospective participants' time away from their normal duties was permissible. Since both libraries and student affairs divisions are often hierarchical organizations with many supervisors in the chain of command, I sought the permission of the chief library officers and chief student affairs officers. 
I examined the websites and publicly available staff directories at the higher education institutions to identify the chief library officers and chief student affairs officers. I sent e-mail messages to those officers, in which I explained the purpose of my study, requested their permission to contact and solicit the participation of librarians and student affairs professionals employed at their institutions, and - if I recruited a sufficient number of participants to conduct focus groups - sought their agreement to help me secure a private location for the focus group meetings. The chief library officers and chief student affairs officers were to have no other involvement in the study in order to diminish the likelihood of coercion of participants. In my e-mail messages, I also included copies of the recruitment letters and the informed consent forms I intended to send to prospective participants. I sent a follow-up e-mail if I had not received a reply within four weeks of my initial message. In no case did I send more than two queries.

Because I wanted to recruit librarians and student affairs professionals employed at the same institutions for site triangulation purposes, my plan was to proceed with the second stage of my recruitment only if I was able to secure the consent of both the chief library officer and chief student affairs officer. Of the 23 institutions I targeted, I received affirmative responses from the chief library officers and chief student affairs officers at five higher education institutions. I chose not to proceed with the second stage of recruitment with one of the five institutions after the chief student affairs officer informed me that I would be unlikely to recruit a sufficient number of participants among the student affairs professionals; they had been recently deluged with similar requests from other doctoral students and suffered "study fatigue." 


\section{Stage 2: Recruiting Focus Group Participants}

Targeting librarians and student affairs professionals at these four institutions (Table 1, below), I proceeded with the second stage of my recruitment. To minimize the risk of coercion from chief library officers or chief student affairs officers, I contacted librarians and student affairs professionals myself after obtaining their names and e-mail addresses from institutional websites and publicly available staff directories. In my email message, I explained the purpose of my study, what the study required of participants, anticipated risks and benefits of participation, and my anticipated timelines for the focus groups and webinars. I also provided a copy of an informed consent form as an attachment they could return via e-mail, fax, or postal mail. Again, I sent a follow-up e-mail if I had not heard from participants within four weeks of my initial message. Again, in no case did I send more than two queries. 
Table 1

Characteristics of the Four Participating Higher Education Institutions

\begin{tabular}{|c|c|c|c|}
\hline Institution & $\begin{array}{l}\text { Undergraduate } \\
\text { Enrollment and } \\
\text { Profile }\end{array}$ & $\begin{array}{l}\text { Basic Carnegie } \\
\text { Classification }\end{array}$ & Size and Setting \\
\hline University A & $\begin{array}{l}13,306 \\
\text { High undergraduate, } \\
\text { selective, higher } \\
\text { transfer-in }\end{array}$ & $\begin{array}{l}\text { Public, research } \\
\text { university with high } \\
\text { research activity }\end{array}$ & $\begin{array}{l}\text { Large four-year, } \\
\text { primarily residential }\end{array}$ \\
\hline University B & $\begin{array}{l}5,830 \\
\text { Very high } \\
\text { undergraduate, more } \\
\text { selective, higher } \\
\text { transfer-in }\end{array}$ & $\begin{array}{l}\text { Private, master's } \\
\text { colleges and } \\
\text { universities with } \\
\text { balanced arts \& } \\
\text { sciences/professions }\end{array}$ & $\begin{array}{l}\text { Medium four-year, } \\
\text { highly residential }\end{array}$ \\
\hline University C & $\begin{array}{l}32,695 \\
\text { Majority } \\
\text { undergraduate, } \\
\text { selective, lower } \\
\text { transfer-in }\end{array}$ & $\begin{array}{l}\text { Public, research } \\
\text { university with very } \\
\text { high research } \\
\text { activity }\end{array}$ & $\begin{array}{l}\text { Large four-year, } \\
\text { primarily residential }\end{array}$ \\
\hline University D & $\begin{array}{l}15,814 \\
\text { Very high } \\
\text { undergraduate, } \\
\text { inclusive, higher } \\
\text { transfer-in }\end{array}$ & $\begin{array}{l}\text { Public, } \\
\text { doctoral/research } \\
\text { university }\end{array}$ & $\begin{array}{l}\text { Large four-year, } \\
\text { primarily residential }\end{array}$ \\
\hline
\end{tabular}

In the course of this recruitment stage, I encountered difficulty with one of the four higher education institutions because the initial response provided by the chief student affairs officer proved ambiguous. Attempts to clarify whether I had secured consent to contact the student affairs professionals yielded no response, leading me to cease recruitment of the student affairs professionals. However, the librarians had 
expressed great interest in participating in a focus group, so I proceeded with a focus group for the librarians. Consequently, my study resulted in focus groups with librarians and student affairs professionals at three institutions and a focus group of librarians at a fourth institution.

All together, I sent recruitment messages to 62 librarians and 71 student affairs professionals. Of these, 30 librarians and 23 student affairs professionals agreed to participate. I screened their eligibility in a subsequent message, and all participants but one met my criteria. These numbers were well within the number of participants I had anticipated interviewing, and each focus group appeared as if it would have no fewer than five and no more than eight participants.

Once I confirmed a minimum of five participants for each focus group, I sent the participants links to a survey I created using Doodle, an online scheduling tool, to identify the best date and time for the participants to meet. Often, I created more than one survey before I was able to secure a mutually convenient date and time. Then I contacted the chief library officers and chief student affairs officers again to secure a location for the focus groups, which in all cases were private conference rooms in either the library or student union building. A week prior to the focus groups, I sent each participant a reminder via e-mail.

\section{Participants}

Altogether, I held seven focus groups at four higher education institutions (Table 2, below). All the focus groups with librarians took place at a conference room located in the library whereas all the focus groups with student affairs professionals took place in rooms associated with the student union. The doors were able to be closed to ensure the 
confidentiality of the discussions. I provided light refreshments such as coffee, bottled water, and bagels for participants at most focus groups, but a few of the libraries had policies against food and drink.

Morgan (2002) acknowledged that no matter what the researcher does, a few participants will fail to show up. If at least four participants showed up, I planned to proceed with the focus group despite the hazard that four participants may not yield rich interviews. If three or fewer showed up, I planned to not proceed with the focus group for fear of collecting too little data to be useful. In that case, focus groups would have to be rescheduled, and additional participants might have to recruited. Although several participants did fail to arrive, I was able to proceed with all focus groups with a sufficient number of participants. 
Table 2

Focus Group Participants

\begin{tabular}{|c|c|c|c|c|}
\hline Institution & $\begin{array}{l}\text { Profession } \\
\text { Type }\end{array}$ & $\begin{array}{l}\text { Number of } \\
\text { Participants }\end{array}$ & Female & Male \\
\hline University A & Librarians & 6 & 5 & 1 \\
\hline University A & Student Affairs & 4 & 3 & 1 \\
\hline University B & Librarians & 4 & 3 & 1 \\
\hline University B & Student Affairs & 4 & 3 & 1 \\
\hline University C & Librarians & 6 & 6 & 0 \\
\hline University C & Student Affairs & 6 & 4 & 2 \\
\hline University D & Librarians & 7 & 6 & 1 \\
\hline
\end{tabular}

\section{Focus Group Procedures}

At the beginning of the focus groups, I summarized the purpose of my study and reviewed the informed consent forms with the participants. Although some participants had sent me signed informed consent forms prior to the focus groups, I provided consent forms for other participants to complete. I employed separate interview protocols to guide the focus group discussions with librarians and student affairs professionals. Arcelus' (2008) interview protocol for his study on collaboration between academic 
affairs and student affairs divisions served as the model for my interview protocols. The interview protocol for librarians consisted of the following questions:

1) What do you perceive to be the role of librarians at this institution?

2) Tell me about your interaction with undergraduate students. How do librarians here interact with students and for what purposes?

3) Let's turn our discussion to student affairs professionals. What do you perceive to be the role of student affairs professionals at this institution?

4) Do librarians at this institution interact with or collaborate with student affairs professionals? If so, tell me about those interactions or collaborations.

5) What other observations or insights about our discussion today might you wish to share?

The interview protocol for student affairs professionals was nearly identical but transposed student affairs professionals for librarians. I intended for the focus group discussions to be semi-structured, so often I asked follow up questions based on something a participant had just said, or I asked for clarification or elaboration on certain points. Occasionally I redirected the discussions back to the interview protocol when discussion veered too far off topic for too long but mostly I allowed participants to respond to each other's comments without further moderation.

Each focus group lasted approximately 90 minutes. Stewart and Shamdasani (2015) indicate that 90 to 180 minutes is typical for focus groups, with longer durations more conducive to thick, rich interviews. However, the lives of professionals are busy with competing demands of work, family, and other obligations; I did not think I could reasonably ask for more than 90 minutes of participants' time, especially given that all 
the focus groups were held during normal business hours. I recorded the entirety of the focus group discussions with a 1800PC digital voice recorder but I also jotted notes in a field notebook. This helped me give additional context to the transcripts.

\section{Data Analysis}

The recordings and the transcriptions of the focus group interviews served as the primary forms of my data. Transcripts do not reflect the way group members use words or the tone with which words are used, which are important sources of information and can radically alter the interpretation of a statement (Gee, 2011). Consequently, I transcribed the interviews myself so that I was able to note the nuances of the discussions that might otherwise be filtered out by a transcription service. Additionally, I listened to the recordings multiple times, often in conjunction with reviewing the transcripts.

Discourse analysis served as the framework for my analysis of the group interviews. Discourse analysis is the study of "language-in-use" and how people use language to create meaning in social, cultural, and political terms (Gee, 2011, p. 3). Although the constant comparison analysis, in which the researcher labels smaller, similar parts of multiple interviews with a coding scheme, is a popular method of analysis for group interviews, it is arguably insufficient for capturing the interactive nature of group interviews and answering such questions as "[W]hy was this said just then[?]" (Myers \& Macnaghten, 1999, p. 173). Indeed, Myers and Macnaghten (1999) claim that identities are negotiated in discourse so researchers should examine how participants set up and work out roles in focus group; that discussion is sequenced, so researchers must consider each response in terms of what came before and after; and that participants reorganize discussions moment to moment, so researchers must examine how participants 
define sections rather than researchers defining sections. Consequently, discourse analysis is an appropriate framework for analyzing the transcripts of the group interviews.

Specifically, I used Gee's (2011) theory of discourse analysis to analyze the group interviews. Gee developed 27 tools for discourse analysis, and each tool represents a specific question to ask of data. Each tool makes the researcher look closely at the details of language and tie these details to what the speakers mean, intend, and seek to accomplish by the way in which they have used language (Gee, 2011). Of the 27 tools, some will yield more illumination from the data than others, and the researcher must determine which tools will be the most appropriate (Gee, 2011). For this study, I found the deixis, vocabulary, intonation, "why this way and not that way," and the intertexuality tools to be the most critical.

\section{The Deixis Tool}

Deictics, or "pointing words," are words whose reference must be understood from the context of the larger speech (Gee, 2011). Speakers make assumptions about listeners' knowledge and experiences and drop from speech words that convey preciseness or explicitness, and deictics help listeners create the appropriate meaning. Common deictic words include "I", "you," "we," "them," "this," "there," and "that." These words often suggest how speakers position their sense of self and sense of belonging to larger groups (Gee, 2011). The deixis tool helped me interpret the situated meaning in participants' discussions by asking asking "How are pointing words being used to tie what is said to context and make assumptions about what listeners already 
know or can figure out?" (Gee, 2011, p. 10). For example, two participants at University D said to each other:

A lot of our students from over there, they're just not ready. (Dorothy) And it's our job to help them navigate here, build them up, and help them be successful here. (Peter)

Yes, that is absolutely why we're here. (Dorothy)

In the exchange, Dorothy used the pointing words "over there" to indicate a lot of students come from a specific economically-disadvantaged area, and "ready" to indicate those students were not prepared for college-level work. Yet Peter employed the deictic word "our" to position himself as part of a collective identity of student affairs professionals charged with helping students become capable of meeting the realities they faced as college students.

\section{The Vocabulary Tool}

With the vocabulary tool, I examined the specific words people used in their discourse. Gee (2011) claimed people employ a hierarchy of vocabularies depending on their social contexts, and formal words signify academic or professional domains. This tool helped me understand how participants' word choices contributed to the shaping of multiple identities. For example, a librarian shifted her vocabulary as she recounted her transition from a student employee in a library to a member of the library's professional staff; she replaced "“day to day stuff" with "daily operations" and "jobs" with "positions," she changed from an identity grounded in her student experiences to an identity grounded in the specialization of her professional identity. In essence, she was 
performing: As she progressed through her career, she embraced language that invokes technical expertise, polish, and experience.

\section{The Intonation Tool}

Gee's (2011) intonation tool highlights the saliency of a speaker's messages by focusing on how they emphasize or modify words. This helped me understand the ways participants designed their messages indirectly for others. For example, the participants emphasized certain words in the group interviews by changing their tone. For example, Greta, a student affairs professional, said, "I've learned to work with faculty and deans," and "I share ideas with them at meetings." Her intonation contributed to my understanding of the importance she placed on collaboration in order to enhance student learning but that working with faculty and administrators required her to approach those colleagues differently than she might have with her student affairs colleagues. Her consistent emphasis of the word "with" in connection with both her student affairs colleagues but also with faculty and administrators emphasized that she considered collaboration a core value of her work.

\section{The "Why This Way and Not That Way" Tool}

Gee (2011) recommends examining participants' grammar and word choices for explanations as to why participants answered questions in a certain way and not in another way; what message are they truly conveying? The "why this way and not that way" tool helped me recognize tension in participants' identities. For example, two librarians discussed their interactions with undergraduate students: 
Interestingly, I talked with some students this week. (Sabrina)

This is such a busy time of year, isn't it? I can barely keep my head above water,

but I actually have spent a few hours with students this week. (Yolanda)

The "why this way and not that way" tool showed me that these librarians were preoccupied with the day-to-day business of running their library, and they found these responsibilities took them away from their work with students.

\section{The Intertextuality Tool}

Lastly, the intertexuality tool brought to light the layers of multiple contexts from which people constructed dimensions of their identities. Gee (2011) suggests intertextuality exists when people's phrases or text refers to other literary or cultural sources; their use of quotes or allusions have certain functions, such as establishing credibility or reinforcing worldviews. For example, the student affairs professionals threaded references to other sources throughout one of the group interviews. When speaking of her work as a student affairs professional, Dorothy referenced the Student Personnel Point of View - "That's what the SPPV says" - when she explained how she had to learn about all dimensions of a student's life in order to resolve a student's problem, indicating its centrality to her professional identity.

\section{Trustworthiness of the Study}

The trustworthiness of qualitative research is often questioned by positivists because the concepts of validity and reliability cannot be addressed the same way in naturalistic work (Shenton, 2004). However, Guba (1981) proposed four criteria that should be considered by qualitative researchers that respond to the issues of validity and reliability. Additionally, Guba (1981) proposed qualitative researchers adopt different 
terminology in order to distance themselves from the positivist paradigm associated with quantitative studies. These criteria include transferability (in preference to external validity), dependability (in preference to reliability), confirmability (in preference to objectivity), and credibility (in preference to internal validity) (Guba, 1981).

\section{Transferability}

Shenton (2004) suggested the researcher demonstrates transferability by explaining the boundaries of the study and assessing the extent to which the findings may be true of people in other settings. This could be accomplished by the researcher describing the characteristics and qualities of the higher education institutions where participants are employed; the number of participants involved in the study; any restrictions in the type of participants; the number and length of the data collection sessions; and the time period over which the data was collected. I accomplished this by sharing anonymous descriptions of the higher education institutions and of the focus groups themselves.

\section{Dependability}

Lincoln and Guba (1985) suggest the study's procedures should be reported in detail, thereby enabling future researchers to repeat the work. Dependability can be accomplished by descriptions of the study's research design, addressing the "minutiae" of what actions the researcher took to complete the study, and by the researcher's appraisal of the research design's effectiveness (Shenton, 2004, p. 72). I accomplished this by detailing the planning and administration of the focus groups. 


\section{Confirmability}

Lincoln and Guba (1985) suggested the researcher must take steps to ensure the study's findings are the result of the experiences and ideas of the participants rather than the result of the researcher's preferences. Beliefs regarding the study's methods should be acknowledged. I accomplished confirmability by explaining the strengths and limitations of focus groups as a research method, by recording my research activities in a research log, and by reflecting upon my experiences with focus groups as a research method in a journal. I shared copies of my transcripts with participants who agreed to be contacted after the focus groups to confirm my transcription represented accurate portrayals of the group interviews. Finally, I confirmed my findings with the participants of the two webinars.

\section{Credibility}

Credibility addresses whether the study's findings are congruent with reality (Shenton, 2004). A number of different provisions could aid a study's credibility, including testing the interview protocol, triangulatng the sites of data collection, checking transcripts and interpretations with members, and including a description of the researcher's background and positionality (Shenton, 2004). I tested the interview protocols for credibility by moderating two test focus groups with three librarians and three student affairs professionals, respectively, who were neither participants in the study nor employed at the universities where the participants were recruited. The purpose of the test focus groups was to ensure the interview questions were pertinent to the research questions and that the interview questions were written in natural language and easily understood by participants. 
Additionally, Shenton (2004) recommends site triangulation as a means "to reduce the effect on the study of particular local factors peculiar to one institution" (p. 66). Site triangulation lends credibility to a focus group study and underpins Dervin's (2003) concept of "circling reality", or "the necessity of obtaining a variety of perspectives in order to get a better, more stable view of reality based on a wide spectrum of observations from a wide base of points in time-space" (p. 124). Consequently, I held focus groups at several higher education institutions in Illinois. This reduced the likelihood that participants were influenced by one higher education institution's particular set of beliefs, culture, or dynamics. I also employed member-checking by sharing the transcripts and my interpretations of the data with the participants who agreed to be contacted following the focus groups' conclusions. Their verification of the transcripts and of my interpretations lend credibility to my analysis and conclusions. Additionally, I offer a reflection of my subjectivity and positionality as the researcher.

\section{Researcher's Subjectivity and Positionality}

As an academic librarian, I see higher education through the lens of librarianship. Weiner (2008) noted librarians tend toward a library-centric view of higher education, in which the library is the "intellectual focal point or "heart" (p. 4) of the institution. This tendency has deep historical roots; Johnson (1939) noted that academic libraries were principally the domain of faculty members and graduate students and were disconnected from undergraduate students and the curriculum through the 1930s. Fearing this characteristic of libraries appeared permanent, Johnson advocated a "radical readjustment in the scope and character of library services" that included the convergence of scattered, departmental libraries into newly constructed central libraries that were the "intellectual 
and geographic heart of the college or university" (p. 15). Johnson (1939) proposed the purpose of the library should be to provide formal instruction on library resources to undergraduate students, to correlate library instruction with classroom pedagogy and the curricula, and to promote social issues, democracy, and "reading for pleasure" (p. 237). Johnson (1939) commented:

The library is the great common denominator of the college, the real democracy where all meet together to gratify their intellectual curiosity. It is a world in epitome to be exploited for the scholar's enrichment, to be the generating station for permanent life interests, to develop an individuality and personality in students, to furnish cultural preparedness for the leisure which modern industry will afford, and is the only real orientation course. (p. 6)

Although many domains of higher education lay claim to the aspects of student development embedded in Johnson's (1939) vision of libraries, I must note libraries have played formative roles in the development of my own identity. As an undergraduate student, the college library was my sanctuary. I grew up with parents who valued libraries. They took me to the public library often, and some of my earliest memories are of the children's reading room.

Despite my parents' encouragement of reading, I was under-prepared for college. I was not an enthusiastic student in high school. I struggled with some subjects and doubted my abilities to be successful academically. My family's socio-economic status and our community's blue collar values did not make higher education a part of my everyday conversation. I surprised myself and my family by enrolling at my local community college after I graduated high school. I placed into remedial education 
because of my low test scores, and I quickly questioned whether I would succeed in college. I sought solace at the college library where a concerned librarian noticed me and asked if I was all right. She offered me a position as a student assistant, and I began employment in the library's media department during my second week on campus. I continued to work at academic libraries even after I had transferred to a liberal arts college to finish my baccalaureate degree and still later when I started law school. Clearly, the libraries provided the continuity and stability I craved during my educational experiences. I decided to earn a master's degree in library and information science when I realized I was more interested in the tools of legal research than I was in the law itself. Thus, I became a librarian rather than an attorney.

I came to the world of student affairs when I accepted a position as the residential life librarian at a research-intensive university, reporting to the division of student affairs. My libraries were located in the undergraduate residence halls and brought me into daily contact with the student affairs professionals employed in university housing, judicial affairs, and minority student services. Intrigued by the work of my student affairs colleagues and determined to better understand their work, I took a course first in student affairs administration and then in theories of college student development. Eventually, I earned a second master's degree in higher education with a specialization in student affairs.

Despite my admiration for my former student affairs colleagues, I consider those four years embedded in the residence halls a brief - if highly informative - diversion from my "real" work as a librarian. I was never entirely comfortable working in student affairs. Student affairs professionals' extroversion, confidence, and willingness to share 
their lives and reflections makes me uneasy at times. As an introvert, I can be exhausted by prolonged interactions with others. I was also taught to not express my feelings to others, so reflecting and sharing can also be challenging for me. The long hours and teachable moments with first-year students wore me out. I returned to a more traditional librarian role in a central library, which feels more like "me."

I will probably spend the rest of my working years in the library community, but I think about applying the lessons I learned in student affairs frequently to the library context: How do I make the library more welcoming and inclusive for students of differing identities? How do I teach information literacy skills to students who aren't cognitively ready for the lesson? Do librarians have roles to play in civic engagement or service learning? So, I'm approaching this study first and foremost as beneficial to the betterment of libraries and of librarians. Hopefully student affairs professionals will benefit, too, but I must acknowledge my interests favor librarianship and librarians.

I must also note that I am male, and that I am also an associate dean at my library. Currently, male librarians comprise only about $17 \%$ of the library profession but hold $48 \%$ of the upper management and executive positions (Davis \& Hall, 2012). The student affairs profession is somewhat better balanced between the genders at $32 \%$ male, but men still hold the lion's share of executive leadership positions (Calhoun \& Taub, 2014). Accordingly, the demographics suggested a strong likelihood that the majority of my participants would be both female and not in leadership positions, especially among the librarian groups. So it is possible that my participants see me not only as a man, but as a man who occupies a position of power within my own organization. 
Kosygina (2005) suggests that women's interviews with male researchers are shorter in length, less reflective, and consist of question/answer dialogues rather than of monologues. Women are more likely to be enthusiastic and reflective on their professional experiences when interviewed by female researchers. Kosygina (2005) claims male researchers should avoid question/answer patterns with female participants and structure interviews conversationally to reduce the significance of power associated with gender in communication. Listening carefully and understanding how women make meaning out of their roles and experiences might be challenges for me, as my natural inclination is to let my attention waver when my question is not directly answered. Ensuring that my participants are not exclusively responding to me as a man, or especially as a male administrator, would be challenging too.

Additionally, I have served on state and national committees related to libraries for a decade and have published regularly in library literature. Consequently, some of my participants in the librarian groups might know me well, and others might know me by name or by sight. I was likely not a bona fide stranger to many participants in the librarian groups. However, I was likely a stranger to many of the participants in the student affairs groups, as I have not participated in any student affairs committees at the state or national level. Morgan (2002) noted that a known identity is a double-edged sword to focus group moderators: On the one hand, participants are more likely to engage in protracted, open, and honest discussions when they know the moderator, and on the other hand some participants may be more likely to please the moderator by editing their discussion to suit the moderator's interests. 
Unlike me, not all of my participants would hold faculty rank and status. Very likely, the student affairs professionals would not hold faculty rank and status. Only approximately half of librarians hold faculty rank and status (Bolin, 2008). Faculty members wield greater power and authority than academic staff at many campuses, so communication between academic staff and faculty might be less frank and less open than communication between academic staff or between faculty. However, I suspected that my participants would not know my faculty rank and status unless I disclosed it. Certainly I intended to so if I were asked, as no part of this study was deceptive; none asked.

In short, privilege and power are threaded throughout the context of this study. To mitigate this, I adopted a less structured approach to moderating the focus groups. Morgan (2002) and Kosygina (2005) suggested researchers should enable conversation amongst participants by allowing participants' interests to dominate the discussion rather than the researcher's interest. Consequently, I enabled this by asking more general questions rather than larger numbers of specific questions; by allowing participants to explore new directions in discussions rather than always refocusing off-topic remarks; by being flexible in the allocation of time per question rather than setting specific amounts of time; and by ensuring that participants address each other rather than addressing me as the moderator.

Lastly, I attempted to reduce bias in how I interpreted meaning from the participants' responses and how the participants responded to my questions. Onuwuegbuzie, Leech, and Collins (2008) developed a framework to help researchers reduce bias by reflecting on key research concepts: the researcher's interview experience, 
the researcher's perceptions of the participants, the researcher's perceptions of nonverbal behavior, the researcher's interpretations of interview findings, the researcher's perceptions of how the study might have affected the researcher, and the researcher's identification of and response to unexpected issues or dilemmas that emerged during the focus group planning and group interviews. I reflected on these six key concepts.

To address Onuwuegbuzie, Leech, and Collins' (2008) six concepts, I used journaling as a means to record my thoughts, feelings, and reactions as I moved through the research process. The journaling process consisted of two instruments $-\mathrm{a}$ research diary and a research log. My research log was a trusty notebook, where I jotted notes impulsively and spontaneously as I moved through the process and where I recorded times, places, and other details of meetings and communiqués. I recorded the journal entries in a Word document on my home desktop computer when I had the time and the opportunity to reflect.

To help me understand the purpose of journaling, I reviewed Ortlipp's (2008) and Newbury's (2009) works. Ortlipp (2008) described her journaling as "a place for writing as a method of inquiry" (p. 695). Ortlipp used her journal to clarify her research aims and approach, and it is where she asked and answered her own ontological, epistemological and methodological questions about what she knew, her relationship to what could be known, and how she might come to know it. "Reflective journal writing," Ortlipp (2008) claimed, “enabled me to articulate my ideas about conceptual frameworks for analysis of the data and led me eventually to reject an interpretvist-constructivist framework" (p. 700). 
Following Newbury's (2009) perspective on journaling, I resolved to scrutinize my own journal entries for three distinct types of notes: observational, in which

"statements bearing upon events experienced principally through watching and listening" and contain as little interpretation as possible; theoretical, in which I reflected about what I experienceed and derived meaning from one or more of the observational notes; and methodological, in which I critiqued my own operations, processes or tactics (p. 3). I hope that I have lived up to Ortlipp's (2008) and Newbury's (2009) advice as I reflected on the nature of my journal entries.

\section{Conclusion}

In order to best address the qualitative purposes of this proposed study, I moderated seven focus groups at four higher education institutions to better understand the participants' perceptions of librarians' and students affairs professionals' roles in student learning and student success. In this chapter, I presented the rationale for employing focus groups within a phenomenological methodology. I described how I recruited participants, conducted the focus groups, and analyzed the data once the focus groups were completed. Additionally, I discussed issues related to the proposed study's trustworthiness.

In the following two chapters, I share the themes that emerged from the librarians' and student affairs professionals' focused discussions. Because I want the participants' perspectives and stories to resonate with readers, I have interwoven participants' exchanges from the focus groups to illustrate the themes. 


\section{CHAPTER IV \\ THE LIBRARIANS’ STORIES}

This study explored librarians' and student affairs professionals' perceptions of each other's roles in student learning and success and sought to identify opportunities for prospective collaborations, as well as the conditions that impede or facilitate prospective collaboration. In this chapter, I share the major themes that emerged from the librarians' responses and reactions to my interview protocol.

First, I am compelled to note the atmosphere and energy of the librarians' focus groups were largely similar to each other but contrasted sharply with those of the students affairs professionals. The librarians warmed quite slowly to the group discussions. Often, they replied to my probing questions with several moments of silence and then a tenuous "I've never thought of that before..." They asked me many clarifying questions, such as what I meant by student persistence or which areas of their university comprised student affairs. While their responses were thoughtful, their sentences were often left incomplete and trailing, leaving me with the impression that they lacked confidence in their own perceptions or that they found formulating responses to be challenging. This is not surprising given the preponderance of librarians with introverted personalities (Maxwell, 2006). Morgan (1998) noted introverted focus group participants tend to struggle with formulating responses due to introverts' need to consider the questions carefully, sometimes leading the moderator to falsely assume the participants are ill- 
informed. I counteracted my own initial assumptions by reviewing my research journal where I recorded my own feelings toward the focus groups.

The librarians checked with each other frequently, seeking confirmation of their perceptions and opinions. Often they expressed surprise at not knowing the stories shared by other participants, many of whom were presumably close colleagues, suggesting the librarians worked rather autonomously and did not regularly communicate their experiences with each other. In fact, many of the librarians were not entirely familiar with the scope of each other's responsibilities despite working together for some time. As introductions were made at University D, a brief exchange between Howard and Deanna encapsulates this lack of familiarity well:

I have to do this [liaison to departments]-Economics, Political Science, and Philosophy. (Howard)

What about Religion? Do you still do Religion? (Deanna)

...No. But...Ahhh.... I guess we just don't talk about it. You're behind. (Howard)

Not until quite near the ends of the allotted ninety minutes together did the librarians seem comfortable and did the discussions flow fluidly and with bits of laughter. Still, an air of uncertainty hung over all the focus groups, which I felt was finally given voice by Sabrina at University D at the very end of the group interview:

We are all so looking forward to the results of your research and learning about all the collaborations the other libraries are doing. I'm not sure that we could really offer you much ourselves but hopefully we can put a good many of those to practice here! 
Tables 3-6 provide brief descriptions of the participants at each institution.

Table 3

Librarians at University A

\begin{tabular}{ccc}
\hline Name & Sex & Years of Service \\
Jeanette & Female & 3 \\
Crystal & Female & 3 \\
John & Male & 6 \\
Beverly & Female & 10 \\
Amy & Female & 7 \\
Jodie & Male & 3 \\
\hline
\end{tabular}


Table 4

Librarians at University $B$

\begin{tabular}{ccc}
\hline Name & Sex & Years of Service \\
Joe & Male & 12 \\
Paul & Male & 17 \\
Alan & Male & 9 \\
Margaret & & 23 \\
\hline
\end{tabular}

Table 5

Librarians at University $C$

\begin{tabular}{ccc}
\hline Name & Sex & Years of Service \\
Lauren & Female & 22 \\
Wendy & Female & 24 \\
Lucy & Female & 12 \\
Jennifer & Female & 5 \\
& & 5 \\
Alison & Female & $($ Table Continues)
\end{tabular}




\begin{tabular}{ccc}
\hline Name & Sex & Years of Service \\
\hline Molly & Female & 15 \\
\hline
\end{tabular}

Table 6

Librarians at University $D$

\begin{tabular}{|c|c|c|}
\hline Name & Sex & Years of Service \\
\hline Rebecca & Female & 3 \\
\hline Deanna & Female & 10 \\
\hline Howard & Male & 21 \\
\hline Sabrina & Female & 10 \\
\hline Ellen & Female & 7 \\
\hline Jessica & Female & 3 \\
\hline Yolanda & Female & 5 \\
\hline
\end{tabular}

\section{Librarians' Roles}

Initially, I asked the participants "What do you perceive to be the role of librarians at this institution?" The librarians were remarkably consistent with their 
responses across the four institutions despite the institutions' differences in mission and character. Their perceptions of the role of librarians are categorized into three broad themes: information purveyor, teaching, and community development.

\section{Information Purveyor}

The librarians' primary role appeared to be what I call the "information purveyor." In this role, the librarians acquired and organized information sources - such as monographs, databases, journals, datasets, etc. - and evangelized the resources to faculty, staff, and students. I note the distinction, if subtle, between what I am labeling “information purveyor" and what one student affairs professional called "information provider." An information provider implies a passive role - the librarians make resources readily available for use by the library's clientele but do not proactively inform clientele of these resources; rather the clientele must actively seek out these resources. However, the term purveyor implies the librarians' role is active, deliberately promoting the resources' existence and usefulness.

I purport the librarians have adopted an evangelical orientation because they employed a vocabulary suggestive of persuasion. When the librarians spoke of alerting their constituents to the existence of resources they thought would be helpful, they chose action words such as "promoting," "outreach," "building awareness," and "connecting." These action words indicate a thoughtful deliberativeness and professionalism that more casual phrases of speech such as "letting them know" or "telling them about" do not suggest. They did sometimes use casual phrases such as "letting them know" when referring to informing students about library hours, policies, and the fact that student ID cards doubled as library cards. However, the librarians adopted the more formal or 
sophisticated words, such as "promoting" when they spoke specifically of the monographs, databases, and other information resources they thought were helpful for research and curricular work.

Furthermore, their other choices of vocabulary suggested they considered their interactions with constituents to be a form of marketing when speaking of information sources. Lucy at University C noted her library had "sharpened its communication" regarding its collection. Jeanette at University A described brochures - surely a common marketing tool - she had designed regarding the 3-D printers the library had recently acquired. Rebecca at University D also spoke of distributing brochures that advertised the library's government documents during her visits to classes and at a student health fair, although she was dubious if the brochures made the library a trusted and relevant organization to students given that she noted with a sardonic tone the brochure's dated age and students' marginal interest. She said:

They're horrible. Dated pictures of people and ugly fonts. No one takes them or even glances at them for half a second. Well, a few do, the ones who talk to me for a bit. They feel bad, probably. But then I just see them in the trash can outside the door when I leave the event. What does it say about the library's relevance to their lives when our materials look like they were printed in the 1980s?

John "delivered presentations" to faculty and to classes on the information resources best suited to courses' topics. He believed his presentations “demonstrated value:" 
Instruction has been my main avenue towards, toward outreach. That, ah, you get into someone's class, you give a good presentation, deliver a good lesson plan, essentially demonstrate value. "Hi, I'm helpful, I'm not a scary monster" and "here's what I can do for you." And then the faculty say to each other "oh yeah, this worked, this worked really well" and then you have your foot in the door with more faculty and thus more students.

This specialized language, coupled with the use of traditional marketing tools such as brochures, indicates marketing is an integral aspect of the information purveyor role. Additionally, I argue this role appears to be the librarians' primary role because the participants described this role first and foremost and emphasized it more frequently than other broad themes I identified.

Much of their purveyor role is exercised through their formal relationships with disciplinary faculty and the students who major in those fields of study. At all of the institutions, the librarians specialized in subject areas that corresponded to the fields of study taught by the disciplinary faculty. For example, Beverly at University A; Alan at University B; and Ellen at University D specialized in music. They were responsible for ensuring their libraries provided print and electronic resources related to music that were current and appropriate to the curriculum. As the "experts" in resources related to music, they also taught music students when and how to use these resources. While one might think a librarian is only as good as the collection he or she curates, several librarians noted their emphasis on building robust collections has dwindled; more resources is no longer better. Instead, the librarians invest great energy attempting to connect students 
with the information resources, as evidenced by these quotations from librarians at different institutions:

We don't do that [building collections] anymore, now, so much. We've done collection assessment, and they're [information resources] so little used and yet so expensive. We've changed our philosophy so that we are not collecting everything but, uh, trying to direct the students to those that are most appropriate. (Lauren, University C)

[Chuckling] Oh, when I think about all the hours I pored over reference guides, reading reviews, comparing what other libraries like us owned that we did not... oh, all those hours I wasted! Then we ran out of time to do all that because - I'm not just the music librarian but also the communication librarian after that librarian retired - we started using jobbers to just automatically send us the new books in our subject areas. But then we looked at how much this stuff is actually used, and it's not really a lot. Like a certain database will have a half dozen searches on it but the annual subscription is like $\$ 10,000$. So now I spend a lot more time trying to tell students that resources actually exist and why they'd want to use them. (Alan, University B)

However, not all the librarians exercised their purveyor role through their relationships with disciplines. Jodie and Crystal at University A and Wendy at University $\mathrm{C}$ evangelized information resources to undergraduate students by participating in activities in traditional student spaces, such as the residence halls and at meetings of student organizations. Jodie and Crystal attended programs associated with living-learning communities in the undergraduate residence halls. Sometimes they chose 
to eat dinner with these students in the dining halls. Wendy spent time with student organizations focused on gender, racial, and ethnic identities. All three librarians attempted to get to know students personally and then informed students of information resources pertinent to the topics the students were researching in their coursework, as demonstrated by the subsequent exchange between Jodie and Crystal:

I go eat in the residence halls and talk to the students. It's easy for me, because, well, I look young so they don't look at me like I shouldn't be there. And I talk to them, really, ask them about their majors, what they hope to do, how they're doing in classes. (Jodie)

Yeah, and then you just... slip it in... about how you know a really great resource that will help them out a lot... in the library [laughter] (Crystal)

Some of the librarians were uncertain if their efforts led to students' increased usage of information resources. Jennifer at University $\mathrm{C}$ was primarily engaged in assessing the library's effectiveness, which included analyzing the usage of information resources. She was able to share with Wendy the usage of databases Wendy had promoted to students associated with her student organizations, but still they did not know whether any increased usage was directly attributable to those students' increased awareness of those databases. Christina at University A said: "Yeah, one of the things I discovered about this institution when I came here... those promotional messages don't really work."

John at University A speculated that increasing students' awareness of information resources required a more consistent strategy over the academic year than what many librarians put into the effort. He said: 
Yeah... one of our ongoing concerns since I have gotten here is that the majority of our outreach efforts...all take place within, say, the first four months of a student arriving here. And then, they then drop off precipitously. So, it's sort of like, it's 'you're really important when you are new..."

John's sentence trailed off in such a way as to imply that students receive the impression that they are less valued after being on campus for a longer period of time. Later, John asked "Are we pissing in the wind?" suggesting he was completely uncertain if the investment of his time produced any gainful returns. Although John asked the question somewhat flippantly, I should note the participants at University A fell silent for a few moments after John's question and did not really respond to a probing question I asked subsequently. When discussion began again, the participants changed topics entirely, coloring my interpretation that John's rhetorical question was particularly poignant.

\section{Teaching}

I purport that the participants perceived teaching to be a significant role of librarians because they spoke of teaching activities in many different contexts and vocabularies. Many of the participants said teaching was one of the principal responsibilities on which their performance as librarians was evaluated. Despite that claim, the participants themselves rarely used the word teaching to describe their role except in the narrow context of formal classroom instruction. However, they used words like "coaching," "facilitating," and "creating experiences" to convey teaching moments outside the classroom in which they introduced new information to students or helped students gain new understandings. 
Formal Instruction. While none of the participants said they taught creditgenerating courses, virtually all of the participants taught what they called "instruction sessions." Through their liaison work with academic departments, librarians worked with faculty to identify the information resources most relevant to the intended learning outcomes of specific courses. Faculty brought their students to classrooms housed in the library, and the librarians taught students searching strategies appropriate to the information resources and how to analyze information for appropriateness and credibility. These instruction sessions were often no more than a single class period, but librarians felt instruction sessions were singularly important to students' ability to locate and synthesize information. The following exchanges between librarians at University A and between librarians at University B demonstrate this. The librarians at University A said: This is the single most important thing the students should get from us. This is really the only way they're learning how to recognize good information from bad. (Beverly)

The faculty complain all the time the students don't use good information in their papers. 'Wikipedia!' they [faculty] moan. Well, bring 'em here. They need an instruction session, and I can change that. (Jeanette) It is really the only time they get that kind of teaching. No one is else is doing it, and it's so critically important. And these sessions seem like the only format in which we can offer the students that sort of instruction. (Amy) At University B, the librarians discussed:

I hate that we usually only get the students once, for a single session. This is vitally important, maybe the most important we offer. (Joe) 
Sometimes, if we're lucky, we can get them for two sessions. The same class, that is. (Alan)

I don't understand why faculty don't build instructions sessions with us into every single class. This is what we do, and the students can't really learn how to search for information effectively without it. They really do write better papers after our sessions. (Joe)

They really need this, especially if this is an upper division course, and the faculty are expecting students will be familiar with certain journals or databases by the end of it. You really need to know PsychInfo if you're a psychology major. You'll be writing so many papers by the time you're in your 300s. It's a very writing intensive major. And, of course, the faculty can tell students about PsychInfo, but they really don't spend the time showing students how to search it, or maybe even not why PsychInfo is the source to find credible information and not, say, Psychology Today. That's what we do in instruction sessions. (Alan) Many participants worked hard to convince faculty members to bring their classes for instruction sessions, yet - interestingly - the librarians evinced skepticism about the value of providing formal instruction. John at University A said instruction was the librarians" "bugbear" when they had so little formal face-time with students and librarians had difficulty demonstrating their sessions increased students' information literacy. He implied formal instruction represented a problem for librarians because it was the established way of teaching students information literacy skills but he questioned the efficacy of this style of teaching. The following exchange between the participants at University A suggest this skepticism: 
In effect, that, that's been kind of one of the big bugbears of instruction programs, especially at the undergraduate level, is determining to what degree we are able to support those, those students in their learning. Uh, or to what degree are we, we really being successful? And, we don't always know. (John)

But, we have to put in some assessment measures to test, like the card swipe machines, so we can see later there on those who attend our sessions are actually going to graduate on time. Or just graduate. (Jodie)

Yeah, those efforts are just being implemented. And so, we hope in, in the coming, oh, forty years, that the data will be used to correlate our activities with student success. There has to be a better way. (John)

No one pays attention in instruction sessions. They're a waste of everyone's time, except for like two or three students who are really paying attention. Maybe we can teach those two or three some other way. But instruction is... well, it's just the way it's done. All librarians teach instruction. It's how librarians teach. So we do it. (Beverly)

Some of the librarians at University D were similarly skeptical:

Well, I feel bad for [name of another librarian.] We just hired her, so she gets the heaviest instruction sessions. (Rebecca)

She gets the burn-out stuff like English 101 where there are dozens of sections, mostly freshman, and no one wants to be there and no one pays attention. The rest of us put in our time, so she gets that stuff and we get the upper level courses (Howard) 
I mean, I guess it's important. It's the best way we demonstrate to the rest of the university that we're teachers too. But, frankly, we just really can't tell if any of it makes a difference. (Rebecca)

Don't you use pre-test and post-tests to see if the students get it? (Sabrina) Well, we tried. But that only works if you see the students at the beginning and at the end of the semester for separate sessions. But most faculty want to pare it down to just a single class session. So, great in theory, hard to put into practice. I think we're actually more effective at teaching students when we're one-on-one, like they have an appointment with us. (Yolanda)

Coaching. The provision of reference services is also a teaching activity for participants, although less formal than instruction sessions. While answering reference questions in-person at a desk or virtually through a chat service could be transactional in nature at time, many of the participants interviewed students about the circumstances that led them to seek assistance. Often, these interviews revealed information to the librarians about how students perceived their assignments and the students' information-seeking behaviors. Rather than locating multiple sources of information for students, librarians demonstrated to students how to search the library's catalog or explained how to use databases to locate the information students needed. While some participants did think of this as formal teaching, several other participants noted that these experiences lacked much depth. The librarians persistently referred to "coaching" or "guiding" students in this setting by asking probing questions about the students' information needs and challenging the students to conduct their own searches. 
Joe at University B noted that many students seemed dissatisfied, believing that students perceived interactions at the reference desk to be more like a customer service experience rather than an educational experience. In fact, Joe speculated that some students resisted this learning moment so significantly that they were subsequently discouraged from interacting with librarians at the reference desk. Margaret at University B built on Joe's speculation and postulated that librarians sitting passively at a reference desk awaiting student interaction conveys an image of customer service to students. She said this image is reinforced by students' prior exposures to librarians at public libraries, where she believed librarians have a less developed educator identity. Margaret argued students' image of librarians as a helping profession first and foremost represents a disconnect from academic librarians' emphasis on teaching information literacy concepts and skills. Paul at University B contributed that librarians themselves are not effective teachers despite the educator identity, as few librarians formally learn pedagogical strategies and techniques. Rather, Paul said librarians are "magically expected to inspire, engage, and challenge" students "by virtue of having earned a master's degree" when most librarians are more likely expert demonstrators rather than teachers. Indeed, many of the participants across the focus groups used words like "demonstrating" or "instructing" rather than "teaching" - formal words that suggest a more mechanical process and a distance from students whereas teaching implies a more intimate relationship with students. Interestingly, many participants referred to disciplinary faculty as "the teaching faculty" when making distinctions between the disciplinary faculty and the library faculty - an interesting distinction when the same participants claimed that their own predominant role was also teaching. 
Creating experiences. Many participants perceived the library as a vehicle for students to make sense of new information. Lauren at University C called the library a "laboratory for learning," and Joe at University B said "the entire library is a classroom." Participants varied in how they perceived this. Margaret at University B said librarians' creation of exhibits that captured students' attention and provided students with new perspectives represented a way that librarians teach. Alan called this passive programming, and the participants at each of the institutions shared stories about creating displays, art installations, or bulletin boards:

We stimulate their curiosity by creating exhibits. We just had one up for a while on graphic novels. I wrote a small grant that helped us get a traveling exhibit here, with illustrated pages from graphic novels. The artists shared their stories, their lives, and how that translated into visual storytelling. We put them up around the walls and brought in a guest speaker from the art department. That's a vital thing we do, to introduce them to new perspectives, it's part of teaching (Margaret)

Well I don't call it teaching per se. It's passive programming. But certainly we're engaging students this way, through the exhibits we create, through our guest speakers. We don't really have a great space in the library though. We've thought about moving our speakers to the student center where they have actual space designed for that purpose. (Alan)

Oh but we don't want to. We think it's really important to have this in the library. It's part of our mission, I guess. (Margaret) 
I think we don't want to give it because, really, the library's the intellectual heart of campus. I think we're threatened in so many different ways, Google and lack of funding, and what not. Letting go of our programming to the student centerwell, no way, that's one more knife in our heart. (Paul)

Jeanette at University A managed a 3D printer station at her library. She encouraged students to create objects both as a way to engage students' sense of innovation and creativity and to enable their familiarity with new technologies they might later encounter in their future careers. Although she promoted the 3D printer primarily to students in engineering and the sciences, she was considering ways to promote the $3 \mathrm{D}$ printer to students in other disciplines as well. Jeanette said her primary role was to demonstrate to students how to use the 3D printer, make supplies available, and troubleshoot technical problems, she was adamant that she creating a learning environment that taught students creativity.

\section{Community Development}

Many of the librarians emphasized the role they - and, by extension, the library played in crafting a relationship between the students and the campus and creating a sense of community. The librarians played a role in community development both by fashioning the library into a premier social destination for students and by participating directly in significant campus events, as suggested by the following exchange between librarians at University A: 
We have Friday night live... I think that's what it's called. We do music in the library after our regular hours end. Sometimes it's jazz, but usually we have student bands who play all sorts of things. We really want the students to see the library as something more than, well, a library. (Jeanette)

Oh, more importantly, this is their building. I mean, really, everything we do here is designed to serve students' needs. We play an important role, or should, in student engagement and bringing students together, and helping them see this place differently, like this place being essential in making them feel like they belong here, on this campus. We even had the mascot repel off the top of the library at the beginning of the semester. (Beverly)

That was weird, but the students all gathered around. They were really excited. It was kinda cool, really, although I did wonder if that was exactly safe. (John) The librarians at University B seemed to be the exception, as they did not offer any evidence that they participated in campus life; rather the small size of the library staff and the complications of administering the library drove them to devote nearly all their attention to activities within the library itself.

Library as student hub. Nearly all the librarians envisioned the library as a hub of student activity - a destination where students congregated not only to study together, engage in research, and interact with librarians but also to socialize, use technology, or appreciate cultural or aesthetic experiences. The degree to which the libraries had accomplished this varied. Many of the librarians noted this was a significant cultural shift that brought new colleagues who weren't librarians into the library and created tension for space when book stacks, offices, or classrooms were reallocated for use by 
these new partners. Additionally, the presence of new services and staff in the library led to students asking the librarians questions about areas outside the librarians' expertise. The librarians at University A and C embraced this evolving role for the library and librarians, while the librarians' reactions at University B and D ranged from ambivalent to tentative.

At University A, the re-imagining of the library as a student hub was a concerted effort encouraged by the dean of the library and the university administration. Jeanette explained:

There has been a recent push not just, um, to promote the research side, side of things, but also to build community on campus. And so, I'm sure we'll talk about this eventually, but we've, ah, partnered with the residence halls and we talk about the library as a place, as well, to come together.

John noted that student success is a cornerstone of the university's strategic plan, and that community development was an aspect of this. Amy followed John's comment with an assertion that student success as a university priority was ill-defined, but she took this to mean the university needed to improve student retention, timely graduation, and academic performance. However, she said the librarians hadn't "figured out how we target that - we mostly just focus on student learning objectives through the teaching we do."

However, Jodie and Beverly at University A noted the librarians were heavily involved in "Set Up for Success," a week intended for first-year and transfer students to receive the logistical help they need to be successful students. Student technology services was now located at the library, and both librarians and technology specialists 
helped students activate their various accounts and passwords. Additionally, the librarians passed out a limited number of electronic tablets for students to use for free for the semester, which seemed so popular a service that most tablets were claimed within days. They explained they also arranged to bring puppies into the library several times a year, which served as a popular stress-reliever for students eager to take a break from their studies to interact with the dogs. The librarians also baked cookies and placed these out for students. They believed they were successful at creating a library that was comfortable and inviting to students, as the library was often filled to capacity with students engaged in studying and socializing.

John said:

Well, I think by, by providing a common areas for study and socializing, uh, the library, uh, as I think of community is this common place where people can come and get together, especially with classes being in, all over the place, online classes taking away from a sense of place. That the library is this sort of beating heart of campus where you just...people from all different areas will have common ground.

Jodie seemed to have worked directly to sell the library as a space where students could come together to work together or share mutual interests. She said:

Yeah, uhm, as far as the different student organizations, that, that being here is really nice. I've been approached by, uh, the Greeks to, to meet here and also start working with us. I haven't pursued that yet but I'd like to. But, they always meet here, as do Athletics and the RSOs. And, I love it when I'm at the gym or something when I hear people say “do you want to meet at the library later?” Like 
“yeah, let's go there." Well, wow! So, it's really nice but then I've noticed that there are many different faculty groups that actually choose to meet here and have, um, communities of interest like within the space as well.

Comparing distinctions between institutions, the participants approached their roles as actors in community development quite differently. Jennifer noted the academic library doesn't serve the same purpose as public libraries, but that her library was working toward creating a sense of community for students by subtly sending messages that reinforce the concept:

But, then, compared to a public library, we don't necessarily have a sense of community in the library sometimes. Our wall is blank. You know, that the community of a public library would have pictures of historic buildings or, uh, an ice cream shop or something like that. That's why they [librarians] go into the archives and find photos that do present our life here. So I think that is another thing about library or librarians, it's part of building a community for the students. That's what campus community really means, or what a particular small library it imparts something to you, and you'll use it. What that community is supposed to be about, isn't it? (Jennifer, University C)

The librarians at University $\mathrm{C}$ believed the library should be a place where students are inspired by the creativity and accomplishments of their peers. Remarking on Jennifer's comment about "blank walls," Lauren said:

I want to touch on the facilities piece with student learning because, again, at the library we do a lot of these little surveys and such. ...Uhm, part of it was trying to find out from the students what of student learning experience they would want 
in the facility approach, and, uh, as a result we've redesigned and put, uh, certain services together. But the thing they wanted was to have some signs, some posters, some images around of other successful leaders - students - rather than just looking at blank walls. To really have things so when they are studying, they can look up and say 'Oh, what an inspiration!' So that's one of the initiatives that we're working on...to develop some of our, uh, images that students can see and be immersed in a successful learning environment. (Lauren, University C) Additionally, Lauren indicated the library served as a cultural and aesthetic space for students. The librarians had deliberately chosen to replace their little-used reference collection for exhibits for student artwork that they believed would showcase student talent:

We're developing a student exhibit area, um, in part where we used to have the reference books that no longer exist. David's working with the Fine Arts and Design program to develop that [space] and then we'll have rotating student exhibits. (Lauren, University D)

It was clear from my discussions with the librarians at University A and C that other factors played a strong role in the librarians' movement toward redesigning the library as a student hub. At both institutions, the librarians seemed knowledgeable of trends in student learning and development. Like the librarians at University A, the librarians at University C found ways to provide stress relievers to students. Lucy implied that librarians' discussions about meeting the needs of the whole student cognitive, psychosocial, and emotional - and their knowledge of theories of wellness led the librarians to create experiences and spaces that allowed students to decompress while 
studying. Lucy also implied she made decisions about building collections based on her knowledge of student development theories and considered whether the complexity of the information resource matched the students' reasoning abilities.

Additionally, library and university leadership seemed to serve as a genesis for the librarians' initiatives in redesigning their library spaces and services. The librarians at University $\mathrm{A}$ and $\mathrm{C}$ indicated their respective deans of the libraries were quite clear in developing priorities that enabled the librarians to craft student-centered learning environments. The librarians understood the reasoning of their deans' messages, and they recognized these messages' connections to the greater university priorities. Both groups referenced the difficulty students had navigating their large campus environments, and the libraries played a role in helping students integrate their academic and social experiences. The following discussion between librarians at University $\mathrm{C}$ illustrate this point:

I actually think that even in academic libraries, especially when you're working with students from a variety of background... (Wendy)

We have a lot of international students who aren't used to American customs. And lots of students from rural communities where this campus is larger than their entire towns. That can be really intimidating. (Lucy)

Right. As I was saying, we have a role to help them in personal situations, in their personal lives. And, um, you know, a lot of the students, especially the LGBT [Lesbian, Gay, Bisexual, Transgender] students have issues with coming out, talking about, about the whole issue of coming out to their family and friends. You know, there's all kinds of eating disorders and sexual assault. You know, I 
think we have a role in helping these students, you know, with issues that they're struggling with, not, not just academic issues but their own personal issues. And I think that's really good connection. (Wendy)

We've seen that need, and also for connection, we do our bathrooms, bathroom stall flyers with these types of issues. Resources to help them. And [the health center] does a great job of providing us with those top things that they see concerning students. (Alison) I am completely affirm that sort of the, um, direct work with the students as far as our role relative to them. Um, and, one thing I think a lot of the discussion here is sort of focused on, um, this sort of formal instructional role that we have. But, um, I think it's also that we have, we spend a lot of time whether one-on-one or in larger settings sort of providing immediate assessment of where a student is at. And so how far we can take them in the given moment or setting, so I agree with [Molly] in that we tend to take an instructional approach but at the same time we are always mediating that with the student's level of anxiety, the skills that they have for coping. I think where [academic librarians] differ from...is... at the public library, if a user resists going into a learning role, then they go without learning. Where our job is to help them lean into that resistance, just to sort of help them find their way through that resistance. (Lucy)

I'm not sure how successful we are. We could do better at integrating students' social experiences on campus with their academic work. I think that's there's a lot more that we could do, and I think our own literature and our own training actually lacks the theory that would help us do some of this better because we 
tend to privilege things which are important in our profession, like more information is always better, but which may not actually match what we know about student learning and development. The other piece, and here I don't want to go on to long so I'll just say this: I think that we have a huge role to play by creating the campus learning environment, and how students relate to the curriculum. (Lauren)

Changes were afoot at the library of University D. The librarians noted the writing center and a coffee house had recently occupied space at the library but several librarians interpreted this as a threat to the library's importance and suggested these changes were imposed upon them by university administrators who had little firsthand knowledge of the library itself or the librarians' work. Howard thought the changes were likely necessary because "nobody knocks on our door, we have to invite them," meaning the students. At the same time, he implied the university administrators didn't see the library as important, noting the library appears in university literature and strategic plans less and less often and suggesting the librarians emulate the strategies of other libraries: "The University is saying 'no, no, no, not good enough, not good enough, so we'll take these spaces from you. These libraries are thriving." When I asked whether he or others were actively developing their own ideas to present to the university administrators, he fell silent.

Howard and Deanna noted the library is much busier with students than it was five years ago, and the library did have more varied and comfortable seating, longer hours, and a greater tolerance for noise. However, they were uncertain as to why the students now found the library a more desirable place than they used to. In fact, 
Deanna's tone indicated she was mystified as to what the librarians should even be doing now with the students. She said:

....there's a lot of people. I don't know what they're doing. A lot of them are just hanging out. They're not doing anything. They're just here, um, which you know... Just get the bodies in the door... once, maybe, they're asking you for a pencil today, but in a few weeks, maybe, they'll be asking you for help later. (Deanna, University D)

However, Sabrina believed community development was essential for the library - and the university - to thrive. She said enrollment had declined precipitously, and she perceived the lack of activities to keep the students engaged partly led to a high attrition rate during students' second year. Yet Sabrina did not feel empowered to advance any ideas on how to solve the problem. Nor did Yolanda and Rebecca, who both expressed shock and dismay that the librarians make little to no attempt to engage students outside the library - something that both said was a regular, expected part of their jobs at their previous institutions.

The librarians at University D agreed that library leadership proved problematic for them in reaching out to other areas of campus; the dean had not - in their opinion ever articulated a compelling vision or plan for the library, and all the library administrators were not particularly visible or communicative. Indeed, Deanna said the librarians' work had not been coordinated for some years and any sustained efforts came about because of librarians' individual ambitions and passions. Jessica agreed, saying everything was due to "scrappy librarians." Despite the lack of coordination, it did not seem the librarians felt particularly empowered. For even seemingly simple tasks, such 
as designing updated brochures for Rebecca to pass out at the student health fair, seemed to lack ownership.

I noted, too, the mixed signals the librarians at University D appeared to send to students regarding the library as a community place. Despite the presence of a coffee house on the library's lowest level, a few of the librarians discouraged me from sampling the coffee there. "It's terrible," said Ellen. She wondered aloud why on earth the students chose to spend time there. A nearby exhibit case served as a seemingly contradictory message regarding the permissiveness of food and drink, which displayed books in various states of disrepair or damage caused by foods and liquids.

The librarians at University B were experiencing discomfort, too, with the concept of the library as a student hub, as evidenced by this brief exchange between Paul and Alan:

I think we're getting a coffee house or something. And we got rid of the long library tables and most of the study carrels. And there is a lot of talking now. I guess it's good, the students seem to prefer that way now. I'm just not really sure how I feel about it yet. It just seems... wrong somehow. What are we giving up about ourselves? (Paul)

Well, the library is changing. Change happens. But I don't know that we're really changing right along with it. Do I need to? I'm not sure. No one is suggesting that I do anything differently, so I'm just not really sure what this all means for me yet but it is vaguely alarming when the library used to be as quiet as tomb, and we were expected to keep it that way, and - wow - and now that students want to practice presentations here. (Alan) 
Margaret said the library's director had encouraged the librarians to proactively consider ways to enhance the students' experiences at the library. However, Margaret was perplexed as to why the librarians should make the effort, noting the student union was only across the parking lot and was filled with students at all hours. However, she conceded the library may not be as welcoming to students as it could be, given the age and worn conditions of the library's furnishings and the lack of adequate seating and wireless connectivity.

Many of the librarians asserted that libraries were once the physical and intellectual hearts of campuses, but both Amy at University A and Deanna at University D lamented recent changes that challenged that notion. Amy observed their 4-year old central library where we held our focus group was on the periphery of campus while the old, no longer used library at the heart of campus had an uncertain future ahead of it. Amy's tone evoked a wistfulness and sense of loss at the librarians' relocation - but whether for the old library building itself or for the old library's location on the campus quad was impossible to discern. While University D did not boast a new library, Deanna said the increasingly westward expansion of the campus placed the library further from the new buildings that attracted students, such as residence halls and the recreation center. Therefore it was more incumbent on the librarians to make the library a more welcoming space for the students.

\section{Interactions with Undergraduate Students}

Next, I nudged the focused discussions toward the librarians' direct interactions with students. I asked, "How do librarians here interact with students and for what purposes?" This question generated the least amount of discussion among the 
participants. John at University A summarized neatly the librarians' responses across all the institutions: "I think we have like five basic areas in which we interact with students. Ah, and that would be in an employment capacity, in an outreach capacity, at the desk, in the classroom, and, uh, one-on-one consultations." I distilled these capacities - to use John's word - into three broad themes that ran through the participants' stories: managing student employees, limited social presence in students' co-curricular activities, and transactions with students.

\section{Managing Student Employees}

Several of the participants claimed the undergraduate students they interact with the most, and consequently know the best, are students they employ at the library. Paul at University B and Sabrina at University D manage their libraries' circulation desks and interlibrary loan operations. They said they employ the greatest number of students compared to other librarians at their libraries. Although they hired and train students to perform specific tasks necessary to the libraries' operations, both Paul and Sabrina emphasized that they are teaching students to be part of the workforce and what it means to be an employee:

These are their first jobs, most of them. They have no idea what it means to show up for work on time and how being late effects the student workers they're relieving. I'm teaching them customer service, how to listen, how to make eye contact, how to make referrals to others... Whether they realize it or not, these are skills, skills that must be learned and mastered." (Sabrina, University D) However, other participants also managed student employees. Jessica at University D is responsible for collecting works by the scholars at her university and 
depositing these in the library's institutional repository as well as advising the library's patrons on digital publishing. Initially, she employed students to handle mundane tasks associated with these responsibilities but she is recasting the student employee positions as internships and focusing more on preparing students with transferable skills when they enter the job market. She said, "I want them to have a really good cache of resumes when they, when they walk away from, from my fold."

It was clear that these librarians found managing student employees to be highly rewarding. Sabrina and Paul said they have remained in contact with many former student assistants over the years, providing references occasionally but also simply maintaining a social connection. Paul felt that he had clearly had an impact on these students' maturity and development. A few former student employees had even gone on to choose careers in librarianship, partly based on their rich experiences working in libraries during college.

\section{Limited Presence in Students' Co-Curricular Activities}

Many of the participants acknowledged that they interact with undergraduate students very little outside of the confines of the library or outside the context of library work; the library's student employees were often the only students they knew by name. Nonetheless, several of the participants said they sought out undergraduate students in the context of their co-curricular activities. Rebecca volunteered as the faculty/staff advisor for a fraternity, which initially perplexed her because she had requested to advise a sorority. Although fascinated by the complexities of fraternal life, Rebecca conceded that she struggled to know how to advise the men appropriately, particularly on conduct. She relegated herself to more bureaucratic activities, such as signing paperwork and admitted 
that she was "not much use" and should be asking the dean of students for training or help.

In contrast, Wendy at University C was highly involved with students who belonged to under-represented identity groups, particularly Latina/Latino students and LGBT students. Wendy attended the programs sponsored by the offices and student organizations that focused on those students. She wanted to be visible in those student communities as a way to humanize the librarians for students whom she believed could benefit from librarians' expertise in ways that aren't strictly related to coursework. For example, Wendy said she buys literature related to the coming out process for LGBT students and makes connections with the parents of Latino students at Latino Family Day in order to help those families understand how the library could help the students acclimate to the campus.

At University A, Crystal and Jodie attended programs at the residence halls in order to develop personal connections with undergraduate students. Crystal said she often attended guest lectures held in the residence halls, went to movies in the lounges, and ate dinner with the students in the dining centers. Crystal said she thought the students were often confused and bemused by the presence of a librarian. She believed making these personal connections would inspire students to ultimately seek her out when needing research help. Crystal said she also better understood student culture because of her involvement.

Jodie was less certain of these potential benefits. In fact, she was pulling back on her efforts because she felt these connections were not rewarded by the library's tenure and promotion system. She felt she could argue that her involvement with students in the 
residence halls is a form of outreach, and therefore a dimension of her librarianship, but her position description didn't include this as one of her librarianship responsibilities. Instead, she felt the tenure and promotion system rewarded the personal connections she cultivated with faculty. Consequently, she was currently making more of an effort to get to know the faculty in the college of business on a personal level rather than getting to know the students.

\section{Transactional Interactions}

In returning to John's response that librarians at University A interact with students "at the desk" and "in class," I am classifying these types of interactions as transactional, or need-based, in nature. When many of the librarians referred to "at the desk" or "desk time," they meant their time spent at either the reference desk or the circulation desk, during which they waited passively for students to approach and ask a question. These questions were often directional in nature, (i.e., "Where is the restroom?"), sometimes technological (i.e., "How do I print to this printer?") and less frequently instructional (i.e., "How do I find sources for my paper on X topic?") These interactions tended to be relatively brief, impersonal, and need-based. Often, the librarians did not learn the students' names and did not encounter the students again after meeting the students' immediate need. If the librarian interviewed the student in a desk setting about their information need, the interview was not focused on the student's thoughts or beliefs so much as on the assignment. Generally, the librarians desired to know if the question was related to a particular assignment and which faculty member had created the assignment. The most successful of these interviews, suggested the 
librarians at University A, yielded a copy of the assignment the librarians could retain at the desk for future reference.

The librarians at University B offered a unique example of a need-based interaction with undergraduate students: They had "door duty," in which they were posted to stand just inside the library's entrance and greet each person who entered. Ostensibly, they were engaged in proactive assistance by asking students what the librarians could help the student with that day and then referring the student to the appropriate person or desk. However, the librarians were also supposed to ask visitors to display a valid university ID; if the visitor was unable to produce one, the librarian disallowed entry. Several of the librarians stated the purpose of door duty was less about customer service as it was about heightening the library's security by barring outsiders. Their director had mandated door duty only this past year, and the librarians found it terribly distasteful and could not understand why they, the librarians, were expected to undertake the responsibility when security guards or support staff could carry it out just as well. In Alan's words, "We have many other, and better, things to do."

Even without door duty to worry about, the librarians at University B found transactional interactions with undergraduate students tough to navigate. Student employees handled nearly all the lending of library materials and answered most reference questions, referring only difficult questions to the librarians. On the whole, most of the librarians' interactions with undergraduate students took place within the context of teaching students how to use library resources and understand concept of information literacy in classroom settings. While their focus group tended to lack enthusiasm for the questions on the whole, I could not help but detect a tone of 
exhaustion that colored their responses. Joe said "There is so much to do that I just run like a chicken with my head cut off..." Margaret invoked one of Raganathan's five laws of library science in a joking but put-upon way:

Raganathan said 'save the time of the user' but what about the time of the librarian? I'm teaching, teaching, teaching... answering questions from faculty... committees... the director has some new idea every few weeks, and then there's a taskforce to study it... but there's only like 7 or 8 of us. That's like one librarian for every 700 students.

Librarians' workloads appeared to be problematic at all of the institutions. Jessica at University D noted the librarians classified as faculty at her library followed a formula for allocating their productivity. Librarianship occupied only $60 \%$ of their time, whereas a combination of scholarship and service demanded the remaining $40 \%$. Consequently, they focused as much of their librarianship time on what Yolanda called "high impact practices" or work that reached the greatest number of students. Yolanda found creating how-to guides in the form of video for a potentially unlimited number of students to watch at their convenience more high impact than teaching a face-to-face class of 27 students. However, she admitted she lost the personal connection she might have made with those 27 students.

Lauren at University $\mathrm{C}$ also emphasized the sheer demands on librarians' time rendered interactions with undergraduate students a lower priority. She said:

I want to be very clear that I am not saying that librarians do not care about undergraduate students. I am saying that the scope of their work, the priorities of the campus, and the way we have historically, um, conceptualized the way we see 
workload...it, it makes it virtually impossible in a number of areas for librarians to develop extensive... [trails off without finish.]

Despite the workload and sense of overwhelm that many of the librarians suggested, there still appeared to be room for re-imagining the library and their work as librarians as student-centered concepts. This was most evident with the librarians at University C, who credited their dean with the genesis for moving away from what Lucy described as the concept of the library with the "Big L" and "very librarian focused" to "moving toward thinking about user with a capital 'U'”. She said, “...we're asking what is, what do our users need? And, I think, that is a big shift for us."

\section{The Student Affairs Professionals' Roles}

When the focused discussions on the librarians' interactions with undergraduate students slowed, I asked the participants: "Let's turn our discussion to student affairs professionals. What do you perceive to be the role of student affairs professionals at this institution?" The participants answered this question with the briefest answers, and they engaged in considerable checking with each other to confirm their thoughts and impressions. Many of the participants switched to different tones than they had used previously, often sounding less certain of their perceptions.

Overall, the participants did not have well developed impressions of the student affairs professionals at their institutions. Many participants said they were simply unfamiliar with the student affairs professionals, having rarely interacted - if at all - with these colleagues. Others perceived the primary role of student affairs professionals to be the provision of students' basic needs for survival, such as housing; meals; and health services. A much smaller number of participants speculated that student affairs 
professionals help students navigate the daily, if complicated, business of students such as financial aid; advising; career services; and conflict resolution. Perhaps surprisingly, those participants who did express a more well developed perception of student affairs professionals were often critical: They perceived student affairs professionals to be disorganized, to communicate poorly with academic affairs generally, and to seemingly inhabit a wholly separate reality of the campus.

\section{Lack of Familiarity}

The lack of familiarity with student affairs professionals hindered the participants' ability to probe and explore my question with each other. Overall, most of the participants demonstrated a lack of awareness of student affairs at all but University C. At University A, the librarians expressed considerable confusion as to who the student affairs professionals were. For instance, Amy asked me "Do you know on our campus what it [student affairs] includes?" The librarians then checked with each other to confirm their suspicions as to who constituted student affairs, naming the office of the dean of students, student programming, the career center, an office for non-traditional students. Jodie summarized their consensus: "Well, it sounds like they have all the life stuff other than like academic, like, everything they need in order to succeed so they can do their academic work on that foundation. Um... almost like a support system."

They remembered the associate dean of students had come to speak with the librarians in the past year or two. He provided the librarians with information about different areas of student affairs that could help students with different problems, and at least Beverly was impressed with a "who to call" flyer he distributed. She remarked that 
she had called one of the offices listed on behalf of a student who lacked anywhere to go on Thanksgiving Day.

At University B, the participants seemed completely at a loss. Their discussion focused on the student union building, which housed student dining, student programming, and the offices of housing and residential life. They recalled that the director of career services chaired the library's board of alumni advisors, but they weren't certain whether career services fit into the realm of student affairs. Ultimately, they concluded that it must because career services wasn't managed by any of the academic colleges. They confirmed that student affairs professionals must tend to students' basic needs, like housing, and entertainment. However, the librarians said their understanding of student affairs was based on their memories of their own undergraduate experiences rather than on their knowledge of their own institution.

Sabrina at University D said “I don't think about [student affairs] very much. I mean, the most I probably think about it is in terms of making sure students have their [ID] cards." Deanna offered that student affairs professionals support students' housing, dining, counseling, entertainment, and financial aid needs. She said that she had interacted with student affairs professionals primarily when students suffered breakdowns in the library due to stress, and she made calls to the counseling staff on the students' behalf. Crystal at University A had made an almost identical remark.

Throughout the focus group discussion at University D, Howard noted his institution suffered declining enrollment and high attrition, endangering the ability of academic affairs to function without stable revenue brought by tuition dollars. He acknowledged student affairs professionals were vital to the financial health of the 
university by successfully reducing students' barriers to persistence and by creating a campus environment that fostered students' interest in returning for subsequent years. However, he perceived student affairs to represent a threat to the primacy of the academic affairs side of the university. He noted the proliferation of student affairs positions corresponded to the decline of the number of faculty positions at University D. He expressed skepticism of student affairs: "We have an awful lot of vice presidents for a school of our size, so if you want to know what we think about student affairs...” The other participants met his unfinished statement with a chorus of laughter but they chose not to offer further discussion when I probed for greater explanation.

\section{The Shuffle}

The diversification of student affairs' functions appeared, according to the librarians, to erect unintended barriers for students and librarians alike. The librarians reported that often students did not know how or where to obtain the help they needed, for instance with financial aid. The students visited multiple different offices, with staff reportedly referring the student on to other offices before the students finally located the correct office or staff member. The librarians noted the students required tenacity and time in order to navigate the myriad student affairs offices successfully, and they did not believe most students showed this commitment. Instead, their problems often went unresolved. The librarians themselves had experienced this phenomenon when attempting to call various offices on behalf of students. Too often, Jessica said student affairs staff proved unhelpful at directing the librarian to a specific person or office, offering only vague advice such as "call financial aid," suggesting to Jessica that student affairs professionals did not have any greater knowledge of other student affairs offices 
than did the librarians or students. Essentially, the diversification of function created silos.

The problem of ongoing referrals was so pervasive and well known among the librarians at Universities A, C, and D that they had named the phenomenon the " $[\mathrm{X}]$ Shuffle," after the institution's mascot or nickname. The librarians at University B did not indicate they or their students experienced shuffles but they did note their institution was physically small enough that most student services were concentrated in a single building. However, a single building for student services did not diminish the shuffle at University A, whose librarians noted the university had centralized student services recently to reduce students' frustration and enhance student retention. Organizationally, they claimed, various offices remained distinct and physically separated within the building. The "shuffle" persisted but was at least confined to a single building.

\section{"Running a Different University"}

Lucy at University C made a remark that I found particularly poignant. She said, "You asked what we perceive their role to be, and I... feel that student affairs is almost running a different university than the academics." She claimed that she could not adequately call the lack of cooperation between student affairs professionals and faculty a divide because a divide implied that she could see the other side. "There is really almost a separate, very separate things," she said. As an example, she explained the perceived struggle between academic affairs and student affairs over the teaching of leadership skills. Students could study theories of leadership through systematic coursework taught by an interdisciplinary group of faculty, or students could earn a certificate in leadership through coordinated co-curricular experiences managed by student affairs professionals. 
However, the program of study and the certificate were not linked. While Lucy initially perceived this disconnect to be the result of the university's decentralization, she decided later that student affairs professionals resisted efforts to be more closely tied to the academic mission. She believed student affairs professionals were attempting to cultivate their own niche in which they could actively teach and educate students but were likely hesitant to partner for fear the academic side of the university would subsume what they had built.

Molly agreed with Lucy, claiming student affairs professionals decide what they think is important in regards to crafting the ideal student experience. She was frustrated that student affairs professionals responded rarely to her invitations to share information or to discuss outreach opportunities at the libraries. She noted the autonomy student affairs professionals appear to enjoy, speculating individual student affairs professionals pursue the opportunities that they believe are worthwhile. When that person moves on, successors or other persons affiliated with the same office won't respond, indicating that the person's colleagues had come to different decisions about what was important for their work. Molly seemed to disapprove of this perceived autonomy, noting that librarians are greatly accountable to each other and "...would be dinged" by their peers during their annual peer-conducted performance reviews for "going off the reservation." Lucy considered whether faculty had unintentionally empowered student affairs professionals to devise their own sets of educational outcomes by abdicating teaching in favor of scholarly pursuits. She said: 
So many of our faculty on campus don't actually ever teach undergrads. They might never actually even teach, but they certainly do not teach undergrads. If the campus has, um, either intentionally or unintentionally essentially created a line of old-time instructional faculty who are not tenure-line faculty but full-time academic professionals - and that's what student affairs people are - especially for looking at undergraduate education. So, it just, it just allows a further distancing of faculty who are...further and further removed.

Alison at University $\mathrm{C}$ had contributed very little to the focus group thus far, but she surprised me with the revelation that she was herself a former student affairs professional. She had worked in career services before she had transitioned into a new career as a librarian at the same institution. Alison lamented that her former colleagues in career services had little interest in reaching out to her now. She imagined many ways career services could be well served by working with a librarian to ensure library collections contained current information on careers, certification programs, and job searching strategies. Similarly, she felt that she could teach the career counselors better information-seeking and analysis skills in order to help them do their jobs better. As a pre-tenured librarian, she said she was unsure about how aggressively to market her skills to her former colleagues and had let her ideas idle. The other librarians in the focus group encouraged her but simultaneously affirmed that she had better focus on her core responsibilities until she earned tenure.

Alison did point out that student affairs professionals need to understand the academic affairs side of the university better. During her years in student affairs, she had the impression that only student affairs professionals provide career counseling, academic 
advising, and other traditional student services at the institution. After her transition to librarianship, she was surprised to learn many of the academic departments perform these responsibilities as well. She said, “...everyone is running a student affairs function. So you could argue there is duplication of effort. But, I really feel a huge, um, disconnect." Alison seemed to feel that student affairs wasn't laying claim to an educational realm that faculty had abandoned so much as they were remaking it in a form all of their own:

Faculty are still advising students, still giving career advice, still reviewing applicants and making admissions decisions, but student affairs put their own spin on it and do things differently with those things. Because they have student development theories, and because they're a lot more in tune with the students themselves. So the same work begins to look and feel, well, different than when the faculty do it.

Alison felt, at times, student affairs professionals forgot that they could have partners to enrich their work.

Lucy returned to her assertion that student affairs professionals inhabit a different university than the faculty. She pointed to governance, indicating that faculty participate directly in the university's strategic decisions. Although faculty from different disciplines may disagree with elements of the university's strategic plan, Lucy contended faculty are largely on the same page in regards to the university's mission and definitions of academic excellence. Student affairs professionals, however, do not play a role in university governance because they are not faculty. This lack of participation in university governance created distance between student affairs professionals and the faculty. 


\section{Collaboration with Student Affairs Professionals}

Next I asked the participants "Do librarians at this institution interact with or collaborate with student affairs professionals at this institution?" While this question elicited a wide range - and often tangential - responses, the librarians were largely consistent across institutions in their assertion that collaboration had not transpired, or at least not with lasting success. However, the librarians' desire to collaborate differed greatly between institutions. At two of the institutions, the librarians were uncertain of the library's priorities or they perceived the library to be undervalued by the institution itself; they did not appear to have given much prior thought to the possibility of collaborations with student affairs professionals. At the other two institutions, the librarians felt the library administrators valued and encouraged collaboration with student affairs professionals, but the librarians themselves had not actively done so. Their reasons varied from a sense of overwhelm with the diverse demands on their time to low returns - or even threats - in their formal reward systems.

\section{Mission Confusion}

The librarians at University B expressed frank surprise at my question. After searching her colleague's faces for any sign that she might be wrong, Margaret answered for the group:

We haven't thought really about it. I'm pretty sure we've never discussed it at all. I think... our director has certainly told us, encouraged us, that we should collaborate more with other people on campus but I'm not sure that we've really understood why we should do that. It doesn't really seem to be a priority either since we don't actually talk about it together as a group. 
The library's director had not provided any further direction other than the librarians should collaborate with student affairs professionals, but Joe and Paul claimed the director had not articulated her desired outcome - to improve direct service to students? To facilitate librarians' teaching of information literacy outside of the context of academic programs? Without further discussion, Joe and Paul felt they were being encouraged to collaborate with student affairs professionals for the sole sake of collaborating - which they believed to be a waste of time without clear goals and outcomes. However, none of the participants had asked the director for greater clarification or had attempted to begin a group discussion. Individually, the participants seemed to have concluded that collaboration with student affairs professionals didn't fit neatly with their library's overall mission to make information resources available for the purpose of teaching and student learning. Thus, group discussion had failed to take place.

The participants at University D offered a nearly identical discussion. However, they were sharply critical of their library administrators whereas the librarians at University B were not. At University D, the participants noted a distinct lack of coordination of the library's activities by the dean and associate deans. The administrators had encouraged the librarians to collaborate with student affairs professionals but had provided no clear desired outcomes, benefits for students, or identified which student affairs functions would be conducive for collaboration. The lack of coordination appeared to be the norm, judging from the participants' open dismay that they are often left to decide amongst themselves how best to accomplish the library's stated goals. Howard and Deanna noted this way of working was counterproductive: 
collective decision-making implied consensus was necessary in order to move in a new direction but consensus rarely occurred and no change transpired.

\section{Perceived Lack of Interest from Student Affairs Professionals}

Unlike their counterparts at Universities B and D, the librarians at University A and C reported they'd engaged in broad discussions about the library's role in student persistence, and they did see collaboration with other groups on campus as a way for the librarians to play different roles. Both groups of participants said their respective deans saw collaboration with student affairs professionals as a priority for the library and was quite clear in what that collaboration could look like. However, both groups reported unfavorable results in their past attempts to collaborate with student affairs professionals and no current initiatives were underway. Jodie at University A reported her attempts at reaching out to the staff at career services had gone unanswered so often she had simply given up. Crystal said she had met with the residential life staff, who did want to collaborate, but no one could come up with any good ideas. Crystal and Jeanette said they received regular invitations from residential life staff to participate in programs or dinners at the residence halls in order to mingle with the students. While they appreciated the invitations, they felt confused and overwhelmed by the sheer volume of activities. They reported receiving at least one invitation per day for a different activity,

and they were unable to discern which activities were important. Consequently, Jeanette attended none. Crystal said she had time for perhaps one activity per week but the inability to pick an activity meant she participated in few to none. Crystal believed individual student affairs professionals were interested but student affairs seemed to 
experience high turnover. When the staff member departed, no other colleagues continued the discussions.

At University C, the librarians felt stymied in their overtures to student affairs professionals as well. Molly remarked that she did not know who in student affairs she should contact, finding the websites unhelpful or confusing. Similar to the "shuffle" experienced by students, Molly said her e-mails or voicemails often went unreturned or endlessly forwarded to other student affairs professionals. Many of the other participants agreed strenuously with Molly, suggesting they had similar experiences. Largely, these efforts to reach out to student affairs professionals centered on the librarians' offer for the student affairs professionals to use the library as a space for meeting with students. Lauren reported that, for a time, the career services and academic advisors held drop-in hours at the library at her suggestion. While students responded favorably to their presence at the library, the drop-in hours ended rather abruptly and without much explanation. Like Crystal at University A, the librarians believed the desire to collaborate was largely based on the individual preferences of student affairs professionals. When these people departed, the drop-in hours at the library ceased.

\section{"The Jenga Pile"}

Many of the participants expressed a sense of overwhelm at the prospect of integrating collaboration with student affairs professionals into their current responsibilities. Joe at University B speculated the small size of the library staff and the daily business of running the library constrained their ability to step outside their traditional responsibilities. Joe and other participants at University B pointed out that they are already balancing multiple roles - liaising with faculty as subject matter experts 
for multiple academic departments, managing the support staff who perform circulation and interlibrary loan duties, and curating the library's website and access to subscription databases and journals. John at University A referred to this jumble of responsibilities as "the Jenga pile," in which individual librarians take on more and more responsibilities as departing librarians aren't replaced or as library operations grow in complexity. John referenced a game called Jenga where the object of the game is to collaboratively construct a tower by removing blocks from the base and adding new layers to the evergrowing peak; the tower's collapse is always inevitable and the player who removes the ultimate block loses.

Jeanette at University A explained that she had little time to think deeply about student affairs professionals because her own position had gone unfilled for years before she was hired. Her predecessors had each lasted only a few years before leaving for other positions. She said the turnover and the library's slowness at filling her position had damaged the library's relationship with the faculty in her assigned subject areas. Initially, they were unwilling to develop a relationship with her for fear that she might leave. Jeanette felt that she had to concentrate her efforts to prove herself to the faculty, as she deemed her ability to search their research interests and those of their students to be what the library valued most from her. While she was still receptive to the invitations she received from residential life to attend programs in the residence halls, she only rarely accepted these invitations.

\section{Reward Systems}

Many participants noted too that existing reward systems do not facilitate "going off the reservation" as Molly at University C said. At University A, John acknowledged 
the reward system for librarians focuses largely on what he called the three core activities: teaching, publishing, and committee involvement. He implied collaboration with student affairs professionals would likely be considered something distinct from any of those core activities. He said the library employed a staff member whose work was principally outreach to students outside of the library but that her work fell so outside the paradigm for faculty librarians that she was not even classified as a librarian. John speculated that supervisors would not know how to evaluate a librarian's efforts at collaboration. He said there are so many factors that could derail the anticipated outcome of collaboration that are not within an individual's control - so is the librarian evaluated for their effort or for the collaboration's success?

The librarians at University B were not faculty and did not have a tenure system. They were evaluated by their director based on the duties and responsibilities outlined in their individual position descriptions; none of their position descriptions reflected any language they thought resembled outreach or collaboration. They did feel that collaboration with other groups could be theoretically added to their position descriptions with their director's support, but they were uncertain as to what that work would look like.

At Universities A and D, the librarians did not explicitly perceive reward systems to be a barrier that prevented collaboration with student affairs professionals. Rather, they suggested the path to tenure was so rigid that little time and energy was left for fulfilling anything but their routine library responsibilities and their scholarly pursuits. The librarians at University C suggested from their simultaneous support and caution of Alison's desire to work more closely with the career services staff that stepping outside 
the traditional norms of librarianship was risky during the pre-tenure years but looked upon more favorably post-tenure.

\section{Conclusion}

The participants in the librarians' focus groups provided rather consistent responses despite the differences in the types of institutions to which they belonged. They perceived their principal roles to be collection purveyors, teachers, and agents of community development. In their collection purveyor role, they build awareness of information resources amongst their constituents in order to facilitate students' and disciplinary faculty members' learning and research endeavors. In their teaching role, the librarians perceived themselves as chiefly responsible for developing students' information-seeking and information literacy skills. As agents of community development, the librarians fashioned the physical and virtual spaces of the libraries to foster a sense of community between students and between students and the institutions.

The participants perceived their interactions with students to be relatively narrow in scope and often confined to the physical spaces of the library. Their primary contact with students was with those employed as student assistants in the library and those the librarians taught in formal instruction sessions. While they valued their contact with students at the reference desks, these interactions were often impersonal and ephemeral. Some librarians interacted with students outside the library through their ventures as advisors of student organizations or as participants in programming hosted by the universities' residence halls. 
When I turned discussion toward the role of student affairs professionals, the participants seemed uncertain. They were often confused as to which functional areas of the university belonged to the student affairs domain. Primarily, they saw student affairs professionals as chiefly responsible for meeting students' basic needs, such as housing, dining, and recreation. At most of the institutions, the librarians expressed concern that students were shuffled between different student affairs offices and did not receive the assistance they needed.

None of the participants reported significant collaboration between librarians and student affairs professionals. While some student services had entered the library, such as advising or writing assistance, some librarians perceived such collaboration as a threat to the library's historic importance. Other librarians reported attempts to explore collaborations with student affairs professionals but were met with disinterest. Many librarians also seemed concerned with the leadership provided by library administrators, who supported collaboration with student affairs professionals but failed to engage the librarians in meaningful discussions of how such collaborations could benefit students or be accomplished. Other librarians were reluctant to pursue collaborations for fear of stepping outside the norms of the library and preferred to postpone such plans until their positions were secured with tenure. 


\section{CHAPTER V}

\section{THE STUDENT AFFAIRS PROFESSIONALS' STORIES}

This study explored librarians' and student affairs professionals' perceptions of each other's roles in student learning and success and sought to identify opportunities for prospective collaborations, as well as the conditions that impede or facilitate prospective collaboration. In this chapter, I share the major themes that emerged from the student affairs professionals' responses and reactions to my interview protocol. Across all three of the focus groups, the student affairs professionals could not have differed more starkly from the librarians in their comportment. Three words summarize my impressions of the student affairs professionals: eloquent, confident, and lively.

Whereas the librarians often spoke in incomplete sentences, garbled words, and often did not match tense to verbs, the student affairs professionals appeared to be masterful public speakers. With nearly flawless grammar, the student affairs professionals spoke clearly and coherently throughout the discussions. They evinced confidence; their replies came so swiftly and so fully formed after I had asked my questions that I felt almost dumbfounded at their nimbleness of thought. I noted, too, that they did not often turn toward each other or seek out each other's eyes while offering their initial opinions - they seemed completely at ease with their personal convictions and had little need for confirmation. They engaged with each other mostly when building off each other's replies, filling out what a previous speaker had said with a story of their 
own unique experiences or when challenging or supporting each other. A portion of the dialog between Lorraine and Michelle at University $\mathrm{C}$ offers an example of this confidence built by mutual support:

I had the opportunity to investigate the incident [a boyfriend/girlfriend dispute] a little further, talk with the students, and explore what would be fair and reasonable. So, I spent probably four hours to five hours with the different students involved in that incident. And, really, I hope and think that I helped them gain some perspective. I think I made a real learning opportunity... I was an authority figure, but I also became someone who offered some insight and advice. (Lorraine)

Oh, I know what you mean. You work in housing, and I'm in the student union but our goals are so similar... we want students to develop their identities, to be exposed to different perspectives, and we find a way to open a dialogue about what those differences are. (Michelle)

Their passion for their work was quite evident, both through the vigor of their excited tones and their liberal use of phrases such as "Oh, I know!" to confirm something their peer had just said, along with emphatic body language such as nodding and hand gestures. They shared laughter often but rarely did I have difficulty getting the discussions back on track. Rather, they remained quite focused.

Tables 7-9 provide brief descriptions of the participants at each institution. 
Table 7

Student Affairs Professionals at University A

\begin{tabular}{ccc}
\hline Name & Sex & Years of Service \\
Kate & Female & 20 \\
Daniel & Male & 7 \\
Peter & Male & 12 \\
Dorothy & & 14 \\
\hline
\end{tabular}

Table 8

Student Affairs Professionals at University B

\begin{tabular}{ccc}
\hline Name & Sex & Years of Service \\
Jack & Male & 17 \\
Alice & Female & 23 \\
Megan & Female & 12 \\
Kimberly & & 9 \\
\hline
\end{tabular}


Table 9

Student Affairs Professionals at University C

\begin{tabular}{ccc}
\hline Name & Sex & Years of Service \\
Robert & Male & 22 \\
Greta & Female & 24 \\
Miguel & Male & 5 \\
Lorraine & & 5 \\
Michelle & Female & 12 \\
Louise & Female & 15 \\
\hline
\end{tabular}

\section{Student Affairs Professionals' Roles}

Initially, I asked the participants "What do you perceive to be the role of student affairs professionals at this institution?" The participants' responses were consistent between focus groups: educating the whole student and contributing to student success. The participants felt quite strongly that their predominant role as student affairs professionals was to spark growth in students' critical thinking and interpersonal skills and to create experiential learning that imbue students with marketable job skills. Many participants felt they as student affairs professionals were chiefly responsible for “adulting” students - as Lorraine at University C jokingly called it - or preparing 
students for entering post-college life. They felt responsible because faculty members' roles were focused either on teaching students the content knowledge of their respective fields or on generating new knowledge through research activities. The participants were also focused on student success, or helping students attain their degrees by reducing the barriers that inhibited students' likelihood of doing so. The ways by which the participants accomplished this varied by institution and were dictated by the institutions' unique circumstances.

\section{Holistic Student Development}

All the student affairs professionals articulated a holistic definition of student development. Each student affairs professional spoke expansively on the particular dimensions of student development that their functional area influenced the most, such as interpersonal skills and managing emotions appropriately. Nonetheless each student affairs professional described student development as how the college experience shapes students: their cognitive processes, leadership skills, career interests, sense of identity, interpersonal skills, and how they see themselves in the world. They described student success as how students move towards attaining a degree. The following exchange between Daniel and Kate at University A summarizes the participants' perspective of their roles:

We have a journalism degree, and you want to be a news broadcaster. Student affairs provides housing, food, recreational opportunities, engagement opportunities, leadership opportunities, the television station where you can practice your things you learned in your courses, in the classroom. (Daniel) 
Learning how to navigate different identities and those types of things, getting the support services you need. We run a gamut basically from getting from major to career. (Kate)

I think it all boils down to that. (Daniel)

Employers are going to be looking for more than just a degree. There's going to be 3,000 other students graduating with your degree. What sets you apart? What makes you different? What makes you the most qualified for that job? And what are employers looking for nowadays - "What did you do outside the classroom that's going to help you succeed in this job here?" So, it's "What did you get involved in?" Planning an activity, getting a team together, show some leadership... (Kate)

So, you know, so we have to encourage. I think everybody, regardless of what umbrella of student affairs you're under, is encouraging students to take the most, take advantage of the opportunities that are here. Um, be involved on campus, grow, change your thinking, change your perspective, meet people different than you, solve problems. (Daniel)

Be a functioning adult, really, with some perspective on life and able to work with people who don't always think like you. (Kate)

\section{Institutional Differences in Participants' Interpretations of Roles}

Despite their agreement on educating the whole student and student success, the participants interpreted the focus of their roles differently based on the student concerns that troubled their university administrators the most. Moreover, the participants within the same focus groups were in agreement as to their interpretations and were highly 
aware that their interpretation of their roles was distinctive to their institutions. They evinced a clear connection between the importance of their work and the goals of their institutions, indicating they perceived their roles to be simultaneously valued by their institutions and vital to their institutions' reputation or fiscal well-being.

At University A, the participants emphasized the high proportion of students from low-income families among the student body. Their presence caused the focus of the participants' work to be making the college experience more affordable for their students. Otherwise, they noted, student retention decreased. Kate, Daniel, and Peter felt student affairs professionals bore great responsibility for retention:

You know, students are coming in and needing more, and what-have-you. And what do we do with this leftover work-study money and who are we going to give it to? How do you engage the students on campus? Because we know that engagement is important for their ultimate success on campus. (Kate) I mean, it all boils down to that. Um, because the student comes here, and they attend some great parties, have great relationships while he is here, met some cool faculty, learn some stuff, but you didn't graduate. And now you are tens of thousands of dollars in debt with money folks knocking at your door. How successful were, uh, we at supporting and, um, moving that student through his...[trails off]. (Daniel)

What good are we, what kind of experiences are the students having, if they fail to graduate but still leave here with great amounts of debt? We have failed them. (Peter) 
At University B, the participants noted student enrollment had declined, endangering their ability to fill vacant positions. Nonetheless, the institution enjoyed a reputation for placing students into their desired careers quickly after graduation, and the student affairs professionals were focused on helping students gain transferable skills. A discussion between Jack, Alice, and Kimberly summarized their position:

All of student affairs is very involved in creating situations where students can learn the skills they need in order to be good candidates for graduate school and for employers. (Jack)

Yeah, we do that really well as a group. (Alice)

I think we spend a lot of time helping students take what they are learning in the classrooms and apply them in real world situations. We're very civic minded, so we encourage them toward the right community service opportunities, "right" meaning "is it giving back to the community in a way that is also connected to their studies?" That gives them experience, gets their name out there too, but we do have to counsel them about quality versus quantity. (Kimberly)

At University $\mathrm{C}$, the student affairs professionals observed the very large size of their campus is often a barrier for students, making students feel overwhelmed, lost, and anonymous. Consequently, the student affairs professionals perceive their role is to help students navigate the campus and find a niche that still makes the college experience meaningful. In the following exchange, Miguel, Greta, and Michelle explained their roles in helping students make personal connections: 
Our first role is really is to [help students] know their community. I think student affairs is right in the middle of navigating this. (Miguel)

Um, I think there's really less engagement from the faculty. The faculty are almost entirely focused on research here, and so many of the lower division courses are actually taught by T.A.'s, who are grad students, in very big lecture halls. Undergrads may not actually interact with anyone but their friends and classmates, well, maybe not until their junior or senior level classes even. The people who are their advisors are not faculty, and so I think they [students] get less engagement, and the academic side seems so much farther away, and the professors are way up here and they don't engage. So the student affairs staff seem more reachable, I would say. (Greta)

I think it takes some time for you as an individual to reach out, you know, and to being involved. There's a lot of opportunities for them to be involved. But, um, I think, you know, it's knowing when to. (Miguel)

We have to help guide them when they step outside of the classroom. Some of them just don't get that connection. (Michelle)

So we all offer opportunities for them to connect. Some get things from the housing, some things from the union. Our students, you know, some do feel isolated still but the majority...I think they do find their niche, you know, whether it's with the cultural houses or the union or their residence halls, and all that. There's a lot of entry points the students can find community, but we have to create those opportunities for community to develop. (Miguel) 
The participants' perceptions of their contributions to student success contrast greatly with the librarians, whose perceptions of their roles varied little between institutions. The student affairs professionals' recognition that they must adjust their roles to correspond to the institution's values supports Walter's (2009) perspective that student affairs is a value-relational discipline, in which practitioners of a discipline are attentive to campus culture and find meaning for their work in what the campus values. However, the librarians' perceptions of their work varied little between institutions, which suggests the library profession may be less value-relational than thought. This may have negative implications for the feasibility of collaboration between librarians and student affairs professionals, as Becher and Trowler (2001) theorized that interdisciplinary work is less challenging when the collaborators belong to disciplines that are value-relational to their institutions' values.

\section{Interactions with Undergraduate Students}

Next, I nudged the focused discussions toward the student affairs professionals' direct interactions with students. I asked, "How do student affairs professionals here interact with students and for what purposes?" I noticed a profound change amongst nearly all of my participants with these questions: They were more lively, leaned closer as they spoke to me, and clearly took pride and pleasure as they shared their favorite moments or relished what they love most about their respective positions. Student affairs professionals used many "helping" words and phrases to describe their work and their relationships with students such as "empathy," “care," "understanding," "advise," and "belonging." Clearly, the participants respected students as individuals who matter and are unique in his or her own personal experiences, circumstances, and needs. The 
predominant themes of the student affairs professionals' responses to my question centered on teaching moments with students and on advocating on behalf of students to the administrations of their respective universities.

I noted, too, that the participants' interactions with students did not appear bounded by spaces or locations, unlike the librarians' interactions. The librarians were aware that their interactions with students mostly took place at specific locations, such as at a service point or within a classroom. Although the librarians managed student employees at the library and occasionally conducted outreach to students outside the library, the librarians still emphasized that these interactions occurred because of the places where the interactions transpired; the librarians may not have had reason or circumstance to interact with students without those parameters of space. Additionally, some of the librarians seemed to have conflict with that awareness - was it constraining or enabling the nature and quality of their interactions?

I had expected the student affairs professionals would similarly reference specific places, such as residence halls or advising centers. They made few such references. In fact, the participants spoke of their interactions with students as if they were not bounded at all by physical spaces, suggesting instead that student affairs professionals feel a sense of autonomy in being able to work with students wherever students might be found.

\section{Student Affairs Professionals as Teachers}

The participants certainly saw their interactions with students as teaching but they generally described these interactions as informal and relatively brief. Many participants used the phrase "teaching moment" to describe an interaction that was short-lived, often less than an hour, such as in a roommate mediation, but purposeful on the part of the 
participant. Greta, Louise, and Robert at University C discussed applying transformative learning to their interactions with students:

I would agree with that, and I would also say maybe learning some of the responsibility they don't get learn in their classroom. For me, as an employer of students, means teaching them. I've had a lot of conversations about what it means to have a job and to have a supervisor and to understand what it means to provide good customer service. Those are skills that you do not learn in the classroom, and so... and so I think that is a majority of my, my job when it comes to the people, to the students, I employ. (Greta)

We stimulate their curiosity. We help them learn outside of the classroom and connect that learning to what they are doing in the rest of their lives. Um, we help them become lifelong learners, and we help them develop their creativity and their critical thinking. We help them communicate well with their peers. Uhm, we help them learn how to make things happen within their sphere of influence, how to organize things, how to be leaders. (Louise)

All of those things. [laughter] I see this transformative piece as being, uh, a reframe opportunity. They have a chance to look at either old things in new ways or to, um, learn entirely new conceptualizations of the world around them, and to, I think the thing that we do in student affairs, we provide that practice ground to do that. (Greta)

Usually, the participant described guiding a student toward a particular outcome, such as a new understanding of a complex situation, through discussion. Some participants referred to this method as "challenge and support," in which they challenged 
verbally students' beliefs by asking many questions such as "why do you think that way?" and supporting students' commitment to a possible new perspective. Michelle at University $\mathrm{C}$ recounted an interaction where she taught perspective-taking skills to a boyfriend and girlfriend engaged in a dispute:

I talked with each of them separately, and then again. I asked each of them questions like "why do you think she responded like that?" and "how do you think he felt when you said that to him when you knew it wasn't true?" Then I bought them together, and I prompted them to say to say to each other what they said to me. I'm not sure, I think I spent maybe 3 hours with them, all told. They seemed to really get it in the end, why their words and their actions to each other incited the other. They're only $18 \ldots$ they have a hard time seeing anything from any angle but their own, at least at first. I think offered them some insight.

Peter and Kate at University A described that student affairs professionals walk a fine line by teaching with the challenge-and-support concept. While it often worked for them, they felt it was successful only when they had developed trusted relationships with students. Otherwise, students less familiar with Peter and Kate were not as open to being challenged.

I think that there is this natural tension between being helpful and being too helpful. You can't lift them over the bar, you've got to show them how to get, uh, up and it's okay to give them a hand every once in a while but you really have to sort of show, teach them to fish. (Peter) I agree. You gotta make the student want to get there. (Kate) Show them... why it is important and turn loose. (Peter) 
It's always started with a relationship with the students. Taking the time, how much ever time that is, and meeting them on their level to develop a relationship. Now, there's a line though. I don't want too much of a personal relationship but there's got to be a relationship there to begin with. So, I always take time to build relationships with the students. Once a relationship is there, you can challenge them and, and they're going to be less resistant to it. I mean like 'who do you think you are?' You know. Well, if I know them, and they know me, then we can have an honest dialog. (Kate)

Challenge-and-support doesn't always work. Sometimes they can't meet your expectations. Often they do, but sometimes they don't. I really don't like this method though. How many students do we reach? This is so dependent on the relationship you build, and you can only build so many. (Peter) Yeah... You know, most students have no idea who we are. They don't interact with student affairs. Who interacts with us? The students who are really in trouble, in crisis, and they're tough to build a relationship with because maybe they're adversarial since they're in trouble. (Kate)

Right. Or the students who want to be involved, so they seek us out. They want to be part of something, be leaders in the community here. So they gravitate toward us for those programming opportunities. Usually they start out as R.A.'s in the halls or maybe as student workers in our offices. They're the ones we build a relationship with but I bet they're less than $10 \%$ of the kids here. (Peter) We never see most. (Kate) 
So I don't think this is a very effective way of teaching, you know? But I'm not really sure what the alternatives are. How do we make a bigger impact? (Peter) Moore and Marsh (2007) postulated that student affairs professionals teach students from "afar" by creating environments and experiences that stimulate personal exploration and growth (p. 7). The participants bear out Moore and Marsh's claim through their emphasis on creating opportunities, programs, and experiences but they also appear to have a stronger teacher identity than Moore and Marsh suggest student affairs professionals have. Moore and Marsh claim student affairs professionals have an educator identity but have yet to intentionally structure interactions with students to lead to intended learning outcomes. The participants' focused discussions suggest that they are doing so but are frustrated by the limitations of their method, namely that interactions are dependent on forging personal connections with students and thus not able to reach as many students as they would like.

\section{Student Affairs Professionals as Advocates}

The participants perceived themselves as advocates on behalf of students and that advocacy played a vital role in student success by ensuring the universities remained responsive and flexible to meet students' needs. They educated university administrators and others on the needs of special populations of students in order to change policies or procedures that remedy disadvantages or unfair circumstances, such as stories Daniel and Kate at University A shared. Daniel recounted his experience working with the chancellor's office to address bias complaints minority students had brought to him; he believed his advocacy on behalf of the African American and Latino students had helped persuade the chancellor to establish a high-ranking position focused on diversity 
initiatives. Meanwhile, Kate observed that students who self-identified as transgender expressed concerns about restrooms, and she was working with the university's facilities managers to plan for gender-neutral restrooms in future renovation plans.

Robert and Louise at University C acknowledged that student affairs professionals walk a fine line between representing students' interests and serving an institution whose culture or goals may not coincide with those interests:

I think that there's this other role that we are called upon to play in terms of the students. We impact the students but how do we make sure the students are impacting [the university] so that we are evolving along the way? And, um, so often there's this tension there that we're, uh, I think student affairs is right in the middle of navigating this. How do we take what students are bringing to us as concerns with the environment that they're in, and of ways that we can advocate for them, ways that we can encourage them to advocate for themselves, and build this structure so that they can navigate it themselves. (Robert)

So it's this... this kind of dance where ultimately they want help, they want to help, help provide the best kind of space for students to have all these things. But we're part of an institution... the bureaucracy is thick [laughter] and um...I think many of us struggle with figuring out how to advocate for them best. (Louise)

\section{Librarians' Roles}

Next I asked the participants: "Let's turn our discussion to librarians. What do you perceive to be the role of librarians at this institution?" I believe this question elicited the most uncertainty from the participants, judging from the lengthier pauses between their responses and the increased frequency of checking their responses with 
each other through direct eye contact. The participants' perceptions of librarians varied across focus groups and even among participants within the same focus groups. Some participants saw - and valued - librarians as educators, influencing students' cognitive development by teaching analytical skills and self-sufficiency, whereas other participants found librarians unresponsive to students' needs and consequently believed librarians were too removed from student learning to be taken seriously as educators. This mirrors the ambivalence that faculty members expressed in Nilsen's (2012) and Schulte and Sherwill-Navarro's (2009) studies, indicaating that student affairs professionals' perceptions of librarians' instructional role is just as complicated and multi-layered as the perceptions of faculty members.

Most participants agreed that librarians are principally resources for students, faculty, and staff by developing collections that enable their constituents to find the answers they seek. Several of the participants referred to this role as "silent partners in higher education" and valued this role. Other participants were disturbed by what they perceived as librarians' diminishing visibility, leading one participant to refer to librarians as "the invisible people."

\section{Librarians as Educators}

The student affairs professionals considered librarians as critical for academic support but whose impact on student development was limited to critical thinking skills. Nonetheless, many participants saw critical thinking skills as vital to problem-solving and not important merely for classroom work. Kate and Peter at University A illustrated the participants' assertion: 
What librarians do is really important. They teach students how to recognize good and bad information. What they're really teaching there is analytical skills. Students need analytical skills in all dimensions of their lives - as they select majors, internships, careers... (Kate)

I agree with Kate, I agree completely. Analytical problem solving is essential for lifelong learning. But in addition to analytical skills, librarians are teaching students self-sufficiency. If they [students] can learn how to search for information themselves - search effectively, that is - then they be self reliant. They can be independent and autonomous adults. That's really what we're trying to accomplish, isn't it? So, yeah, I do hear students say they don't really need the librarians all that much, but I tend to think that's because the librarians have already done their job, providing a strong foundation for these students to find and use the information they need to be successful. (Peter)

Despite many participants perceiving librarians to have an important educator role, some participants seemed less convinced. These participants felt librarians were more interested in the organization of information rather than in students, which they believed was evidenced by the language librarians used:

Librarians are concerned with information, which is detached and something external to the student - something to be found, to be analyzed, to be digested, whereas we [student affairs professionals] are more concerned with knowledge, which is a synthesis of information and experience, shaping it into how a student then sees the world or approaches a problem. (Louise, University C) 
It goes beyond what Louise said. I'm really confused by the language they use what is "user services?" That is the phrase they are using now for the check-out desk, I think. What is a user, exactly? I mean, I know they're talking about the people who use the library - all of us, students, staff, faculty... But, really, it's so impersonal, we're not interchangeable, and the language they use makes them seem very impersonal and unapproachable when I know they're trying to achieve the exact opposite. It's actually very off-putting. (Michelle, University C) Alice and Megan at University B suggested librarians are not very responsive to students' needs:

[Librarians] push things around - do they even know what students need? (Alice) Responsiveness needs to be in their work now. (Megan) You know very few of them teach students how to think about information. Most of them might spend a few minutes showing students how to make sense of a call number or how to build an effective search in a database, but all of that is 'library literacy' in a way and not how to think about 'information' in a critical way. I think they're so caught up in the tremendous amount of administration it takes to keep a library running that they dedicate three or so librarians to teaching students and the rest order books, catalog the books, check out the books, or maybe answer very specialized questions from faculty and graduate students. [pause] And actually I only know that much because I worked with the librarians to bring my University 101 class to the library, and there's a librarian I talk to in my water aerobics class. (Alice) 
Yeah... Younger students have less attachment to the library as a physical space because they interact with the library digitally. They don't see the space as a resource, and they only interact with the librarians if they are physically in the space. Although most students won't know it, I know the library assigns its graduate students to reply to reference questions asked by text message or by instant messaging - and really that's probably how most undergraduates prefer to ask their questions now. (Megan)

They need to restructure their information literacy lessons because first-year students aren't ready to absorb the lessons. (Alice)

Library 101 needs to be 'where is it, what does it offer, and how do I get it', and a 'level two' function needs to happen in students' third year when they're cognitively ready to critique sources and synthesize conflicting sources. (Megan) Miguel at University C speculated the librarians are "trapped in the library" due to the amount of time and expertise that must be required to review books, journals, and databases and then make these resources available for faculty and students. Louise agreed with Miguel's speculation, but she and Greta believed the librarians make a decision to not be involved with matters outside the library:

I see the librarians as a resource, not for myself but for the students. When I recognize a student is struggling academically, I always suggest they meet with their librarian even before I suggest meeting with their advisor. However, I'm not sure students today understand what a librarian does, especially if they came up through a K-12 system that didn't place librarians in their schools. So, I've thought about this, and I've tried to work programmatically with the librarians so 
they'll come to where the students are. That's been such a struggle. The librarians just won't do it. They say 'well, refer the student over to me' and I'm saying 'no, they won't go see you. You need to come over here to where the students are but then I don't hear from them again. They really seem to miss the whole point. (Louise)

Well, I'll be negative. I'm an advisor for undeclared students, which means I'm in the student affairs division and came up to that from being a residence hall director. So I see the students when they're in crisis, usually right after their first tests or essays. I don't think they [students] really get the research help they need until they're taking upper division courses, usually after they've declared a major. Then they're assigned a librarian who specializes in that particular major. So the librarians under-serve these undeclared students. I've been trying to talk to them about that... and I'm telling you, it's taken five years. Five years for the librarians to remember that I exist. (Greta)

Oh, I know. I think my frustrations with the librarians is that they're coming from academic affairs but no one in academic affairs thinks all that much about the students. They're always talking about student learning - "we support it, we support it" - but very few of them can actually show how they support it. (Louise)

\section{"The Invisible People"}

Jack at University B said: “A great librarian is one that you don't even know is there because they've built relevant collections and libraries that are so easy for you to find what you're looking for that you take it all for granted." Many participants 
explained that librarians work principally behind the scenes in students' lives: Librarians select books, journals, and databases that students will use for their studies. Unlike student affairs professionals who worked in a variety of settings on campus, the participants associated the librarians only with the library. Their assumption was that librarians are engaged primarily in administrative duties - the "behind the scenes" work that must be necessary to keep the library operating smoothly. Many of the participants seemed somewhat surprised by this realization, which is illustrated by an exchange between Jack and Kimberly at University B:

Come to think of it, I never see them outside the library... That's the only place I see them, really. I do go to the library pretty often. I just took a new position here in a different part of the [student affairs] division, and the job is so different than anything I've done before... so I've been going to the library a lot to read up with the journals they have, just to try to give myself a stronger foundation in my new role. But, really, I only see them there at the library, and really once I found the journals I needed, I didn't even really interact with them again after that. I just go straight to what I need. (Jack)

Huh. I don't ever see them either, Jack, but I don't go to the library at all. I think they might be the only group of people on campus that I truly never see... I see the faculty at programs, at committee meetings. I talk to the facilities staff and the technology folks all the time, of course. Even the directors of development sometimes. But I never see the librarians. I guess they are always busy running the library? It must take a lot of work to run a library. I've never really thought about this. (Kimberly) 
I think we don't see them outside the library because they need to be near the books. Those are the tools of their trade, and that's the whole reason they are here, isn't it? In one way, it doesn't make sense for them to be out of the library much, away from the books. On the other hand [long pause], the students are getting what they need from digital sources and probably aren't seeking help for finding things as much as they used to... so maybe the librarians do need to get out of the library more, just to now be a different kind of campus citizen. To contribute differently. (Megan)

While they did, in fact, recognize librarians as tied closely to the academic mission of the university in regards to helping students connect with information, most of the participants acknowledged that they'd had little to no significant contact with librarians since beginning their professional lives. Their interactions with librarians were largely in the past, during their years as undergraduate or graduate students. With a few exceptions, most of the student affairs professionals said their primary interactions with librarians was the result of referring students to the library or because of committee work. During all of the focus group discussions, most of the participants said they didn't need to use the library for assistance with solving problems in their daily professional lives; rather, their sources for trusted information were other colleagues across the student affairs profession. This revelation spurred many of the participants to ponder librarians' relative invisibility. Many participants speculated that librarians were simply too preoccupied with the administrative business of reviewing and selecting information sources to be well known as colleagues. 
Robert at University C explained "librarians honor traditions and preservation, whereas student affairs [professionals] are concerned about making an impact and about immediacy." He indicated student affairs is a broader discipline than librarianship, with highly diverse skill sets and talents found amongst the people employed in residential life, culture centers, student unions, Greek affairs, and counseling services. The skill sets and talents found amongst librarians are more uniform, he said:

I think most outsiders looking in at student affairs can see a profound difference between the student affairs staff who manage a career center versus a cultural house for minority students. I think most outsiders looking in at a library can't tell the difference at all between the people who work in libraries.

At University A, the participants speculated that librarians were increasingly less visible because of the recent changes to library spaces and technologies. Daniel, Kate, and Peter at University C marveled at the recent changes they'd observed at their university's library but wondered what the changes had meant for the librarians' roles:

There are lot of things that happen behind the scenes, like interlibrary lending and maintaining computers and redesigning the building so it's modern. Uh, I would imagine that what makes the library have those books, and rooms, and computers, and all those things available. I don't think there's a lot of acknowledgement to the librarians of their library administration. Did you know they have music rooms now? Where you can practice an instrument - in a library! That's amazing. (Daniel)

I didn't know that. Really? Wow. I have to imagine the world of a librarian has changed over the course of the last 20 years. Before the Internet, you had to go to 
the library to find anything. And now you just don't have to go to the library. You can Google something, and you'll get a million different things but chances are something on that first or second page is pretty close to what you need. And the students would much rather look at something online now. So, I bet the librarians at this point are wondering: "What am I doing here?" (Kate) The librarian used to be the person who hands you a book, stamped it, and told you when it would be late. They were the keeper of the knowledge and that, you know, they'll allow you to have it for short periods of time. But, yeah, [Kate] is right that students do everything online now. I have no idea what those librarians must be doing now instead, but the library is definitely a changed place with cafes and food, specialized software, and even self-check stations like you see at the grocery stores. They must be busy managing all of that, but they're very much out of the public eye. (Peter)

The student affairs professionals at University C purported that librarians are saddled with an image as people who sit behind reference desks, passively waiting for students to call upon them for help. However, they acknowledged the librarians at their institution are spending fewer hours at reference desks in favor of providing more specialized research services. Yet they felt the librarians' exploration resulted in greater invisibility:

I think especially on this campus it is really hard for students to learn how to navigate the library. I've spoken with colleagues at the university library, and the librarians think students are there. They're "there" but they're not really there because they're only studying and not really making use of the library's 
resources. The librarians don't show them how to make a library account, how to request books. They assume the students know how to use libraries because our students are typically from upper class, upper middle class schools. (Greta) They assume the students know to use [libraries] but trust me, they don't even know how to use the catalog. I'd been sending students over but it's not that easy now. Like, you can't just say 'go and see this librarian' anymore because a lot of the librarians changed their [reference desk] model, and you have to make an appointment now. That model assumes students are planful, but our undergrads haven't really learned those planning skills yet, haven't quite figured out they need to look at their assignments way ahead of time and think about what they might need. No, they're still starting papers pretty close to when the papers are due. (Lorraine)

Right. And the students can't talk to the librarians when they need them now. They have to talk to a graduate assistant instead. It's very few times when a librarian is actually there to help them. So, yeah, the librarians are getting pretty advanced with being able to help students with statistical modeling now and things like that, but who are they serving? Only a very small segment of the students who are ready for that. (Greta)

I think students' basic needs aren't being met well anymore. I'm not sure where the librarians are if they're not accessible at the library's service points. We don't see them outside the library, but we don't see them in the library either. The vanishing librarians - where are they? [laughter] (Robert) 


\section{Collaboration with Librarians}

Next I asked the participants "Do student affairs professionals at this institution interact with or collaborate with librarians at this institution?" While none of them did and they were not aware of any such collaborations, they did have insight into the reasons why collaborations with librarians may not have been explored. Many of the participants simply lacked familiarity with the librarians at their institutions. The participants at University A drew their impressions almost entirely from the librarians they remembered from their own student days and confessed that they didn't know any of the librarians at their university personally. Other participants perceived librarians somewhat negatively and believed the librarians at their institutions were neither flexible nor persistent in their past attempts at collaboration. Curiously, only the participants at University C noted an organizational gulf between the student affairs and academic affairs division whereas the participants in all of the librarians' focus groups remarked on the "otherness" of student affairs professionals.

\section{Persistence and Flexibility}

Several of the participants at different focus groups indicated the librarians had attempted to collaborate with student affairs professionals in the past, but the efforts had not been fruitful. The participants felt the librarians had given up too quickly. If the librarians had persisted by adapting their programs or workshops, they might have stood a great chance of success. Greta and Michelle at University $\mathrm{C}$ discussed a failed venture:

I think some libraries have tried to do that from what I heard, but it seems like everyone I know was “didn’t work, not doing it again.” So, um, that's a bad philosophy to have that it didn't work that time so it won't work this time. What 
can we evaluate and do a little differently and try again instead of giving up on the first time? Because, I know we had, we had the [name redacted] Library here in this building and no one [students] used them because no one knew they were actually there. So the librarians stopped coming. (Greta)

Do you mean in our old building? (Michelle)

No, this building. (Gretchen)

Oh. Did I even know that? (Michelle)

Like two years ago we had... the librarians would have hours twice a week for two hours each time, and nobody [students] came to them for research help or whatever. And they're [the librarians], like, "we're done, we're not going to come back.” (Greta)

Two hours isn't much time. (Michelle)

No, and it was...right in the middle of the day. There aren't any students here because they're in class or working. I tried to explain, told them they should come back from 7 to 9pm, when the students are finishing dinner and coming back to the halls. Nope - they're strictly "business hours" people, I guess. Too bad. (Greta)

At University C, Kate remembered that other student affairs colleagues had developed programs with librarians to create awareness among the students for the resources the library offers. Students did not attend, and the collaborative programming was later abandoned. Kate and Dorothy shared their reflections but I could not help but detect a note of sadness, or perhaps futility, in their voices during this exchange: 
I don't know that students see [the usefulness], and I don't know if I was a librarian, how you would get the message across. I don't know. I don't have a great answer to that question but I'd just say, you know, from my experiences in student affairs, it's, you know, trial-and-error and keep trying. And, try different ways, and you know, even if it seems like a crazy idea, try it. What's it going to hurt at this point, you know? (Kate)

And I'm just saying that collaboration, you know, we do so much collaboration, but as I think about it, we really don't collaborate much with the library. I mean, I used to promote the writers' workshops and things like that, and refer students to our learning support services, but it would be nice to have the librarians...maybe even in the summer, when it's a little slower...to come and really interact with student affairs folks and let us know what services they provide, so that we are better equipped too as we interact with students to say "Oh, you need to go see soand-so. Or, did you know the library does this?" So come and better inform us and also allow us to inform as to what we do. (Dorothy)

Greta, Michelle, and Robert at University C observed that librarians' and student affairs professionals' concepts of programming are different, and this difference may prevent them from knowing how to work together. They perceived the librarians relied heavily on passive programming, such as creating exhibits and displays to showcase library resources, whereas the student affairs professionals are used to designing experiences that make students interact with each other: 
I think it's a new concept for librarians thinking of programming. I don't think they know how to do programming or what they would program about. (Greta) They do more workshops, it seems, than programming. (Michelle) They do a big...I think I'd say it's a display... with banned books. It's an awesome display and really touches on freedom of speech. I think the archives does displays sometimes too. But I'm not really sure what my part in something like that would be... I'd want to talk about something, get the students to talk. I think the librarians just put up their display, hope the students take something away from that, and they're done. Back into the woodwork. They need to try something different if their goal is student engagement. (Robert)

\section{Perceptions of Librarians' Personality Traits}

Perhaps one of the biggest barriers to potential collaboration between the participants and librarians is the participants' perceptions that librarians do not possess personality traits that student affairs professionals commonly believe are essential to working together successfully. One participant speculated their "high touch skills" were not sophisticated, such as empathic listening or making personal connections with students easily. Alice, Jack, and Megan at University B explain how the librarians' lack of communication skills reinforces their negative stereotype of librarians:

Maybe this is just the stereotype... everyone has that image in their head of the biddy librarian with her hair in a bun. Very severe. Probably owns a lot of cats. [laughter] (Alice)

But maybe it's also kind of true? (Jack) 
Yeah... I mean, when I think about our librarians here. Wow, they are kind of severe. They won't let you even come inside the library unless you present your ID first... and I've worked here for years and they haven't let me in. (Alice) I've gotten in without my ID plenty of times. (Megan) Well, this is such a barrier to using the library. I don't get why they started this. But they look... soooo sour and miserable when they're at the door. Not only can they not really explain why they have this policy... they just repeat over and over “you need to have your ID" without really seeming to listen to why you're asking... but they really don't look too pleasant about it either, so that doesn't really make me want to really work with them. I can only imagine what the students must think. (Alice)

At University C, Greta recounted a story of a student harassing the librarians at the reference desk. Greta had encountered the student before, and he was later found to be experiencing a serious mental health crisis. Greta reported the librarians lacked the confidence to handle the situation themselves:

They were like, "Oh we'll talk to [Greta], and she'll tell her people to deal with it, and we'll just leave it at that." I took care of it but I was annoyed because they lack the confidence and skills to even approach a student who appears to be in crisis, much less know what to actually do when they learn what that crisis is or what the student is experiencing. It's scary at first, but then you do it and then... (Greta)

Surely the librarians have to deal with plenty of that... (Robert) 
I am sure there are some real stressed out students in the library at $2 \mathrm{am}$ and $3 \mathrm{am}$. [laughter] And, are they trained in mental health or...? (Lorraine)

Nope. I think it's the [support staff] that handle those students. I don't necessarily know the librarians... I think they're not there at night. (Louise) It would be helpful for them to have some kind of training. I reached out to them and approached them. Nope. Not interested. The head reference librarian seemed pretty mystified too that I even asked. She said "well that would be a good thing but I guess it's easier for us to just call you?" (Greta)

If they really want to be partners in student success, they really need to step outside their box. They need to realize that we're all in this together, and they need to show a genuine commitment to students' well-being. I realize a lot of faculty would rather just call us too, but a lot don't. They ask for us to help them know when and how to refer a student. We teach them to actually walk a student over to the counseling center so they know the student actually goes to get the help they need. They seem really thankful for that. (Louise)

I guess I would expect the librarians would be more willing to do that than faculty. I'm surprised to hear that. I've always thought librarians had such a really strong service tradition. (Robert)

\section{Focused on the "Here and Now"}

Some of the participants noted that librarians tend to be very deliberate in the plans they make. Greta at University C observed that librarians at her institution wanted to schedule their outreach hours at the residence halls with her months out in advance but she found that she didn't know that far ahead of time when her student organizations 
would be putting on programs that might compete with the librarians. Understanding Greta's predicament, Miguel explained that student affairs professionals have difficulty planning because they work so closely with undergraduate students, who are still mastering time management and planning skills. He said this makes it difficult for student affairs professionals themselves to commit to plans when coaching students towards established schedules for programs and events is a constant work in progress. Additionally, Miguel said student affairs professionals' lives are dominated by a sense of immediacy, which he suspected isn't the case with librarians' lives:

There is always a crisis. A parent can't reach their child by phone, and you're sent to make contact with the student and make sure everything is okay. A student is talking about self-harm, and you're finding them counseling. Everything is disruptive, and everything needs an action from you right away. (Miguel)

I think that's much worse in your area [residential life], but I do agree. I work in service learning and civic engagement, and I'm amazed how many things fall through at the last minute. The work site can't take as many volunteers as we have interested - like, they're telling you hours before you're supposed to load people on the bus to go there. And here I am calling other sites trying to make last minute arrangements. Or... far more students show up than had registered, and now I need to find a second bus and drive. Like, now. (Louise) So, we don't, because of time. We don't plan ahead, and we don't think ahead, and how can we pool the resources together in, uh, a timely fashion, and that's not 
because we're slacking just because there's so many other things that are interrupting. Um, some of the things that are more secondary to... (Miguel) We're dealing with roommate conflicts, and then students who are in crisis and then "Oh, I have to do this too now..." We're really living in the here and now. (Michelle)

I'm guessing librarians don't live their work lives like that. I guess students need help at the last minute for papers, but there aren't really... aren't really library emergencies, I guess? (Miguel)

\section{Conclusion}

The focus groups with the participants yielded insights into how student affairs professionals likely view their roles in higher education. They are deeply committed to students and perceive themselves as chiefly responsible for preparing students to succeed in their post-college lives by developing students' cognitive and interpersonal skills and helping them navigate experiences that translate into marketable job skills. They are committed to student success by identifying the barriers that make it difficult for individual students to attain their degrees, and they mediate between the student and the bureaucracy of the universities to reduce those barriers. The participants took different interpretations of how they tend to students' success by understanding clearly the predominant challenges students face at their particular institutions and framing their work around those challenges; this suggests student affairs is indeed a value-relational profession. 
The participants saw themselves quite clearly as teachers and as advocates for students, but they noted limitations in the methodology of their teaching. Their method of challenge-and-support relied on the participants' ability to forge close relationships with students, but they conceded this reliance meant their impact was limited to only those students they knew reasonably well and missed a great many other students. Their ability to advocate, too, required a fine balance between representing the students' interests and working for an institution whose culture may not value the advocacy role.

The participants were less certain of their perceptions of librarians, as a number of them indicated they had no meaningful interactions with librarians. Their perceptions varied in whether or not they saw librarians as valued educators or as administrators too preoccupied with the daily business of running a library to be effective at teaching. In fact, these respondents doubted librarians' sincere commitment to students. The participants remarked, too, that librarians too often seemed invisible on their campuses, rendered to the marginality of their thoughts regarding potential collaborators.

While none of the participants reported significant collaborations with librarians, they were aware of past attempts at collaboration on their own campuses and at other institutions. They had heard that these collaborations did not meet with success and were abandoned. The participants felt librarians had not taken the time to evaluate what they could have done differently to make the collaborations more successful, and that librarians could demonstrate more flexibility in how they approach such collaborations. Some participants doubted librarians possessed very sophisticated interpersonal skills, making it difficult for librarians to relate to students and making them appear to be less convincing collaborators to the participants themselves. Lastly, the participants 
recognized that student affairs work is often disrupted by students' crises and abrupt changes to the logistics of program and activity planning endeavors. They acknowledged this need for immediacy in their work made it challenging to actively plan long-range collaborations with others, and that librarians particularly seemed desirous of advance planning. 


\section{CHAPTER VI}

\section{THE DIVERGING AND SOMETIMES INTERSECTING WORLDS}

\section{OF LIBRARIANS AND STUDENT AFFAIRS PROFESSIONALS}

In the two previous chapters, I shared the stories of the librarians and the student affairs professionals as they responded to my interview protocols, and I organized their focused discussions into themes. This chapter has two major sections. In first section, I discuss how the themes from the two preceding chapters represent the diverging and, sometimes, intersecting worlds of librarians and student affairs professionals. In the subsequent major section, I revisit the study's research questions and elaborate how the focused discussions shed light on librarians' and student affairs professionals' perceptions of their own roles and each other's roles, and what these perceptions mean for building prospective collaborations that improve student learning and student success. My findings highlight some of the reasons why collaborations between librarians and student affairs professionals might be difficult to achieve but are also suggestive of areas where collaboration might be more possible than in other areas.

\section{Diverging Worlds}

\section{Differences in Predominant Roles}

I noted the starkest distinction between the student affairs professionals and the librarians in their predominant roles and how they perceived these roles to be valued influenced their perceptions of each other. Across the focus groups, the student affairs 
professionals were very clear on the purpose of their work: to ensure students' persistence and to help them leave college with higher-order soft skills valuable to the working world and adult lives. The focus of this purpose varied, depending on the particular student issues troubling the higher education institutions most. Nonetheless, the student affairs professionals exuded confidence that their work was valuable and valued, regretting mostly that their usual teaching method of challenge-and-support, as explicitly noted by the student affairs professionals at University A, depended on a high degree of student contact, thereby limiting the reach and impact of any one student affairs professional.

Contrastingly, the librarians seemed somewhat uncertain as to how they fit into the larger educational mission of their institutions. Their primary role had shifted from one historically focused on collection-building to support research to one of purveying to faculty and students a more curated collection of resources. They found this shifted role challenging, as demonstrated by the concern shared by the librarians at University A that they had a difficult time creating opportunities raising faculty and students' awareness. The librarians' emphasis on the information purveyor role was to ensure faculty, staff, and students knew about and used the collections the librarians acquired with increasingly scarcer resources. They were skeptical of the efficacy of their other predominant role - teaching students information-seeking skills and information literacy - as they found it hard to demonstrate evidence that their teaching made a difference. Their role in community development was still important, but reshaping the library into student hubs represented both opportunity and threats to the librarians. 
Organizationally aligned with academic affairs at their higher education institutions, some of the librarians expressed discomfort, if not suspicion, about the increase of student affairs administrators while their own numbers declined along with the faculty. This discomfort suggested they perceived student affairs to be on the ascendancy while they perceived themselves to be on the decline in the context of the power structures of their institutions, as Howard at University D appeared to express. Lucy at University $\mathrm{C}$ alluded to this discomfort when she said student affairs professionals were "running a different university" in the struggle over primacy over the teaching of leadership skills. At the same time as the librarians were re-imagining libraries as student spaces, they were also ambivalent about sharing those same spaces more permanently with student services, suggesting they found the conversion of library space into computer labs, coffee houses, and spaces managed by student services to encroach upon their domain.

Because of the sharp distinction in confidence of purpose between librarians and student affairs professionals, I question the likelihood of these two groups reaching out to one another. The librarians may potentially see the student affairs professionals more as vaguely defined threats rather than as partners, while if the librarians aren't clearly able to further student affairs professionals' goals ,the student affairs professionals may not see a clear need to reach out to librarians at all. Yet the most profound barrier might be the lack of familiarity or, worse, the relatively poor impression, the groups have of each other. 


\section{Lack of Familiarity, Structural Barriers, and Differing Perspectives on Expertise}

It is difficult to find common ground if one does not know much about the other.

Overall, the librarians were considerably confused as to who student affairs professionals were or what they did. They had a vague sense that student affairs professionals tended to student maintenance, such as housing or health services, but they had little notion of student affairs professionals' educational roles. When participants did demonstrate knowledge of student affairs professionals, they voiced considerable frustration. They perceived the student affairs professionals to contribute to the seemingly impenetrable "shuffle" that sent students - and librarians' attempts to help students - between offices without often finding the help they needed. They also perceived student affairs professionals to demonstrate a lack of interest in working with the librarians, as evidenced by student affairs professionals' failure to respond to messages or to follow through with commitments.

The student affairs professionals suggested the nature of their work emphasized the "here and now," forcing them to juggle priorities constantly due to the needs of daily student crises. They acknowledged they had difficulty meeting librarians' apparent needs to plan out activities well in advance. At the same time, they criticized librarians' lack of persistence and perceived willingness to abandon plans when the outcomes of those plans did not immediately yield a return on the librarians' investment of time. The librarians indicated "the jenga pile" of many competing demands on librarians' time, including absorbing other colleague's responsibilities when positions went unfilled, prevented them from focusing on work that did not have a relatively quick pay off. In fact, they noted concern their reward systems did not reward trying new things, and several participants 
affirmed this for a newer librarian in the group. This lack of time, coupled with inflexible reward systems, poses a significant structural barrier that is very likely to inhibit prospective collaborations between librarians and student affairs professionals.

The student affairs professionals were more aware of librarians than vice versa, but they found the librarians to be "invisible people," confined to the library due to the many complexities of running such an organization. However, they were only marginally more favorably disposed to librarians than librarians were to them. Some participants indicated respect for the contributions librarians do make to student learning, but others were ambivalent about the value of librarians' role, noting progress in technology reduced students' need to seek librarians' expertise. They perceived librarians to have a rather narrow skill set, suggesting librarians do not make the impact on students' lives as student affairs professionals do, given the diverse skill sets and talent found in distinct areas of specialization in student affairs, such as cultural houses, student unions, counseling services, and residential life. To these participants, librarians seemed to have little to offer that the participants thought useful to the participants' work with students. This finding implies student affairs professionals and librarians may not have an appreciation for the expertise that each would bring to a collaboration, which Arcelus (2008), Kezar (2006), and Becher and Trowler (2001) claim is necessary in order for interdisciplinary work to be successful.

Becher and Trowler (2001) observed that collaboration between disciplines is most successful when the disciplines share a common language. The shared technical language of the disciplines help the groups engage in mutually satisfying dialog, another crucial aspect to interdisciplinary collaboration (Kezar and Lester, 2009, Becher and 
Trowler, 2001). However, the student affairs professionals noted differences in the ways librarians spoke about students or about their services. Nearly consistently, the librarians employed impersonal or clinical language to describe their relationships with students, such as "patron," "user," and "instruction." Some student affairs professionals found the language off-putting and ascribed a lack of commitment to students to librarians partly because of the impersonality of the language they used. While the librarians drew no particular observations about the language student affairs professionals use, I did note the student affairs professionals often spoke very personally about their work with students, perhaps reflecting the closer relationships they developed with the students whose growth they supported and challenged. The lack of a shared language portends librarians and student affairs professionals may not have the utility to engage in mutually satisfying dialog, particularly if student affairs professionals find the impersonal language librarians use to be uncomfortable.

\section{Differing Interactions with Students}

Arcelus (2008), Kezar (2006), and Becher and Trowler (2002) claimed collaborative work based on improving the student experience necessitates a shared understanding of students and of student learning. Librarians and student affairs professionals appear to diverge considerably when it comes to their types of interactions with students. While both librarians and student affairs professionals communicated a commitment to students, they experienced their commitment in fundamentally different ways. Librarians' interactions with students were predominantly of a transactional nature, whether at the reference desk or circulation desk. They had a limited presence in students' co-curricular activities; although they sometimes attended programs in 
residence halls or advised student organizations, those participants expressed profound uncertainty about the roles they were expected to perform with those students. Even in librarians' teaching environments, they did not often have the opportunity to develop relationships with individual students unless students sought them out for more personal research consultations following instruction sessions.

The librarians were more focused on creating environments that supported student learning than perhaps impacting students directly. They wanted to inspire students, as the librarians did by putting up posters of student leaders at University C. They wanted to provide students with the technology and spaces they needed to do well in their courses, as the librarians did at University A by creating music practice rooms in the library and participating in Student Success Week to help students set up their various technology accounts. However, there was not much evidence that librarians changed students' lives, as the student affairs professionals set out to accomplish by challenging the way students conceived their identities, enabling students' leadership skills by putting them in charge of programs and organizations, and negotiating relationships by helping students understand others' perspectives. In the end, I believe student affairs professionals and librarians have very different perspectives on the ways they interact with students. Given these different perspectives, it would prove difficult for librarians and student affairs professionals to collaborate unless they focus the collaboration on student affairs professionals' more direct impact role in student learning or on librarians' more facilitative role in student learning. 


\section{Sometimes Intersecting Worlds}

\section{Teaching Students Transferable Skills}

Despite the widened gap that appears to exist between the worlds of librarians and student affairs professionals, their worlds do appear to sometimes intersect. These are perhaps the best areas in which collaborations between librarians and student affairs professionals are likely to be successful. The most significant intersecting area between the groups is teaching students skills that the curriculum may not be teaching and that students could easily transfer to their professional experiences in the working world. The librarians explained that they view the library as a "laboratory for learning," and they want to offer programs, services, and experiences that enable students' creativity and identity development. As employers of student assistants, they teach students skills relevant to the working world, such as customer service and time management. Similarly, the student affairs professionals were highly interested in helping teach students skills that allow them to enter the job market easily.

Both groups appear to have teaching students transferable skills in common, but librarians appear to have more limited means to teach students those skills, working primarily through the relatively few students they employ. The student affairs professionals may be able to create opportunities to teach a greater number of students, both those they employ and those they reach through the many programming options and student organizations they manage. This suggests that librarians and student affairs professionals might have a converging perspective on the direct, teaching contributions each group thinks they are able to make to student learning and to student success. 


\section{Student Learning}

Although their interactions with students differed significantly, the librarians and student affairs professionals appear to intersect in regards to their understanding of student learning. While the librarians did see their influence on students' critical thinking skills as the most significant way they could contribute to student learning, they did envision ways they could influence students' identity and psychosocial development. Very similar to the student affairs professionals, they focused on creating experiences that stimulated students in different ways. The student affairs professionals were more directly involved in these experiences, such as organizing service learning experiences or overseeing the work of student leaders managing programs or student organizations. The librarians employed more subtle means, such as making 3-D printing technologies available for students to explore their sense of creativity or practice their problem-solving skills. Librarians and student affairs professionals both appeared to teach from afar, deliberately creating experiences or environments that stimulated students' personal growth.

Themes that emerged from the previous chapters suggest the worlds of librarians and student affairs professionals diverge in profound ways. Librarians' roles have evolved from a predominant focus on collection-building to a new focus on information purveyance, although a teaching role is also still significant. However, the librarians' focused discussions revealed uncertainty about their purpose and place within their higher education institutions and acknowledged a distrust of student affairs professionals, recognizing their growth in number and teaching of students while their own numbers decline along with those of the faculty. Structural barriers, including a profound lack of 
familiarity with each other's roles, lack of flexibility in librarians' reward systems that might penalize collaborative work with student affairs professionals, and differing approaches to time and planning accentuate their diverging worlds and diminish the likelihood of librarians and student affairs professionals working together. Additionally, a lack of a shared language and differing perspectives on their interactions with students are significant divergences.

However, librarians and student affairs professionals do bear similarities. Their worlds intersect in regards to the way they approach student learning. Student affairs professionals strive for holistic student development, focusing on students' identity and psychosocial development. While librarians are focused on shaping students' cognitive development, they appear to have a growing interest in advancing students' identity and psychosocial development as well. Both student affairs professionals and librarians are approaching holistic student development largely by teaching from afar, in which they create experiences and environments that stimulate students. In the subsequent major section of this chapter, I revisit the study's research questions and elaborate how the focused discussions shed light on librarians' and student affairs professionals' perceptions of their own roles and each other's roles, and what these perceptions mean for building prospective collaborations that improve student learning and student success.

\section{Descriptions of Student Learning and Success}

My foremost research question asked how librarians and student affairs professionals described student learning and student success. Many of the librarians were not familiar with "student success," and had little more to say when I shared Tinto's (1987) definition as persistence to graduation, as well as an affirming satisfaction with 
their learning and overall experience. Moreover, they never specifically described what student learning looked like or meant to them but instead discussed what they do on behalf of students to facilitate their learning. Nonetheless, their perspectives on student learning may be inferred by their focused discussions.

Their perspectives on student learning are different but complementary: Librarians are chiefly focused on furthering students' cognitive development by teaching information literacy skills and helping students achieve information fluency, whereas student affairs professionals think of student learning more broadly in mutually supportive cognitive, psychosocial, and identity dimensions. Librarians and student affairs professionals do share greater similarities in student success, as each group recognizes they bear responsibility for supporting students by reducing barriers to persistence.

The librarians revealed a strong educator identity in their focused discussions. While they did teach students formally in classroom settings, they rarely described their activities as teaching in the traditional sense. Instead, they conveyed their instructional roles through their word choices, such as "coaching," "facilitating" and "creating experiences" that suggested their teaching opportunities were less formal and often more individualized with students. Their educational settings included one-on-one interactions at the library, often at the reference desk, or via interactive technologies. In these endeavors, their focus was usually, if not always, on furthering students' cognitive development.

The student affairs professionals ascribed a broader definition of student learning. They were focused on holistic student development, of which fostering students' cognitive skills were only a part. They aspired to imbue students with the skills they 
perceived as necessary for success in their post-college lives such as leadership skills and cultural competencies. Many of the student affairs professionals specialized in specific functional areas, such as student conduct or service-learning. They described how they design their services and programs to support holistic student development. They recognized cognitive, psychosocial, and identity development as interconnected and complementary, so they valued faculty and librarians' focus on students' cognitive development. They did, however, differ from the librarians on how they thought about cognitive development. Several of the student affairs professionals said the faculty and librarians teach students content knowledge, yet the librarians spoke about teaching students how to think rather than introducing content, suggesting at least some of the student affairs professionals may misinterpret the way their colleagues in academic affairs approach teaching.

The librarians were not entirely focused on advancing students' cognitive development. They believed heartily in creating experiences that enabled students to explore their own sense of creativity, aesthetics, and identity. They accomplished this largely through passive programming activities that included exhibits, art installations, and bulletin boards. Lucy and Lauren at University $\mathrm{C}$ described creating posters of student leaders and innovators so students might be inspired as they studied together in the library. Alan and Margaret at University B and Jeanette at University A described their planning of makerspaces, in which students learned to solve problems by designing objects with 3-D printing technologies. Lauren at University $\mathrm{C}$ referred to the library as a "laboratory for learning," which certainly conveys the sense that the librarians understood - and valued - that they are capable of influencing positively students' interpersonal and 
identity development. The concept of the library as learning center where students explore new technologies, practice presentations together, create media, solve problems in groups, and seek innovation through creativity is a rather new and emerging role for libraries and librarians (Lankes, 2011). This concept bears some similarity to Lozano's (2010) conclusions regarding the types of activities students perform together at cultural centers - often a domain of student affairs professionals - in order to stimulate their identity development in a culturally responsive and supportive space.

Interestingly, both the librarians and the student affairs professionals taught from "afar" by creating environments and experiences that deliberately stimulated students' personal growth (Moore and Marsh, 2007, p. 7). Yet both groups seemed to have a much stronger educator identity than Moore and Marsh (2007) credited the student affairs professionals and Schulte and Sherwill-Navarro (2009) credited the librarians. Both groups considered their one-on-one interactions with students to be forms of teaching. The student affairs professionals taught primarily through their concept of "challenge and support." However, this teaching method predicated a reasonably personal relationship with students or the participants believed the method risked failure when students were not close to the participants and thus not receptive to the participants' probing questions and direct feedback. Additionally, the student affairs professionals questioned the utility of this concept as they were able to make an impact on only a relatively small number of students.

On the other hand, the librarians had an arguably greater repertoire for teaching students. Like the student affairs professionals, they perceived that they bore at least some responsibility for preparing students for their post-college years by teaching 
students skills necessary for the working world. They taught students customer service skills, time management skills, and organizational skills. The librarians' opportunity for teaching these skills were primarily through their personal relationships with the student employees they managed. However, the librarians also taught students informationseeking and information literacy skills through their transactional relationships at the reference desk and in their formal instruction sessions as part of students' curricular experiences.

I conclude that librarians and student affairs professionals' descriptions of student learning and student success are converging. Student affairs professionals perceive students' cognitive development, psychosocial development, and identity development as intertwined and mutually supportive. While the student affairs professionals are concerned with shaping students' interpersonal skills and sense of identity, they recognize and value faculty and librarians' traditional emphasis on teaching students critical thinking skills. While librarians remain more focused on shaping students' cognitive development than are student affairs professionals, they are re-imagining the library as a vehicle for shaping students' interpersonal and identities as well.

This new emphasis on the library as a student hub potentially offers the best space for librarians and student affairs professionals to discover opportunities to shape student learning together. The librarians perceive the library as the a central location for enhancing student learning by designing spaces where students study together in groups, practice presentations, and work collaboratively to solve problems. The student affairs professionals have largely not yet connected with the library as a hub for student 
activities but several of the participants noted the libraries are evolving to meet student needs that they did not typically associate with the library historically.

O'Connor (2012) found that a lack of a shared understanding of student learning and success is one of the predominant factors that inhibit student affairs professionals and faculty from working together collaboratively, but my finding suggests that student affairs professionals and librarians are more likely to have common ground for collaborating. The greatest challenge is possibly that librarians are not yet conversant with student learning and student success as the other group defines it. To bridge the gap, Swartz, Carlisle, and Uyeki (2006) recommended that student affairs professionals "read the literature [librarians] are reading" (p. 118). While this advice is still commendable, the reverse should also be recommended. If librarians read the literature student affairs professionals are reading, they will become familiar with the grounded research that student affairs professionals use to design their services and programs focused on educating the whole student.

\section{Perceptions of Librarians' and Student Affairs Professionals' Roles}

My second research question explored how librarians and student affairs professionals perceive their own roles and each other's roles in student learning and success. The librarians perceived themselves to juggle several key roles, including information purveyor, teacher, and community developer. While the librarians carried out their teacher and community developer roles through their teaching activities and reshaping the library as student hubs, their primary role appeared to the information purveyor, in which they attempted to increase faculty and students' awareness of the library's information resources. They perceived this role to be their greatest contribution 
to faculty and students' research endeavors. Many of the librarians were assigned to certain disciplines, and they focused their awareness-building activities on the faculty and students associated with those disciplines. However, several of the participants were beginning to step outside of this traditional framework for information purveyance and were evangelizing information resources to student communities that shared interests, such as student organizations and living-learning communities in undergraduate residence halls. These participants tailored their messages differently to support interdisciplinary work.

The student affairs professionals' roles varied based on the overriding concerns of their institutions. While their emphasis on educating the whole student remained at the forefront of their work, they were attuned to the predominant issues the students at their institutions faced. These predominant issues included preparing students for the job market, reducing financial barriers to graduation, and helping students navigate very large campus environments. The student affairs professionals developed services, programs, and other experiences in order to reduce students' barriers to graduation and increase success.

Librarians' and student affairs professionals' perceptions of each other roles in the educational process is arguably the most significant barrier to collaboration. Although the student affairs professionals demonstrated greater familiarity with the role of librarians than vice versa, a lack of familiarity with each other's work was prevalent among the participants. Several organizational factors appear to contribute to the lack of familiarity, including librarians' lack of time and their perceived widening gap between academic affairs and student affairs divisions. Additionally, the focused discussions 
revealed that both groups held somewhat negative perceptions of each other based at least in part on dissatisfying past interactions.

Many of the librarians had little impression of student affairs professionals at all; some remarked that they were uncertain which functions even constituted the student affairs division at their respective institutions. Despite this underdeveloped familiarity, the librarians perceived the student affairs professionals as playing an essential role in the provision of student services and student maintenance. In the words of Jodie at University A, the student affairs professionals served "almost like a support system" for the students and providing "everything [students] need in order to succeed" with their academic work. The librarians associated functions such as housing, student unions, financial aid, health services, counseling, and recreation with student affairs but most participants had limited contact with these areas. If the librarians perceived the student affairs professionals to have roles beyond the provision of student services, they did not speak much of it. The profound lack of familiarity mirrors Peltier's (2014) finding that faculty's understanding of student affairs professionals' roles is limited to managing student issues outside of the classroom. This indicates that student affairs professionals must communicate their educational focus on student development differently - if they are communicating the message at all - to their colleagues in other divisions of higher education.

When the librarians did have reasons to interact with student affairs professionals, they were not satisfied with the quality of the interactions. Some of the librarians encountered a lack of helpfulness participants termed "the shuffle," in which students and the librarians who attempted to help the students - were passed between different 
student affairs professionals or between different student affairs offices without receiving the information or the help the student had been seeking. Consequently, they perceived student affairs professionals as disorganized or as poor communicators. They also perceived students affairs divisions as opaque, lamenting their difficulty identifying the right persons to contact in student affairs; the paucity of information shared by student affairs professionals except by occasional brochures or guest speakers; and student affairs professionals' non-responsiveness to librarians' inquiries.

Some of the participants were skeptical of student affairs professionals' motivations and suspicious of their seemingly increasing ranks compared to the dwindling number of faculty and librarians. Lucy and Molly at University D did perceive student affairs professionals as educators but did not find student affairs professionals open to their overtures of collaborating on outreach to students. They speculated student affairs professionals resisted collaboration out of fear they would lose their autonomy and authority as educators. Howard and Deanna at University D believed student affairs professionals were outpacing faculty and librarians in terms of new hires, structurally displacing academic affairs' roles in teaching. Their thoughts were evident in two exchanges:

You call it collaboration. I call it cannibalizing the library. Whether we want [collaboration] or not. It's not shared. It's been taken from us. And the computer lab here - it's not the library's [now.] If you want to use it, you have to jump through hoops. (Howard)

The computer lab is on the third floor. It's not good either. (Deanna) It's just they [student affairs professionals]... (Howard) 
[The computer lab] is still going to be there for a while. (Sabrina)

Good. (Deanna)

For a while. But, um, I mean eventually, I think it will... sort of... be something else. (Sabrina)

Phaw! See? Just wait, come back in six weeks, and there's going to be a student services office in it. (Howard)

At a different point in the focused discussion, Howard grimly offered the following words, and none of his peers in the focus group replied, perhaps indicating their acceptance of his perspective:

I'm on the academic senate, representing the library. I'm very concerned - we're very concerned - about the number of vice presidents and other administrators the university is hiring. All student affairs, mostly. Diversity, first-year experience, consultants for retention, now second-year experience since the consultants told us we need that. Some vice president or some other administrator says we need a new person in charge of something, and we get it. It's like they're selfpropagating over there in student affairs. But do we get new faculty, new librarians? No, almost never. And when we do, they're hired on limited term contracts. I've never heard of a student affairs person on a limited term contract. In Arcelus' (2008) study, faculty perceived student affairs professionals as diminishing faculty’s “academic primacy” (p. 167.) Certainly, the suspiciousness evinced by Lucy and Molly at University C and by Howard and Deanna at University D suggest librarians might harbor similar concerns. The importance of these negative experiences as potential barriers to collaboration should not be underestimated. Rodem 
(2011) identified trust, comfort, and effective communication as essential factors in successful collaborations between faculty and student affairs professionals. If librarians perceive student affairs professionals as ineffective communicators and are mistrustful, they are unlikely to be open to collaboration without some positive experiences to change their perceptions.

Although relatively few of the participants had interacted with librarians since their own student days, the student affairs professionals seemed more familiar with the work of librarians. Many participants recognized librarians as playing a critical educational role by teaching students critical thinking skills through information literacy. They indicated students' cognitive, psychosocial, and identity development were mutually supportive. Because of this, these participants suggested cognitive development was essential for the holistic student development that student affairs professionals espouse as a fundamental purpose of their work. Consequently, these participants perceived librarians as partners in higher education, and they gladly referred students to librarians when they encountered students with academic difficulties.

In contrast, the student affairs professionals did not uniformly share this perspective. Others believed librarians were predominantly administrators, chiefly concerned with the mechanics of operating libraries. They also emphasized the difficulty they believed students had navigating the library and felt that librarians were too out of touch with students' needs to effectively design services or learning environments. The student affairs professionals' concerns mirror those of the faculty in Nilsen's (2012) study that librarians are too concerned with running a library to be effective educators. Nilsen's (2012) conclusion was that faculty and librarians may be simply too different to 
craft lasting, effective collaborations. However, the student affairs professionals seem like they should bear greater similarity with librarians since student affairs are similarly charged with managing services and offices just as librarians do.

\section{How Do Librarians and Student Affairs Professionals See Their Work Intersecting?}

My third research question asked how the librarians and student affairs professionals saw their work intersecting, if at all. I am skeptical the participants in my study truly saw the work of librarians and student affairs professionals as potentially intersecting. They seemed more aware of barriers and perceptions that prevented them from exploring working together in a serious way. However, many of the participants implied librarians and student affairs professionals have similar goals in enhancing student learning outside of the classroom. Although the emphases of their work might be different, the librarians and student affairs professionals are concerned with holistic student development. Additionally, both groups teach students valuable skills that prepare students for their professionals lives through their management of student employees. Finally, they also act as information resources for students but may have varying levels of information-seeking proficiency and access to reliable information.

While the librarians in my study did not all together recognize the student affairs professionals' role, they did express a desire to positively effect students' holistic development. Because of their emphasis on information literacy, the librarians were certainly concerned with students' cognitive development; many participants described working with faculty to bring students to the library for instruction sessions, in which they taught students information-seeking and analysis skills specific to the courses' intended learning outcomes. Yet many participants acknowledged they could not 
demonstrate whether they effected meaningful change in students' critical thinking skills and thus doubted whether their focus on students' cognitive development was time well spent. At University A, the librarians discussed this skepticism intensely, summarized best by John:

In effect, that, that's been kind of one of the big bugbears of instruction...is determining to what degree we are able to support those, those efforts. And are we 'pissing in the wind?' Uh, or to what degree are we, we really being, being successful. And we don't know.

Despite their skepticism of their efficacy teaching critical thinking skills, they implied they were increasingly concerned with educating the whole student. Lucy at University $\mathrm{C}$ described her efforts at helping students decompress while they were studying at the library and using theories of wellness to design library spaces that enable students to relax. Lauren wanted to inspire students studying in the libraries at University $\mathrm{C}$ and identified student leaders and innovators whose posters might serve as role models to students. Two librarians at University D advised student organizations or were involved in student conduct. Robert, a student affairs professional at University C, described a librarian mingling regularly with students at a cultural house for minority students and showing interest in the cultural issues those students faced at the university. Most of the participants indicated they saw the library as increasingly a student hub that provided students with not only information sources but spaces, technologies, student services, and aesthetic experiences that increased students' interpersonal and other skills. 
While student affairs professionals appear to have more significant interactions with a greater number of students than might the librarians, the student affairs professionals and the librarians are both preparing students for the professional world. Lorraine at University C referred to this as "adulting" students. Kimberly at University B said this was a focus of the student affairs professionals' work: "I think we spend a lot of time helping students take what they are learning in the classrooms and apply them in the real world." As a manager of student employees, Greta at University C was explicit in that she taught students crucial skills such as customer service, time management, and meeting the expectations of supervisors. Lorraine and Michelle at University $\mathrm{C}$ described teaching students perspective-taking and empathy by helping students put themselves in other people's shoes and seeing problems through the lens of other people's experiences.

Librarians, too, taught these skills to students. The participants acknowledged they have a limited presence in students' co-curricular activities, unlike the student affairs professionals, but they do manage student employees. In fact, nearly all the librarians referenced student employees, whether they supervised students themselves or participated in student employees' training or worked alongside them at the circulation or reference desks. They found managing student employees to be highly rewarding and had influenced the career decisions of more than a few such students. Paul at University B said "I think I teach students maturity. I really hold them to a high standard of customer service - answer the phone by the third ring, make direct eye contact, greet people as they enter." Sabrina at University D reported that she managed the greatest number of students at her library, and teaching these students job skills was one of the most important aspects of her work. She said: 
I ask them to think about how they are treated in customer service situations what do the employees do to make you feel welcome and like you got the best service you could. I ask them to think about why making direct eye contact is related to customer service.

Paul and Sabrina were in agreement that they considered themselves to be teaching skills to students that they could directly translate to the working world, and that these were skills they might not be taught in a classroom setting. Jessica at University D had a different perspective - that she was providing students with job experiences that helped them gain a competitive edge over their peers. In response to Sabrina, she said:

Of course customer service is an important skill, but I'm also giving them experiences that they could put on a resume. I have [my student employees] advise faculty and graduate students on digital publishing strategies. More than a skill in customer service, work in digital publishing is something employers will notice on a resume.

The emphasis on helping students find jobs certainly rang true for the student affairs professionals at University B, who prided themselves on their very high job placement rate for students after graduation, and at University A, where the student affairs professionals feared students couldn't find jobs with their majors despite the high cost of tuition and living expenses. Even at University C, Miguel and Robert noted that putting students in charge of developing programs, guest speakers, and dances helped imbue students with skills directly translatable to the job market. The librarians' and student affairs professionals' mutual interest in teaching students skills they do not necessarily learn in their coursework and preparing students for entering the professional 
world does not appear to be an intersection explored in the literature. This may represent an area where librarians and student affairs professionals could come together to share ideas and discuss how they might work together to adequately prepare students for their transition from college to their post-college years.

Lastly, the work of librarians and student affairs professionals appears to intersect as providers of information to students. Alison at made a poignant remark that I wish I had probed more deeply with the focus group of librarians at University C. In her story about transitioning from a student affairs professional working in career services to a new role as a librarian, she remarked her surprise at learning that many academic affairs departments also perform some kind of academic and career advising to students. She observed, "...everyone is a running a student affairs function.”

She said that student affairs professionals forget they could have partners to enrich their work. She implied that student affairs professionals - like librarians - steer students to information and help students make decisions based on that information. She recounted how career counselors refer students to books on interviewing, job search strategies, and websites for investigating potential employers. She felt career counselors and librarians could work together to ensure students have access to the best information possible, feeling that librarians could teach career counselors better information seeking and fluency skills and ensuring that libraries' collections on career guides match the trends career counselors know. Her suggestion echoes ideas Forrest (2005) and Hollister (2005) proposed a decade ago. In my literature review, I found the substance Forrest and Hollister's arguments somewhat condescending to student affairs professionals but perhaps these are worth revisiting if the framework is not librarians teaching student 
affairs professionals but working together to ensure the information librarians and student affairs professionals provide to students is seamlessly curated.

There also seems to be opportunity for student affairs professionals to work with librarians to ensure the content librarians acquire for their collections is appropriate for students; Lucy at University C said that she attempts to use theories of student development to understand whether the complexity of information resources matched students' abilities. The librarians at University A and C were similarly emphatic that they wanted to design student-centered learning environments and understood libraries played a role in helping student integrate their academic and social experiences. Yet the librarians acknowledged their contact with students was limited, perhaps justifying the student affairs professionals' concerns that librarians were too disconnected from students' lives to truly comprehend their needs. This is perhaps not a new thought: Gatten (2005) argued that student affairs professionals, as experts in student development, have much to teach librarians about students that could ultimately improve the practice of librarianship. Gatten's work appears to have made little impression on library literature but perhaps the participants' focused discussions illustrate there is space for these discussions to take place between librarians and student affairs professionals.

However, there are opportunities for collaboration yet to be explored. Alison at University $\mathrm{C}$ noted that many academic departments - including the library - do perform some student affairs functions, such as advising. Jack at University B described briefly his experience as an academic advisor in student affairs; he practiced a strategy called "intrusive advising" and thought it a useful strategy librarians should consider. Both librarians and academic advisors note concerns that students - particularly first-year, 
first-generation, minority, and low SES students - do not reach out for advising or research assistance early enough for help to be effective (Emmons \& Wilkinson, 2011; Gordon, Habley, \& Grites, 2008). Advisors are assigned to certain students and then identify the points of the semester when the students are likely to struggle academically and socially, based on information from residential life staff and from the course syllabi supplied by the advisees' faculty (Gordon, et al., 2008). The advisors advise "intrusively" by contacting students of their own initiative during those pressure points rather than waiting for advisees to ask for help.

Librarians often have assigned students, too. However, Louise at University C noted that most reference librarians are assigned students only when students declare a certain major. Moreover, she suggested that most reference librarians do not initiate contact with their students except perhaps at the time of assignment to greet the student and to explain how the student might reach the librarian. This was an area of special concern for the student affairs professionals at University C, who believed the students were already unfamiliar with the work of librarians. Kate at University A noted this, too, as she observed many students graduated from school districts with increasingly fewer librarians to guide them.

If librarians and advisors could partner together for intrusive librarianship and advising, they could proactively ask at different points of the year what the students are working on in their classes or having going on in their lives. Based on the information they receive, they could advise the student accordingly or help the student develop theses statements and locate relevant resources. This strategy would help both librarians and advisors develop a more holistic understanding of their students' academic and social 
progress, but more importantly help students recognize the advisors and librarians' purposes. If advisors and librarians could assist students earlier and more consistently in the academic year, students will likely be better equipped to be successful and have greater academic performance and persistence. Certainly this idea should appeal to student affairs professionals and to librarians' core values of service to students and to equity and social justice; since lower SES, minority, and first-generation students will then navigate their college experiences more easily.

At University A and University C, the librarians indicated an interest in bringing the student affairs professionals into the library to provide career services and advising to students at a central location, while they had also attempted to offer their services - albeit unsuccessfully - in the undergraduate residence halls. Rather than simply holding outreach hours, the librarians could consider taking a step further and embed in student affairs divisions rather than working predominantly within the library. How might the career center's programs and services change if a librarian belonged on the permanent staff? Such a collaboration might prove fruitful in regards to teaching citizenship and instilling social responsibility among students. A career services librarian could belong to the career center staff and research employers with good records of environmental and corporate responsibility. Additionally, a career services librarian could instruct students on issues to consider when applying for positions, such as identifying whether specific employers have family-friendly policies or support social issues that align with students' values. Such a partnership could help students bridge the transition between college and employment and aid students with finding satisfying positions. 
A final example in which librarians and student affairs professionals could collaborate is embedding librarians into bridge or TRIO programs. These programs orient students to higher education, provide a peer mentoring program throughout the college years, and create the cultural capital students need to succeed to persist to graduation. Given Solis and Dabbour's (2006) and Whitmire's (2004) studies that students from under-represented minority, lower socio-economic status, or firstgeneration student backgrounds are less likely to use the library, bridge and TRIO programs seem fertile opportunities for student affairs professionals and librarians to collaborate. Student affairs professionals could integrate librarians into activities and programs so students could become familiar with librarians, the library, and how to use library resources effectively very early in their college experience. If students are enrolled in remedial education, perhaps librarians and student affairs professionals could design assignments together in which students must use library resources. Such a collaboration should appeal to student affairs professionals and librarians who are committed to equity and social justice and wish to support students who lack the cultural capital to navigate the campus environment easily.

\section{How Might Librarians and Student Affairs Professionals Approach Collaboration?}

My fourth research question begged how librarians and student affairs might approach collaboration together. Firstly, librarians and student affairs professionals must simply gain greater familiarity with each other's work and how each contributes to student learning. However, I am skeptical that either group would take meaningful steps toward collaboration without other forces pushing them toward each other. Kezar (2006) identified eight core elements that are necessary to create the conditions that enable 
collaboration between groups: mission, integrating structures, campus networks, rewards, a sense of priority from senior administrators, external pressure, values, and learning. My findings confirmed that at least some of those elements must be present before librarians and student affairs professionals are able to collaborate in ways that lead to meaningful and lasting ventures that effect student learning and success. Of these eight elements, I believe the most crucial and the most foundational are mission and a sense of priority from administrators. I believe these elements are also the most likely to propel librarians and student affairs professionals toward each other in order to gain greater familiarity with each other's work. Campus networks, rewards, and values were also implied or explicitly addressed by the participants in my study.

\section{Clear Mission and Collaboration as Priorities from Administrators}

In the librarians' focused discussions, a theme of mission confusion emerged as a significant impediment of the likelihood of collaboration with student affairs professionals or - perhaps - with any actor outside of the libraries. The librarians at University A, B, and D complained of a lack of coordination of the library, resulting in librarians who performed their duties very autonomously and a lack of confirmation that their energies were well spent. The librarians seemed distinctly aware that the libraries suffered from unclear goals. Even at the libraries where the chief library administrators had clearly expressed support for collaboration with student affairs professionals, the librarians remained uncertain as to the desired intended outcome. For example, Beverly at University A said "Our dean is really big into working with student affairs. She talks about it a lot, but I'm not really sure what that looks like for me." Seemingly, 
interpretation or clarification was not sought or did not produce the clarity they felt they needed. Instead, they took little or no action.

This seems contrary to Whitchurch's (2013) descriptions of librarians as thirdspace professionals. In her study, she interviewed librarians who recognized the ambiguity of their libraries' missions. Her participants found the ambiguity freeing, and they were able to experiment with new services and roles by working with faculty and other actors in higher education differently. However, the participants in my study seem to fit Lankes' (2011) claim that "There is great advantage to working across boundaries...but without a strong sense of purpose...librarians can have great difficulty working in [interdisciplinary] teams" (p. 196). This underscores the importance of strong leadership to articulate the need for such collaborations and the benefit of working with experts that are organizationally outside the library. Lankes cautioned further that without leadership providing clear purpose "[Librarians have] a form of professional insecurity that often sees other skill sets...as competition. ...It leads to a sort of schizophrenia whereby members of the profession are looking for innovation and, when they find it, see the innovators as...a threat" (p. 196). Whitchurch's (2013) participants were primarily at institutions of higher education in the UK, and it is possible librarians at UK institutions work under different realities than might librarians at US institutions, particularly in terms of reward systems; I will address reward systems presently but those reported by the librarians in my study appear to inhibit the librarians' willingness to try new things. 
Seemingly, the student affairs professionals seemed to suffer much less from mission confusion. They recognized major student concerns at their respective institutions - retention at University A; career placement at University B; and adjustment to a large campus at University $\mathrm{C}$ - and oriented their work accordingly. However, they did not indicate they collaborated much with colleagues outside of student affairs, except to serve as resources for faculty and librarians when those colleagues encountered troubled students. If their leaders and the mission of the institutions encouraged the student affairs professionals to collaborate with colleagues in academic affairs, they gave no sign of such encouragement. However, the student affairs professionals felt much more comfortable with the ambiguity of their missions, seemingly enabling the autonomy that Whitchurch (2013) noted as a facet of blended professionals working in the third space, but also what the librarians noted and seemed to envy:

Um, the fact that we have a mission and a vision so we're aligning ourselves with that. So for us right now, uh, uh, transformative learning is a big buzz word, which is broad and vague. So a lot of us are challenged to see, to think what this transformative learning means in context. There's not a lot talking that goes between us [student affairs functions] and um, we're all doing our own things, it feels like at times. (Miguel, University C)

That's the beauty, really, to being student affairs. No one is paying a lot of attention to us, meaning the academic side. They're preoccupied on research and their own teaching, and so we're out here to do our own thing. (Louise, University C) 
Librarians and student affairs professionals seem to be converging in their perspectives of student learning and are demonstrating interest in student success. Therefore, it should be incumbent upon the chief library and student affairs administrators to create missions that emphasize holistic student development. The leaders should articulate clearly to librarians and to student affairs professionals that they value collaboration and see it as the best mechanism for carrying out the mission and vision for student learning. The leaders should also be prepared to have multiple discussions to demonstrate the importance and affirm that librarians and student affairs professionals understand what the leaders hope to achieve. This should be especially true for the chief library administrators, as the librarians seemed less willing than the student affairs professionals to create their own interpretations of the expectations for their work.

\section{Campus Networks}

Kezar (2006) suggested campus networks that bring diverse actors together must be present for collaboration to unfold as a meaningful activity. Kezar noted campus committees that cross organizational boundaries, centers, conferences, and other bodies may serve as such campus networks. However, there seemed to be a lack of campus networks that could bring librarians and student affairs together. This lack of space for cross-boundary discussion between librarians and student affairs professionals was evident in the student affairs professionals' claims that librarians were invisible people or were trapped in the library. Many participants noted that they rarely see the librarians at their institutions, except on the occasional committee, unless they had a reason to visit the libraries themselves. For their part, the librarians indicated that they rarely crossed into 
the student affairs professionals' terrains, except when invited for specific purposes such as attending programs in the residence halls or dining with undergraduate students.

It might be incumbent upon the chief library administrators and chief student affairs administrators to initiate the spaces that will allow campus networks to flourish. Applying Whitchurch's (2013) spaces dimension to the focused discussions suggests the library as a student hub may be a safe psychological - and literal - space to begin a campus network. Committees or working groups could be proposed that bring student affairs professionals and librarians together to identify the student services that might serve students best in a centralized location. Another opportunity may be cross-training or a campus service institute similar to centers for teaching, learning, and technologies but specifically between librarians and student affairs professionals on the expertise that each possesses. An example might be working together to address students in crisis: Louise and Greta at University C desired the librarians to demonstrate a greater commitment to students' well-being by learning how to identify and respond to students in crisis, particularly in regards to mental health. The librarians at University D indicated they desired to help such students. Although they were uncertain how or where to refer such students, they felt not making an effort to understand students' distress was akin to abandoning their duty to serve students.

\section{Reward Systems}

Kezar (2006) suggested that reward systems must accommodate and recognize collaborative activities in order for collaborations to be successful. The student affairs professionals' focused discussions suggested they did not perceive reward systems to be a barrier. While it was unclear if their reward systems valued student affairs professionals 
developing collaborations with persons outside of their functional areas, their discourse implied a degree of agency to chart the direction of their work unimpeded by the potential constraints of reward systems. Gee's (2011) intonation tool highlights the saliency of a speaker's messages by focusing on how they emphasize or modify words. The student affairs professionals emphasized certain words in their discussions by changing their tones. For example, Dorothy at University A said, "I've learned to work with faculty and deans," and "I share ideas with them at meetings." Dorothy's intonation contributed to the importance she placed on collaboration in order to enhance student learning. Her consistent emphasis of the word "with" in connection with both her student affairs colleagues but also with faculty and librarians emphasized that she considered collaboration a core value of her work; this emphasis was common among the majority of the student affairs professionals at all the universities.

When the student affairs professionals did reach out to faculty, librarians, and other people outside of student affairs, they stressed their agency by emphasizing their identities. Greta at University C said, "I saw an opportunity to talk with the faculty on this committee about plagiarism, and that led $m e$ to talking with the graduate school about maybe starting a program on plagiarism for international students starting their degrees here.” They also suggested they had agency by having some latitude to write their own evaluations. Alice at University B said "I think the way we evaluate here, it's very informal. It's like 'I know you've been doing good work so just write something that says what you've done so I can submit it.' That was the conversation I had." Her statement resulted in agreements from her colleagues and essentially represented the extent of the importance they placed on performance reviews. At University C, Robert 
said "You sort of do a self-evaluation to, to an extent. It's more a sort of bulleted list of the things that you've accomplished that year. Your supervisor takes that and puts it in a template. So if you have an idea to do something, all you have to do is really just justify it.," to which Louise replied with "I never get any real feedback," and Lorraine with "We're doing good. You really have to screw up around here to drop to a 'no merit' or even a 'standard merit.",

From the participants' focused discussion, the librarians' reward systems do not reward librarians for "stepping outside the box" as Greta at University C said librarians need to do. In fact, the reward systems seemed to reinforce librarians' traditional roles and inhibited the likelihood of collaborating with student affairs professionals. While the librarians at University B didn't comment on reward systems, the librarians at University A and University $\mathrm{C}$ explicitly discussed tenure or methods of annual performance as disfavoring activities that rely on collaboration with units outside the library as this exchange between John, Amy, and Jodie suggest:

For non-tenure track librarians, we write our own contracts, kind of. Like, we submit documents that's like eight or ten things I want to do this year and work with our supervisor to figure out, you know. So you can absolutely write it as "outreach" like I have, but it depends what you have worked out with your supervisor. (John, University A)

Well... it's just basically up to the supervisor how much they value that. I would say it pretty much depends on the supervisor. Some, some supervisors don't value it as much. So. There's that. Why take the risk? Especially if you never hear your supervisor talk about [collaboration] in the first place. (Amy) 
I think, looking at the operating paper, you, it isn't really rewarded. It's something that if someone has a lot of energy, they can, and will do, but doesn't necessarily get them what teaching, publishing, you know, those core activities are going to get them. (John)

So, the person now doing the most outreach in the library is not even a librarian. She's, uhm, a [support staff.] She just took it upon herself. (Jodie) Yes, in a lot of ways, it's a, it's a pursuit of passion. Ah, but we don't have a good, in my opinion, a good and sustainable reward system for anything along those lines. Where frankly or a way to evaluate its success which is one of the real nightmares of, of outreach, that you can do everything right, and timing could, could be such that nothing's going to happen. Or there could be a change of personnel in charge of a program, and they could decide "Oh, I don't like you, and so we're not going to be a part of this." Then how does your supervisor evaluate? Like, is there an A for effort or is there only for success? (John) Clearly, the librarians' reward systems must adapt to imbue collaborations with value and to encourage librarians to undertake such collaborations. The librarians' reward systems serve as a barrier to collaboration with other actors in higher education similar to those Borst (2011) identified, indicating that faculty who move outside the traditional domains of their disciplines may not have their work understood or rewarded by supervisors or by tenure and promotion committees. 


\section{Changed Roles and Identities for Librarians and Student Affairs Professionals}

My final research question asked how might the work and identities of librarians and student affairs professionals change because of collaborations they might pursue together. I believe this question requires additional research to answer fully. The librarians and student affairs professionals in this study had relatively little familiarity with each other, making it difficult to parse how their professional identities might evolve when working in a third-space that combines elements of each other's expertise. Nonetheless, the focused discussions suggest the librarians recognize a need to serve students more holistically, potentially reframing their expertise as student specialists rather than as information specialists. Similarly, the student affairs professionals appeared to desire a greater range of instructional skill sets at their disposal, as they recognized the limitations of their challenge-and-support method of educating students. By working with librarians, student affairs professionals might evolve from an educator identity to encompass a teacher identity.

\section{Librarians as Student Specialists}

If librarians augment their teaching role and skills with theories of student development, their teaching role expands to a more comprehensive educational role. Rather than teaching students how to find information that just serves their curricular needs, librarians will be able to diagnose students' information needs in other dimensions of students' lives. Teaming with academic advisors, they could assist students with locating and understanding financial aid information or assist with selecting majors by recommending sources that help students' explore and understand the skill sets and competencies each major develops. This would complement the librarians' primary role 
as information purveyors but also expand their teaching roles. Essentially, librarians will teach not only information literacy but will apply other theories of student development to their interactions with students. They will foster students' ability to synthesize information with their academic and daily activities. This change suggests librarians' roles will expand from a teaching role to specialists on holistic education.

However, librarians must forge personal relationships with the students they serve in order to perceive the connections between students' social and academic lives and aspirations. This engagement with students likely means that librarians must leave the library and participate more fully in students' lives - they must go where the students are. The librarians noted they have a limited presence in students' co-curricular experiences. This might represent a significant departure for some librarians who are wedded to the library. Yet this engagement would potentially introduce librarians to contact with students that moves beyond the largely transactional interactions they reported as representing the bulk of their contact with students, excepting their management of student employees.

\section{Librarians as Active Programmers}

By collaborating with student affairs professionals on programming, librarians might also change the way they create experiences for students. The student affairs professionals at University C noted librarians and student affairs professionals' concepts of programming are different. Whereas the student affairs professionals design experiences that make students interact with each other in order, the librarians tend to rely on passive programming such as exhibits and displays. While the participants perceived this difference as a barrier to collaboration, this could yet represent an 
opportunity for student affairs professionals to teach librarians to develop active programs that enable students to work or to socialize together with an educational purpose. The empowerment of librarians to design experiences for students that influence their interpersonal or identity development may cause librarians to reinterpret their teaching roles and to articulate learning outcomes that are not applied exclusively to students' information literacy skills.

\section{Student Affairs Professionals as Teachers}

Student affairs professionals' collaboration with librarians appears to be a natural progression of their link to faculty partnerships. Student affairs professionals could shift from enablers of student learning to teachers and adopt a more traditional teacher identity. By collaborating with librarians, student affairs professionals could benefit from librarians' expertise in curriculum design and pedagogical principles that are designed to spur students' cognitive development. Together, they could create formal learning experiences that are designed to apply cognitive lessons to students' social interactions. Through integrating student affairs professionals' deep knowledge of students' out-ofclass experiences and student development theories with librarians' instructional expertise, a partnership could emerge that brings student affairs professionals closer to the academic realm. Moore and Marsh (2007) noted student affairs must reframe their educational role from enablers to teachers and extend themselves from merely creating environments that usher student development to intentional teaching of students individually. By collaborating with librarians, student affairs professionals could learn curriculum design strategies that will enable them to move from teaching "far" to teaching both near and far. 


\section{Conclusion}

My findings suggest librarians and student affairs professionals enjoy similar and converging - perspectives on student learning and student success on which they could found future collaborative work. Student affairs professionals value students' holistic development and recognize that cognitive, interpersonal, and identity

development are mutually intertwined. They are deeply engaged with the issues students face at their higher education institutions, and they orient their work to ensure students face fewer barriers to persistence and are better prepared for their post-college years. Despite the librarians' emphasis on shaping students' cognitive development by the teaching of information literacy, they are also influencing students' interpersonal and identity development by reinterpreting the library as hubs of student activity. Librarians are also interested in preparing students for their post-college years by teaching students skills related to career development and by creating passive programming that shapes students' personal development.

Despite converging perspectives on student learning and student success, librarians and student affairs professionals demonstrate little familiarity with each other. Most of the participants developed their understanding of each other based on their own days as students rather than as professionals. The widening gap between librarians and student affairs professionals maintains a silo-ing effect between the two groups. Some participants' stories suggested strong negative perceptions, indicating the librarians perceive student affairs professionals as disorganized whereas the student affairs professionals perceive the librarians as uncommitted or too removed from students and somewhat lacking in interpersonal skills. These negative perceptions could be reduced 
by two committed leaders communicating a mission and vision for seamless learning and bringing the two groups into greater contact. Campus networks could be founded in which librarians and student affairs professionals work together to teach students skills in, perhaps, a center for teaching, learning, and technologies oriented to post-college preparation. Although student affairs professionals seem to enjoy agency in directing their work, librarians appear to be less empowered and less likely to initiate collaborations due to the demands placed on their time and reward systems that do not value collaborative work. 


\section{CHAPTER VII}

\section{REVISITING THE CONCEPT OF THIRD-SPACE PROFESSIONALS}

In this chapter, I return to Whitchurch's (2010) concept of third-space

professionals and offer a critique of the conceptual framework. First, I summarize the concept of third-space professionals and the features of blended professionals, the typology to which Whitchurch (2013) claims librarians and student affairs professionals belong. I review the librarians and student affairs professionals' focused discussions in the context of the four dimensions of third-space professional identity and discuss where these dimensions led me into new insight about the participants' professional identities while working in the third-space.

The previous three chapters provided insight into the ways librarians and student affairs professionals demonstrate profound divergences from each other in the way they work, in their perceptions of the other group, and the way they interact with students. While they do suggest some intersecting areas in the ways they approach teaching students and navigate their teaching roles, the findings lead me to question whether librarians and student affairs professionals are, in fact, blended professionals who operate autonomously in the third-space of higher education institutions. I propose that librarians, at least, do not fit Whitchurch's (2013) claim that they are, and I express skepticism that student affairs professionals exhibit the characteristics Whitchurch suggests. 
I employed Whitchurch's (2010) concept of third-space professionals as the study's framework because the study ultimately explored the identities and boundaries of two groups of people whose work blends higher education's professional and academic domains. In her interviews with librarians and student services staff at UK institutions, Whitchurch (2013) concluded that both groups exhibited the characteristics of blended professionals, the typology of professional identities prevalent in higher education that most exemplifies the third space, or the interweaving the professional and academic domains into a new academic identity. Whitchurch (2013) claimed these groups represented blended professionals regardless of institution or institutional type because the factors that foster the blended professional identity are transmitted to individuals through disciplinary and institutional networks that shape the individuals' experiences and thinking. These premises led me to believe that Whitchurch's (2010) concept of third-space professionals, together with Gee's (2011) tools of discourse analysis, would illuminate the commonalities between librarians and student affairs professionals that could ultimately serve as the foundations for prospective collaborations in student learning and success.

Whitchurch (2013) articulated four dimensions of third-space professional identity: spaces, knowledges, relationships, and legitimacies. I examined the participants' focused discussions against these broad themes in order to understand how librarians and student affairs professionals - as blended professionals - make sense of their identity and work lives. What are the spaces they claim as their own in higher education, and where might those spaces intersect? How do they integrate their professional and academic knowledge into theory-to-practice? What are the networks 
they create to support their work? How do they achieve credibility with actors in other fields and disciplines? Gee's (2011) discourse analysis tools helped me interpret how the participants negotiated their professional identities within the context of Whitchurch's four dimensions.

\section{Spaces}

In the spaces dimension of Whitchurch's (2010) concept of third-space professionals, blended professionals recognize multiple realities of their institution and the ambiguities of their working conditions. Whitchurch (2013) claimed blended professionals tend to find the lack of boundaries stimulating and a cauldron for creativity but the ambiguity brought blended professionals a "dark side, involving the interanimation of different voices of which struggle, conflict, and difference are an essential part” (p. 85.) Consequently, blended professionals redefined physical, virtual, and psychological spaces as they sought to exercise agency and autonomy (Whitchurch, 2013). At first, I interpreted Whitchurch's (2013) spaces dimension quite literally as physical spaces. While virtual space had not entered any of the focused discussions, libraries, residence halls, and - broadly - campus environments emerged as the physical spaces where the participants perceived their work unfolding.

When librarians and student affairs professionals entered each other's spaces, there were signs they were redefining these spaces. At University C, the student affairs professionals recounted librarians spending time - albeit with some marked hesitation in the residence halls and the cultural houses in order to reach students in different ways. The librarians at University A were regularly invited to programs and events held by the student affairs professionals in the residence halls, but the librarians had difficulty 
making sense of how they fit into the goals of the programs. At University C, the librarians had invited the student affairs professionals into the library to hold programs or conduct outreach activities whereas the librarians at University B perceived the library itself to be contested territory as the student affairs division slowly encroached upon their work by converting spaces in the library into student services offices.

For the librarians, libraries were distinctly evolving into representations of working in the third-space. Libraries represented the historically safe spaces where the librarians practiced their craft and interacted with students the most. They perceived, too, that libraries were or should be the intellectual hearts of their campuses. However, the librarians recognized that libraries were becoming more risky spaces now caught in the identity tension between librarians' traditional role as custodians of collections and a newly emerging role as facilitators of student learning. Many of the participants believed the libraries are or should be hubs of student activity, where students not only studied and engaged in research together but also socialized, experimented with new technologies, and appreciated cultural or aesthetic experiences.

Next, I considered spaces in the abstract, as intangible spaces that nonetheless affect people's thinking. Whitchurch (2013) theorized that the spaces dimension is also psychological. Arguably more interesting than the participants' perceptions of their evolving physical spaces is the participants' awareness of the abstract space between the student affairs professionals and the librarians. Arcelus (2008) referred to this concept as the "widening gap" (p. 22), in which student affairs and academic affairs inhabit seemingly different realities of the same institution and rarely interact. The librarians at University $\mathrm{C}$ and $\mathrm{D}$ were cognizant of this widening gap, suggesting student affairs 
professionals "ran a different university," as Lucy at University C said, from the faculty and the librarians. In her view, the student affairs professionals resisted librarians' efforts to reach out in order to establish their own legitimacy as educators. Of the student affairs professionals, only those at University $\mathrm{C}$ indicated an awareness of a widening gap at their institution:

I think we're teaching more than we used to, like actual teaching. A lot of us teach a course on social justice and diversity in the College of Education. (Michelle)

I'm teaching a class in human resources this semester. (Miguel)

You are? I didn't know that. That's so wonderful. (Lorraine)

So, it's weird. Because the more we teach, the more distant I feel like we are from the faculty. The education faculty asked us to teach this social justice course. A faculty member had a grant to develop the course, and it was supposed to be co-taught with student affairs. We jumped at it. But, then, the faculty slowly disappeared from the course. Like, the more student affairs wanted to be involved and wanted to teach it, the faculty stepped back from it. I think the course has been taught for quite a few years now, and it's exclusively taught by student affairs now. The faculty aren't even involved. (Michelle) Yep, it's like that leadership certificate we offer. It's entirely run by student affairs now. So is the "One Book, One Campus" program. That was started by the English faculty, I think. Maybe. I think they get tired of it, and they look for a new home for it, and it's us. (Lorraine) 
They're not interested in what we do. At least, not here. I think maybe it's different at a liberal arts college. They're busy doing research here, maybe teaching grad students. They don't respond, really, when we approach them with ideas. We're not part of the governance body here. It's called the 'faculty' senate. We have no representation. (Miguel)

I think the faculty are impenetrable. I don't even know how to get information, or who the faculty even really are. I've been here for years, and the most I know about any of the academic departments comes from the academic advisors or from the stories our students share. We just don't move in the same circles. (Michelle) The participants' perspectives would seem to indicate the widening gap between student affairs and academic affairs at several of the institutions is resulting in O'Connor's (2012) silo-ing effect. O'Connor found the widening gap between student affairs and academic affairs played a powerfully inhibitive role in regards to collaboration by disconnecting communication between the two groups. Additionally, the participants' perspectives support Arcelus' (2008) findings that the gap widens when student affairs professionals perceive faculty as little concerned with students and when faculty are suspicious of student affairs professionals' assumption of teaching roles.

\section{Knowledges}

Whitchurch (2013) described the knowledges dimension as the integration of research and theory with practice. In a sense, third-space professionals are knowledge brokers by applying new discoveries to the practice of their work in the higher education setting. They analyze and interpret the results of their applications and generate new professional knowledge by sharing the lessons learned with colleagues through their 
professional and institutional networks (Whitchurch, 2013). Most importantly, Whitchurch argued that blended professionals forge new networks - or collaborations with other actors in higher education based on the application of their knowledge and tend to experience loosening ties to their professional or disciplinary bodies. Whitchurch claimed the new networks lead to convergence of disciplinary knowledges and results in the emergence of coalesced services and programs where students might receive different types of assistance, a concept similar to the integrated networks that Kezar (2006) said are a necessary element to collaboration between disciplines.

The knowledges dimension yielded fewer insights into the study than did the spaces dimension. None of the participants indicated that they reviewed professional or scholarly literature regularly as a way to apply discoveries to their professional work, although the student affairs professionals shared stories with colleagues at other institutions about strategies that worked or did not work. The librarians and the student affairs professionals appeared to have relatively little access to information they felt would be useful to making decisions, although it was not clear on what information they drew upon to make their decisions. Both groups relied on counting as a means of defining whether a service, program, or activity was successful or not. Howard, Deanna, and Sabrina's exchange at University D exemplify this reliance among the librarians:

I'm told the library is busier than ever... our gate count is through the roof, much better than last year. (Howard)

That's great to hear. We must be doing something right. (Deanna)

Well... what do those numbers tell us? Just that people entered the library. They could have come in for any reason at all - just passing through maybe. They 
don't tell us what people did while they were here, or whether they got the help they needed. (Sabrina)

I understand. Our reference transaction statistics don't tell us that either. Did the information we provided help someone get a better grade? Or did it help them think about something differently? Unless people come back to us later and say "oh thank you, without your help, I would have gotten a worse grade" - and very sometimes we do get those stories - [interrupted]. (Deanna) Very, very sometimes. (Howard)

- then we don't really know if we were of any good at all. (Deanna) At University B, Kimberly and Jack shared a similar concern regarding the quality of Kimberly's service-learning programs:

How do you know a volunteer opportunity was successful, Kimberly? (Jack) Well...I count. The number of students who participate. Most of them go away again, like it's a one-off type of activity for them. (Kimberly) Do you follow up? We try to do that with the students who come for career advising. Thankfully, they have to give us their names and stuff when they request an appointment, so we know how to get in touch with them and ask them to comment on our service. (Jack)

Does that work for you? (Kimberly)

Sometimes. Usually we hear if someone got a great internship or a job, or had a response right away. They might get back in touch with us and tell us how helpful our advice was to them. But mostly we don't hear back. We don't know if that's because our advice didn't pan out for them or what. (Jack) 
Yeah. I can sometimes tell whether students engage with the service learning as meaningful to them because they keep going back to the sites, and the coordinators tell me that. But the point is to make students more civically minded, more engaged with citizenship. Have I accomplished that because they're continuing to participate? Or are they really thinking about the problems of society and how they might be able to address those problems on a deeper and broader way? I have no idea, really. So I just do what I do because the numbers seem to suggest the likelihood of success somewhere. But I really couldn't produce any evidence whatsoever. (Kimberly)

They did, however, communicate with colleagues at other institutions who shared the outcomes of their experiences and their perceptions. None of the student affairs professionals reported any experiences working with others outside of student affairs, but they knew of student affairs professionals who collaborated with librarians on programs at other institutions. However, the stories they shared from colleagues regarding these collaborations were largely negative and emphasized their colleagues' failures to produce the outcomes they desired. Consequently, the student affairs professionals did not see much point in reproducing their colleagues' initiatives at their own institutions.

However, the focused discussions yielded some implicit evidence of the coalesced programs and services that Whitchurch (2013) indicated spring from the knowledges domain. The librarians at University A and University D indicated they shared spaces in the libraries with student services functions such as tutoring, career advising, and services for students with disabilities because they had heard from their chief library administrators that coalesced services were increasingly of interest to students. None of 
the participants had direct experience with these areas and could only comment that they believed students found such co-location convenient.

\section{Relationships}

In the relationships domain, Whitchurch (2013) explained that blended professionals depend on relationship-building in order to achieve their goals, and thus they forge highly effective working relationships with an expanding network of actors. Whitchurch claimed blended professionals' relationship-building activities - often focused on faculty - cause the blended professionals to renegotiate their own identity by constantly interpreting situations and navigating interpersonal dynamics and circumstances differently. The participants' stories bore out some aspects of Whitchurch's claims. Deanna at University D said:

Librarians collaborate all the time. It's just what we do. We have to collaborate with faculty in order to be effective at our jobs... otherwise, how will students know about us or care what we can provide them? So we have to understand faculty in order to be a resource for the students. We have to know what's important to the faculty, what they teach, what they expect the students to be learning.

The following exchange between John, Amy, and Crystal at University A highlights how the librarians renegotiate their sense of academic identity based on their cultivation of relationships with faculty:

Students don't care about good information unless faculty make them care. So our jobs are really dependent on having good relationships with the faculty. So that's where we spend most of our time, or should. Talking with faculty, trying to 
be involved in research projects with faculty, making suggestions on resources when we review syllabi... (John)

Wow, it's tough. I've only recently started making in-roads with the business faculty after three years. They said "why should we bother with you because you're probably going to be gone in three years" but I'm here. (Amy) I have to be a researcher because of the faculty. You know we're supposed to be research experts... but we just know how to find published research. We don't necessarily know research methods, or how to write a literature review, or... (Crystal)

Or especially how to analyze data. And that's all the rage right now, is data services for faculty. We're supposed to be helping faculty with data management plans because grants are requiring them to do that. What the hey? I don't know anything about that, so now I've got to learn this in order to be more helpful to the faculty. (John) ...well, back to what I was saying, I didn't know any of those things... so I had to actually teach myself those skills. Because those are skills. And when I could talk to faculty using that language... the language of research... and thought of myself that way too, then suddenly a few of them seemed to look and talk with me differently. Now they come to me. But, I didn't know those things before and frankly those things are not explicitly required of our jobs. But I think they're necessary now in order to have those relationships. (Crystal) 
When the librarians had attempted to establish relationships with student affairs professionals, they had felt rebuffed as the librarians at University C had reported, or they were uncertain as to how they could or should collaborate. Jeanette at University A recounted meeting with the student affairs professionals at the career center to discuss how they might collaborate; she provided them with resources regarding business information but she had no clear idea how they might work together or on what. Jeanette's story suggests that the librarians may not have taken the time to fully comprehend what the work of their potential collaborators entailed. Crystal's story about learning research skills to foster her relationship with the business faculty changed how she perceived herself - she was a researcher as well as a librarian, blurring the lines between librarians and faculty - could serve as a lesson for the librarians in building more effective relationships with the student affairs professionals. They must learn more about the work that is important to student affairs professionals and demonstrate a commitment to that work.

The student affairs professionals did not speak much of their relationships with faculty or the need to develop such relationships. When they spoke of their relationships with librarians, they critiqued what they perceived as the librarians' lack of commitment and persistence in their efforts to provide outreach to students. The exchanges between Greta and Michelle at University C regarding the librarians who abandoned outreach hours at the undergraduate residence halls when students failed to interact with the librarians underscored the difficulty with relationship-building. The student affairs professionals acknowledged the emphasis on the "here and now" nature of their work contrasted with the librarians' need for long-term planning. Given the librarians' 
frustration with the "jenga pile," or the increasing demands on their time, it seems necessary that the student affairs professionals may need to partly adjust their style of working in order to accommodate collaborations with librarians. They may need to recognize a balance between their tolerance for disruption - resulting in their focus on the "here and now" - and moments of planfulness in order to achieve effective working relationships with their colleagues who require that style of working.

\section{Legitimacies}

Whitchurch (2013) claimed blended professionals' use of language influenced the legitimacies domain of third-space identity. Blended professionals interpret and translate between constituencies, often shifting their language from the discourse of their own discipline to another's in order to achieve credibility in the eyes of others (Whitchurch, 2013). Blended professionals are then able to challenge the status quo by demonstrating that their expertise benefit the higher education enterprise. Gee's (2011) discourse analysis tools revealed a number of insights into how the participants crafted their identities and navigated their relationships with others in higher education to demonstrate the legitimacy of their expertise.

Gee (2011) suggests intertextuality exists when people's phrases or text refers to other literary or cultural sources; their use of quotes or allusions have certain functions, such as establishing credibility or reinforcing worldviews. Both the librarians and the student affairs professionals threaded references to other sources throughout their discussions. At University A and University C, the librarians referenced Oakleaf's (2010) report The Value of Academic Libraries. Because of the report's call to librarians to demonstrate their impact on student learning, the librarians saw the report as a guiding 
document in helping steer their efforts towards designing libraries as student hubs. An exchange between Lucy and Lauren at University C demonstrate this:

The Value of Academic Libraries - we all know the report, so I don't have to explain it to you - really says we [librarians] need to demonstrate the value we provide to our institutions by making a difference in the students' academic performance and success. (Lucy)

And we can really interpret that quite broadly, but I think, I think most librarians are looking at that report and asking themselves "what are we good at, and what do we have to offer?" and that, of course, is experience students have at the library. We need to make that valuable in a different way than before. (Lauren) Several of the student affairs professionals referenced the Student Personnel Point of View (SPPV), which provided the philosophical and organizational foundations for the student affairs profession as it stands today (Young, 2003). At University A, Dorothy mentioned "That's what the $S P P V$ says." when she explained how she had to learn about all dimensions of a student's life in order to resolve a student's problem. At University B, Megan used the $S P P V$ to somewhat jokingly scold Kimberly when Kimberly questioned whether student affairs professionals should truly be as concerned with students' cognitive development as faculty are:

I'm not always sure how to shape students' thinking. I'm really focused on service-learning, which does have a lot of critical thinking elements to it, you know, to appreciate the citizenship aspect. But service-learning has much to do with developing empathy, and that's really where I think I can do the most good. The faculty are much better positioned to teach students how to think. (Kimberly) 
Kimberly! [Jack and Alice, simultaneously]

You need to read your SPPV again. [laughs] (Jack)

Well...yes, of course, you're right. We really need to be attentive to all of a students' developmental needs. (Kimberly)

The differences in vocabulary between the librarians and student affairs

professionals suggested, too, their demonstration of their expertise as a legitimacy.

Throughout my study, I defined collaboration as the process of creating a shared

meaning, based on the investment of resources, talent, and power into a new creation that neither party could have achieved on their own (Schrage, 1990). Additionally, I thought of collaboration that is long-lived, meaning the process had derived an outcome valued by the organization and is maintained by the organization long after the original actors had ceased involvement. When I used Gee's (2011) vocabulary tool in my analysis of the focused discussions, I found a significant vocabulary difference in the way librarians and student affairs professionals speak about collaborations generally. Rather than using the phrase collaborating, the student affairs professionals often spoke of "developing partnerships" with faculty or other actors in higher education in order to further a goal. Their consistent use of the word partnership indicated they valued the relationship as a formal, lasting relationship in which they contributed as equally as their collaborators. I do not believe the librarians conceived of collaborations this way. While the librarians did use the words "collaboration" and "collaborate" during our discussions, more often they used less formal phrases such as "working together" or "cooperate with" or "team up together." When they spoke of collaborations using informal phrases, they provided examples of themselves as individuals discovering a mutual interest with 
someone outside the library, often by serendipity, and coming together to solve what they perceived as small, short-term problems. Jodie, a librarian at University A, befriended a student affairs professional who lived in the apartment below her; she participated in the living-learning programs in the residence halls because of her friend's encouragement. Meg, a librarian at University B, collaborated with a student affairs professional at career services whom she met at a water aerobics class to design brochures indicating the library held job-seeking and interviewing sources. In other words, there was no organizational impetus propelling the librarians towards collaboration; those that collaborated with colleagues outside the library did so for reasons borne out of mutual, personal interest. This phenomenon reinforces Rodem's (2011) and Peltier's (2014) findings that faculty members engage in collaboration out of an independent interest to fulfill a perceived need rather than acting to fulfill an organizational goal. The librarian participants in my study appeared to share that phenomena with the faculty in Rodem's and Peltier's study.

\section{Conclusion}

In the end, I question whether librarians and student affairs professionals are truly the blended professionals that Whitchurch (2013) found them to be in her interviews with librarians and student services staff at UK higher education institutions. I examined the participants' focused discussions in light of the four dimensions of third-space professionals - spaces, knowledges, relationships, and legitimacies - using Gee's (2011) tools of discourse analysis. I sought to identify the spaces they claim as their own in higher education, and I sought to understand how those spaces intersected. I did not find strong evidence that student affairs professionals were reshaping the virtual or physical spaces they inhabited, although they did periodically enter traditional library spaces when 
invited by the librarians to share space for programs or services but they were, in fact, beginning to teach credit-bearing courses that faculty had developed originally. However, the librarians' redefining of their libraries as hubs of student activity that allowed the librarians to create environments and experiences for students that facilitated students' identity and psychosocial development certainly seemed to credit Whitchurch's assertion that librarians are weaving their professional and academic domains into a new professional identity.

In the knowledge dimension, I explored how librarians and student affairs professionals integrated their professional and academic knowledge into theory-topractice, but I found little evidence that either group was actively doing so. They appeared to share stories with colleagues at other institutions about what they thought worked and what did not, and they interpreted whether those ideas were worth trying or not. However, I was not able to adequately understand how they made their decisions. Both groups appeared to lack access to information they thought would be helpful in making data-driven decisions. Although they were coalescing student services with libraries at some of the institutions, the participants at those institutions did not seem fully aware of why they were doing so.

Whitchurch (2013) claimed blended professionals are highly effective at building working relationships and expanding their professional networks. Consequently, they renegotiate their identities by navigating interpersonal dynamics and circumstances differently. Librarians negotiated their relationships differently in order to establish effective working relationships with faculty, as evidenced by Crystal's story that she mastered skills with various research methods in order to more effectively work with 
faculty as a partner in research. Other librarians pursued new skills in data and other areas that were not strictly required of their roles in order to demonstrate their value to faculty. However, student affairs professionals spoke little of their relationships with librarians or with faculty. When they did, they focused on their negative perceptions and acknowledging the differences in how the groups approach their work. They displayed little evidence that they renegotiated their identities by attempting to work differently or that they strove to expand their professionals networks to include colleagues from outside their own domain.

I examined librarians and student affairs professionals' use of language in order to understand how they achieved credibility with persons outside their domain. I could not adequately explore this dimension partly because I shared the participants' professional identities as a librarian and as a former student affairs professionals. Additionally, I held the focus groups for librarians and student affairs professionals separately, so they had little need to switch the language of their discourse. However, both groups referenced well known sources in their fields, which served to establish their credibility as professionals or to reinforce their perceptions and actions. Their differences in vocabulary when discussing collaboration as a concept suggested that librarians and student affairs professionals approach interdisciplinary work quite differently, indicating they would need to become more familiar with the language of the other's field in order to engage in mutually satisfying dialog and develop a shared vision for collaboration.

In the end, I am now skeptical of Whitchurch's (2013) claims that librarians and student affairs professionals are blended professionals working in the third space. I found some evidence that they do exhibit some of the characteristics Whitchurch articulated. 
However, they appeared to be lacking characteristics of several of the four dimensions, suggesting they may not belong to blended professional typology. I note Whitchurch focused her study primarily on UK institutions, with a much smaller number of US institutinos included in her study. It is possible UK higher education institutions or librarians and student professionals trained and working in the British conventions are simply different than their US counterparts, and this difference influenced her interpreations. At the very least, I believe the librarians and student affairs professionals in my study indicate they are not blended professionals navigating new academic territories by interviewing professional and academic identities into a new identity. Rather the participants in my study suggest they represent one of the other, more bounded typologies in Whitchurch's (2010) hierarchy of third-space professionals. 


\section{CHAPTER VIII}

\section{DISCUSSION}

In this study, I explored librarians' and student affairs professionals' perceptions of their own role and each other's roles in student learning and student success, identified potential avenues for collaboration, and identified conditions that may impede collaboration. At four higher education institutions in Illinois, I conducted focus groups with 23 librarians and 14 student affairs professionals about their perceptions. Based on my findings, I conclude the work of librarians and student affairs professionals intersects in some ways, but their work diverges in profound ways that makes the groups much less likely to collaborate successfully on improving the student experience. At the same time, the findings may help librarians, student affairs professionals, and other educators approach prospective collaborations between the two groups in ways that may overcome the barriers.

In this concluding chapter, I review the preceding chapters and provide reflections on the study. I discuss the study's major conclusions and reflect on how the study has changed my own thinking on collaboration between librarians and student affairs professionals and revise my assumptions that initially guided the genesis and design of this study. Next, I discuss the study's significance and address the study's implications for practitioners. With the study's findings, librarians, student affairs professionals, and other educators will develop insight into whether and how successful collaborations to 
improve the student experience might be approached. Finally, I offer

opportunities for future research.

\section{Overview of the Study}

My first chapter outlined an argument that librarians and student affairs professionals have common ground, at least philosophically, on which to base potential collaborations, particularly when those collaborations are intended to increase student learning or improve student success. Hinchliffe and Wong (2012) and Swartz, Carlisle, and Uyeki (2007) found little evidence that librarians and student affairs professionals had worked together, while Strothman and Antell (2010) found the relatively few collaborations that had taken place had not endured. Arcelus (2008), Kezar (2006), and Becher and Trowler (2001) studied successful collaborations between interdisciplinary groups and concluded participants must have a shared understanding of student learning, ability to engage in mutually satisfying dialog, and an appreciation for the expertise that each group brings to the collaboration. Therefore, understanding prospective collaborators' perceptions were vitally important in order to approach collaborative work focused on the student experience.

Tenofsky (2007) and Walter (2007) suggested librarians and student affairs professionals are largely unfamiliar with each other's work and do not fully understand how the other group contributes to student learning and to student success. In fact, student affairs professionals' roles were largely unexplained in, and their perspectives completely absent from, the few case studies in the literature where librarians discussed collaborative work with student affairs professionals - work that many of the authors reported as not persisting despite some of the librarians' efforts. How librarians and 
student affairs professionals perceived each other's educational roles was a gap in the scholarly literature. Therefore, this study addressed the question of how librarians and student affairs professionals perceive each other roles and what their perceptions might mean for potentially working together to improve student learning and student success.

My second chapter consisted of a literature review. I identified several overlapping core values guiding the work of librarians and student affairs professionals, including service to students, community development, equity and social justice, and citizenship (Alire \& Evans, 2010; Crume, 2004; Laosebikan-Buggs, 2006; Leckie \& Buschman, 2007; Reason \& Broido, 2011; Roberts, 2003; Rubin, 2010). Next, I explored the phenomenon of collaboration in higher education and found collaborative work between different disciplines requires those disciplines' members to have a shared understanding of students, a shared vision of learning, and the ability to foster mutually satisfying dialog (Becher and Trowler, 2001). The higher education institutions themselves must also nurture collaborative work by demonstrating a clear mission and interweaving integrating structures, campus networks, rewards, a sense of priority from administrators, external pressure, values, and learning in order to create contexts that enable collaboration in organizations (Kezar, 2006; Kezar \& Lester, 2009).

When I reviewed case studies of collaboration between student affairs and academic affairs, I found most addressed structural issues that either impeded or facilitated the collaborations between faculty members and student affairs professionals, particularly the power of the silo-ing effect between academic affairs and student affairs, which isolated groups from each other and provided little reason for different groups to interact (O'Connor, 2012). Arcelus (2008) found the "widening gap" between academic 
affairs and student affairs was driven at least partly by lack of trust between the groups (p. 124). Predominantly, librarians' collaborations were with faculty to enhance students' information literacy and other critical thinking skills or to integrate library resources into course learning outcomes but faculty found librarians' expertise narrow and only marginally helpful (Bowles-Terry, 2014; Nilsen, 2012; Schulte \& Sherwill-Navarro, 2009; Raspa \& Ward, 2000). Lastly, I examined case studies of collaborations between librarians and student affairs professionals but found that many of the initiatives undertaken in the case studies did not persist, and student affairs professionals' voices and perspectives on the collaboration were distinctly unclear or lacking.

In my third chapter, I reviewed my research method and data analysis. I employed a qualitative, phenomenological research design in order to explore how participants made sense of their work and of the other group in the context of Whitchurch's (2010) concept of third-space professionals. Morgan (2002) proposed group interviews allow researchers to explore how and why individuals accept or reject others' ideas, which is critical when collaborative work or other activities in which individuals must have a shared perspective. Consequently, I utilized focus groups as my research method. I drew my sample of focus group participants from four higher education institutions in Illinois. The institutions represented a range of institutional types, including size of student enrollment and private or public in character as denoted by Carnegie classification. The participants were employed full-time at those four higher education institutions and had been employed in their respective profession for at least three years. I conducted seven focus groups, involving 23 librarians and 14 student 
affairs professionals. I held focus groups for the librarians and the student affairs professionals separately. All the focus groups lasted approximately 90 minutes.

I used Gee's (2011) theory of discourse analysis as my framework for analysis and interpretation of the focus groups, and I coded the transcripts using Gee's deixis, vocabulary, intonation, "why this way and not that way," and intertexuality tools. To aid the study's trustworthiness, I had tested the interview protocol prior to conducting the focus groups, selected several sites for triangulation, and provided a description of my background and positioning as the researcher. Later, I confirmed my findings with the participants in two webinars I held for that purpose several months following the focus groups.

Following my treatment of conducting the librarians' and the student affairs professionals' focus groups separately, I similarly organized their stories separately in the fourth and fifth chapters. I examined the themes that emerged from their stories in the sixth chapter, which pulled the themes together to compare and contrast the librarians and student affairs professionals' primarily diverging and sometimes intersecting worlds and addressed the study's research questions. I revisited the concept of Whitchurch's (2010) concept of third-space professionals and questioned whether librarians, at least, and student professionals truly represent the blended professional typology Whitchurch (2013) claimed in her conception of professionals working in the academic third space. In the next section of this chapter, I reflect on the genesis for the study and my assumptions that guided my thinking as I crafted the study. Then, I review the study's major findings and reflect on how these findings have reshaped my own thinking on collaboration between librarians and student affairs professionals. 


\section{Reflection on the Genesis of the Study}

I am a librarian who, for several years, intruded into the work of student affairs professionals. I practiced my craft in a setting unusual for my profession - wholly within the undergraduate residence halls on the campus of a large research university. I managed eight small libraries whose collections and services supported the programmatic goals of the living-learning communities and were tailored to reflect and to challenge the identities and interests of the first-year students residing there. As I observed the work of my student affairs colleagues in the residence halls, I was intrigued by the great responsibility I perceived these professionals to bear. My colleagues counseled and mentored individual students, helped students navigate their first year at college, and created intentional learning environments. My colleagues both supported and challenged students' critical thinking, sense of identity, and interpersonal skills. I thought my student affairs colleagues and I shared much in common at the heart of our work: We stood outside of the university's established curriculum, but still we shaped students' learning as finely as the faculty by our one-on-one teaching moments with students and through the environments and experiences we designed to facilitate students' success. We were in league.

At the same time, I was also a stranger in a strange land. Each time I collaborated with student affairs professionals on a program, I wondered why the collaboration had been so difficult to begin. I had found myself frequently explaining the nature of my work as a librarian, why I was working outside the library, and how students benefited from my participation in a student affairs initiative. To my librarian colleagues, I had also found myself explaining the nature and purpose of the work of the student affairs 
professionals. I speculated that despite our mutual interest in student learning outside of the classroom, librarians and student affairs professionals were dwelling in different worlds. We were alike but our differences made us strangers. I asked myself: In which ways were we so different, and how profound were these differences in working together toward a common goal? In which ways were we alike, and could these likenesses frame successful collaborations together for the betterment of our students? These questions were the genesis of my interest in this study.

At the beginning of my journey, I assumed librarians and student affairs professionals had reason - and desire - to collaborate in order to improve the student experience. After all, I had been employed in a position myself that led me to work with student affairs professionals on designing programming, services, and spaces to support students. Moreover, I knew service to students is not only a deep commitment but the very ethos for academic librarians and for student affairs professionals alike. We belong to helping professions, and students are the reasons for our calling. This assumption guided my exploration of this study.

When I began my journey, I assumed - quite naively - that if one cared deeply in a value and was willing to try something in a new way, one had only find like-minded people and the collaborative work would unfold. At worst, the collaboration might not yield the outcomes one had hoped, and one would revise one's strategies accordingly. Naturally, I approached my study with high expectations. I undertook my study with the intent of making a difference in the way librarians innovate and create a more deeply integrated learning environment for students. In her call for collaboration between librarians and student affairs professionals, Forrest (2005) asked "Do they even exist?" 
(p. 12). At the beginning of my journey, I said to myself "I will find them. And if I do not find them, I will find the germs of ideas among the librarians and the student affairs professionals. I will help those germs grow and bloom into the ideas that others will then emulate and adapt for their own institutions.” Perhaps one day, I thought, higher education might even see the rise of libraries blended wholly with student services. Students might visit a single building on campus where they could exercise, attend a program in a space dedicated to under-represented students, and find staff capable of providing academic and career advising as well as expertise on information in all its multitudinous domains. Perhaps librarians and student affairs professionals might experience such great change to their work and professional identities, their expertise might even expand to encompass the skills of both professions. These were exciting, even revolutionary, prospects to me.

At the four higher education institutions where I conducted my focus groups, I did not find librarians and student affairs professionals working in collaboration. Because I did not find collaborative work taking place between any of the librarians and the student affairs professionals in my study, I was not truly able to identify any specific conditions that facilitated collaborations between the two groups but found conditions that may impede collaborations, such as lack of familiarity and shared languages, differences between each other's ways of working, and the gap that isolates the two groups from each other. Only a couple of the student affairs professionals knew of collaborations - and unfortunately failed ones - between librarians and student affairs professionals undertaken at other institutions. In fact, I found few germs of ideas for working together at all. To many of the participants, the concept was completely new and maybe even a 
bit strange. In explaining the purpose of my study as I began to facilitate the first of my focus groups, a librarian interrupted me with the rather alarming question: "What is that phrase you're using - student affairs?" This seemed like an inauspicious but telling beginning to my research. In the next section of this chapter, I will summarize my major findings from the study and then return to my reflection in order to illustrate how these major findings caused me to rethink whether librarians and student affairs professionals should and could collaborate to improve student learning and student success.

\section{Major Findings}

My study's purpose was to explore librarians' and student affairs professionals' perceptions of each other's roles in student learning and success, to identify opportunities for prospective collaborations, and to identify the conditions which impede or facilitate prospective collaboration. Through the voices of librarians and student affairs professionals at four higher education institutions, I explored the following research questions: How do librarians and student affairs professionals describe student learning and student success? How do librarians and student affairs professionals perceive their own roles and each other's roles in student learning and student success? Where do they see the work of librarians intersecting with the work of student affairs professionals? How might they approach collaborations in these intersecting areas? How might the work and identifies of librarians and student affairs professionals change because of these collaborations?

In my study, the librarians and student affairs professionals never specifically addressed their perspectives on students or, more specifically, on student learning. Instead, they discussed what they did on behalf of students, and I inferred their 
perspectives. They do not yet have a shared understanding of students or of student learning, but I believe they are capable of reaching a shared understanding. Student affairs professionals are strongly focused on the holistic development of students, while librarians are principally focused on teaching students' critical thinking skills. However, some librarians were demonstrating a greater interest in holistic student development by emphasizing ways they could design programs, services, and spaces at the library that allowed students to practice problem-solving skills and creativity. This suggests librarians and student affairs professionals have begun to see students not as empty vessels to be filled up with content knowledge but as growing in multidimensional ways and influenced cognitively, psychosocially, and self-conceptually by the environments and experiences each group creates.

However, librarians' and student affairs professionals' perceptions of each other's predominant roles are quite dissimilar. Many of the librarians had virtually no impression of student affairs professionals whatsoever, except in regards to student maintenance. Many of the student affairs professionals were ambivalent toward librarians but they emphasized librarians' rather narrow focus at helping students locate information, a need many of the student affairs professionals questioned in the face of improving technologies. They questioned librarians' commitment to students, suggesting the language librarians used to describe students and libraries' services was off-putting.

They did not really view their work as intersecting. Again, their negative perceptions of each other might have prevented them from imagining the possibilities. While they did acknowledge that libraries were changing and that bringing student services into the library might be beneficial for students and therefore desirable, the lack 
of interaction between librarians and student affairs professionals seemed profound. Arcelus' (2008) widening gap seemed a strong force at play here. The student affairs professionals remarked upon the librarians' invisibility, which was likely true and created by the librarians' sense of the "jenga pile" - in which librarians' experienced increasing demands on their time - and an inflexible system of evaluation and tenure prevented them from taking risks outside their core job duties. I believe differences in their ways of working contributed to the widening gap as well. The student affairs professionals lived in the "here and now," a constantly shuffling of priorities driven by immediate student crises, while librarians required planning to build opportunities for trying new activities into their schedule and then abandoned those activities quickly when they failed to see a significant return on their invested time. These are significant structural barriers that prevent librarians and student affairs professionals from spending time in each other's worlds. Therefore, they have little opportunity to form perceptions or change their somewhat negative perceptions of each other and begin to talk about how their work might intersect.

My assumption that librarians and student affairs professionals could and should work together to enhance student learning and student success framed this study. Now, I doubt the validity of my assumption. While the work of librarians and student affairs professionals do intersect in some interesting ways and their perspectives on students and on student learning do seem to be converging, but other factors keep them farther apart than I had thought. Structural issues inherent in their work - such as the librarians' sense of being overwhelmed with responsibilities or the "here and now" nature of student affairs work - inhibit their ability to connect with each other and exacerbates their lack of 
familiarity with each other's educational roles. They are skeptical of each other's capacity to work together successfully, with perhaps librarians mistaking student affairs professionals' lack of follow-through or planning as disinterest while the student affairs professionals doubt librarians' interpersonal skills could make them suitable collaborators.

Becher and Trowler (2001) claimed disciplines with relational values are more likely to reach consensus and build successful interdisciplinary endeavors. The disciplines must share a common vision of learning, a common perspective on students, a common language, and the ability to foster mutually satisfying dialog. John-Steiner (1998) suggested individuals must possess a set of relational dynamics, such as trust, autonomy, and creativity in order to express both the desire and the capacity to engage in collaborative work. Consequently, librarians and student affairs professionals must demonstrate evidence of convergence in their perspectives on learning and students, they must trust the members of the other group, and they must be open to new ideas and experience sufficient independence to work in new ways without the reward systems penalizing their willingness to step outside their traditional domains and ways of working. My findings suggest librarians and student affairs professionals diverge more significantly than they converge in these areas, thereby making long-lived collaborations between the two groups less likely.

\section{My New Thoughts}

In some ways, this study was discouraging. Because of my findings, I believe now that librarians and student affairs professionals dwell in different worlds and are more dissimilar than I had previously thought. Where I was idealistic in my belief that 
librarians and student affairs professionals could and should collaborate together to improve student learning and success at the beginning of my study, I am now skeptical that they are appropriate prospective collaborators. They do not appear to share sufficient similarities that allow them to experiment with new ideas and enable long-lived, successful collaborations to flourish. While their lack of familiarity with each other is profound, they doubted the validity of the other group's educational contributions, did not trust each other's interpersonal skills or planning abilities, and appeared to differ markedly in their sense of autonomy or agency. I think back to John-Steiner's (1998) assertion that collaborators must possess a set of relational dynamics that include intellectual ownership, trust, autonomy, and creativity in order to express both the desire and the capacity to engage in collaborative works with people outside their discipline. I did not find much evidence in the focused discussions to suggest these relational dynamics were shared by the participants in my study, suggesting the desire and the capacity to engage in collaborative work may not be present at all.

At the beginning, I did not yet appreciate the invisible forces at play in higher education. I knew, at least abstractly, of the isolation most groups working on higher education institutions feel from each other. What I did not recognize until I thought deeply about my findings was the breadth and the incredibly powerful role of the widening gap between student affairs and academic affairs, to which librarians usually belong.

I am also concerned the implication is that librarians will become increasingly isolated in higher education without partners who find librarians' expertise valuable in the educational enterprise. Oakleaf (2010) reported librarians and libraries' value in 
higher education are increasingly questioned, and librarians must demonstrate greater accountability for student learning by establishing how they change students' lives. She recommended that librarians collaborate with student affairs professionals in order to demonstrate that librarians may positively contribute to student persistance and to student learning outside of the classroom. Melling (2013) found the cultures of librarians and information technologists to be poor fits for working together successfully. Nilsen (2012) and Sherwill-Navarro and Schultz (2009) concluded that faculty do not perceive librarians as valued collaborators in student learning. If librarians and student affairs professionals are also too dissimilar to work collaboratively on improving student learning or student success, librarians are left rather alone to craft the future of their profession. As a librarian, the implication brings me much disquiet.

\section{Significance of the Findings}

Hinchliffe and Wong (2012) and Swartz, Carlisle, and Uyeki (2007) noted that little collaboration between librarians and student affairs professionals appeared to have taken place. Strothman and Antell (2010) claimed collaborations between librarians and student affairs professionals were not successful and did not persist. Becher and Trowler (2001) and Kezar (2006) noted that successful collaborative work focused on improving the student experience requires interdisciplinary groups to have a shared understanding of student learning and an appreciation for the expertise that each group brings to the collaboration. In Arcelus' (2008) and Kezar and Lester's (2009) studies of successful interdisciplinary collaborations, the groups' perceptions influenced the willingness and ability of different professional groups to work together, but student affairs professionals' 
perspectives were absent from the relatively few case studies that explored collaborations between the two professions (Aguilar \& Keating, 2009).

My study gave voices to student affairs professionals and shared the perspectives of both groups. While librarians and student affairs professionals do intersect in some ways in regards to student learning, they do not appreciate the educational contributions that each could group could potentially bring to collaborative work focused on improving the student experience. Based on my findings, librarians, student affairs professionals, and other educators may recognize that prospective collaborations between the professions may be fraught with difficulties. At the very least, readers interested in laying the groundwork for collaboration between the groups will need to assess the level of familiarity and the accuracy of the perceptions that each group has of the other at their higher education institutions. Negative or misperceptions may need to be counteracted with greater contacts between the group, and each group may need to alter their message about how they contribute to student learning. This may be especially true for the librarians, who student affairs professionals perceive as narrowly focused on information skills. Readers may find value in the germs of the ideas for improving the student experience that emerged from my findings and develop insights into the conditions that are likely to impede prospective collaborative work.

\section{Implications for Practice in Higher Education}

Librarians and student affairs professionals who hoped to find new and interesting collaborations to implement at their own institutions are surely to be disappointed with what they found - or, perhaps more accurately, with what they did not find - in my study. I am too, at least in that regard. Indeed, the challenge of collaboration between librarians 
and student affairs professionals is not about specific ideas for collaborations at all but how to reorient librarians and student affairs professionals towards collaborative work despite the realities of their diverging worlds. Collaboration between the two groups will not be easy at the best of times because of the differences I identified in this study. Instead, a cultural shift may be required in order for librarians and student affairs professionals to perceive each other as worthwhile collaborators. The institutional cultures that support the necessary characteristics for interdisciplinary collaboration to occur must be present first.

Based on my findings, I do not believe collaboration between two interdisciplinary groups with such marked differences as librarians and student affairs professionals can happen though a major policy change initiated by campus leaders. I agree with Kezar's (2006) finding that higher education institutions must demonstrate certain necessary conditions before collaboration between interdisciplinary groups could emerge with lasting success. Kezar identified those conditions as a clear mission, integrating structures, campus networks, rewards, a sense of priority from administrators, external pressure, values, and shared perspectives on learning. Arcelus (2008) concluded that institutions moving toward the cultivation of those conditions require "a combination of leadership, dialogue, and willingness to re-evaluate one's viewpoint while learning about people's perspectives" (p. 416). Based on what I came to learn from the literature and from the focused discussions, I believe the widening gap between student affairs and academic affairs is the most serious barrier to collaboration for institutions who desire to create seamless learning environments to overcome. How are librarians and student affairs professionals to learn more about each other's work and change their perceptions 
of each other if the invisible force of the widening gap prevents them from truly coming together?

However, the gap may be overcome if institutions redefine their missions and guiding philosophies. The institutional leaders must work toward a mutually agreedupon educational philosophy that in turn guides the tenor of academic and co-curricular programs, the allocation of resources that support the philosophy, and the adaptation of reward systems that actually reward, or at the very least not penalize, the librarians and student affairs professionals who are willing to blend collaborative work into the exercise of their roles. The gap will be narrowed by a shared ethos, and that shared ethos will emerge when librarians and student affairs professionals exhibit confidence and trust in each other, support each other's work, and then create a coherent campus experience for students. So I believe the greatest indicator for long-lived, successful collaborations between librarians and student affairs professionals will be at higher education institutions where institutional leaders are interested in the enhancement of student learning through the establishment of seamless learning environments.

Finally, Kezar (2006) noted "micro-changes" might also be potentially important in reorienting institutional culture to value collaborative work. As an example, she offered a story of faculty inviting faculty from another department for an informal coffee to talk about their work. Kezar did not examined these micro-changes but speculated these moments might be as powerful as the institutional conditions she had outlined. Although interactions between librarians and student affairs professionals are stymied by the differences in how they plan and use their time, individuals who wish to explore collaborations between the groups must find a way to interact, if at least quite informally. 
However, I propose these informal interactions must unfold in a group context rather than as individuals with mutual interest reaching out to each other. Alison, a librarian at University $\mathrm{C}$, expressed interest in working with the career advisors, but the other librarians in her focus group discouraged her until after she had earned tenure. In order to counteract the negative reinforcement that individuals might experience from colleagues, chief library officers and chief student affairs officers should organize joint meetings to discuss librarians' and student affairs professionals' work.

At University A, the librarians remembered that the dean of students, or someone else from student affairs, had indeed come to speak to the library staff. However, they did not recall very much about what he had to say or even his name, but mostly that student affairs professionals were to serve as resources for librarians when they encountered students in distress. That meeting was about what student affairs professionals could do for librarians on behalf of students - but making students themselves the focus of the discussion may influence a new direction to their interactions. I suspect the two groups could go a long way toward demystifying each other if they were simply brought together with students as the focus of their meeting. It seems simplistic to change the purpose of joint meetings from talking about how, when, and where to refer students in crisis but instead about how students are learning and how both groups change students' lives through the intentional interactions they design. Yet there may be real gains in approaching the conversation in such a way to capitalize on librarians' and student affairs professionals' shared ethos of service to students.

In short, chief library officers and chief student affairs officers must place a shared emphasis on collaboration between the two groups. This emphasis must be 
explicitly stated, and the anticipated outcomes of collaboration must be clearly articulated for the benefit of librarians and student affairs professionals who may not understand how their work is expected to change. The chief library officer and the chief student affairs officer should make students the center of discussion between the two groups. In order to better understand the context of each other's work, librarians and student affairs professionals should share how they contribute to student learning and student success and specifically discuss the actions they take to carry out their work. Through mutual dialog, librarians and student affairs professionals should develop keener insight into each other's work and may develop ideas for working together to improve the student experience.

I recommend librarians and student affairs professionals focus their discussions on identifying and addressing social justice issues students face at their institutions. As a core value common to both professions, librarians and students affairs professionals should be able to survey the campus climate of their institutions to identify how and where students encounter systemic institutional barriers toward their persistence. Together, librarians and student affairs professionals might be able to develop new approaches or services designed to provide better outreach or address inequities.

\section{Opportunities for Future Research}

This study focused on small groups of librarians and student affairs professionals at four higher education institutions in Illinois and was intended to be an initial exploration of the question rather than a comprehensive study. Clearly, my study is constrained in its generalizability. Additionally, I did not specifically seek out higher education institutions that demonstrated seamless learning experiences as a core 
institutional value. If I had, I might have found librarians and student affairs

professionals with different perspectives because presumably Kezar's (2006) eight conditions for inter-group collaboration might already be present, and the silo-ing effect of the widening gap might not have been the powerful factor as I suspect it was for the institutions I selected for my study. An opportunity for study would be to explore whether collaborations between librarians and student affairs professionals exist at such institutions, or whether the librarians and student affairs professionals are more familiar with or perceive each other differently than did the participants at the institutions I selected.

Additionally, my study drew participants who did not report having significant past interactions or collaborations with members of the other professional group. My study does not include or attempt to understand the voices and perspectives of librarians and student affairs professionals who may have made satisfying connections with each other. They may be few in number, but they are almost certainly out there somewhere in the world of higher education since the several case studies included in Hinchliffe and Wong's (2012) edited work drew upon librarians' experiences working with student affairs professionals, at least in a limited way.

Although the four institutions I selected for my study had a large number of undergraduate students in residence on their campus, I realize now the number of undergraduate students enrolled is not a good indicator that institutions are actually strongly focused on undergraduate education. Several of the institutions were characterized as research universities, and research universities tend to lack a sharp focus on undergraduate students; their librarians, at least, are often juggling the very different 
needs of multiple constituent groups than are librarians elsewhere (Alire \& Evans, 2010).

I speculate that a similar study that drew upon participants from faith-based institutions or small liberal arts colleges might possibly lead to different conclusions due to the more focused missions of those institutional types. For practitioners, it would be helpful to compare the perceptions of librarians and student affairs professionals at research universities with those at faith-based or liberal arts institutions. It may be that collaboration between librarians and student affairs at some institutions is simply not very feasible because institutional type is a more controlling mitigating factor than are the dissimilarities between the professions.

An additional opportunity for study would be to explore the perceptions of librarians and student affairs professionals who might have already worked together and describe what conditions brought those actors together and how their collaborative work was enabled or impeded by the forces at play at their institutions. There may be value in understanding the ways these collaborators engage with each other so that mutuallysupportive collaborations might be explored between librarians and student affairs professionals. This might prove especially helpful for librarians who are weighing the merit of reshaping their libraries into student hubs and thinking about how they can influence the learning and development of students who are likely to frequent there.

\section{Conclusion}

In this study, I explored librarians' and student affairs professionals' perceptions of their own role and each other's roles in student learning and student success. I found librarians and student affairs professionals may not be suitable partners for working together to improve the student experience because they do not share strong similarities. 
They do not recognize, or appear to value, the expertise that the other profession may offer to collaborative ventures. Some librarians perceived student affairs professionals as disorganized, while student affairs professionals perceived librarians as uncommitted or removed from students and somewhat lacking in interpersonal skills. Although they diverged in powerful ways, such as skepticism of each other's expertise, ability to engage in mutually satisfying dialog, and shared language and perspectives on interactions with students, librarians and student affairs professionals appear to be converging in their perspectives on students and their possible contributions to student learning. I concluded that collaboration between librarians and student affairs professionals may, in fact, be difficult but still possible when the bases of collaborative work spring from the intersections of their worlds, namely supporting and challenging students' cognitive, identity, and psychosocial development.

Additionally, I suggested a few potential avenues for, and possible approaches to, collaboration between librarians and student affairs professionals such as the practice of intrusive librarianship or the embedding of librarians into bridge or TRIO programs. In addition to the differences between the professions that may impede collaborations, I identified other conditions that may also inhibit the likelihood of successful collaborations, including inflexible reward systems for librarians, librarians' sense of overwhelm regarding their duties, and the powerful silo-ing effect of the widening gap between student affairs and academic affairs at higher education institutions. The findings of this study should prove useful to librarians, student affairs professionals, and other educators who are seeking insight into the possibilities and limitations of building 
collaborations between these professions in order to enhance student learning and student success. 


\section{REFERENCES}

Accardi, M. T., Garvey-Nix, R., \& Meyer, L. A.(2012). Plagiarism education, prevention, and student development: A collaborative approach to supporting academic integrity. In L. J. Hinchliffe \& M. A. Wong (Eds.), Environments for student growth and development (pp. 73-87). Chicago, IL: Association of College and Research Libraries.

Acocella, I. (2012). The focus group in social research: Advantages and disadvantages. Quality \& Quantity, 46(4), 1125-1136. doi: 10.1007/s11135-011-9600-4

Aguilar, P., \& Keating, K. (2009). Satellite outreach services programs to underrepresented students: Being in their space, not on MySpace. The Reference Librarian, 50(1), 14-28. doi: 10.1080/02763870802546365

Alire, C. A., \& Evans, G. E. (2010). Academic librarianship. New York, NY: Neal Schuman.

American Association for Higher Education, Task Force on Student Learning. (1998). Powerful partnerships: A shared responsibility for learning. Retrieved from acpa.nche.org/sites/default/files/taskforce_powerful_partnerships_a_shared_respo nsibility_for_learning.pdf

Arcelus, V. J. (2008). In search of a break in the clouds: An ethnographic study of academic and student affairs cultures. (Doctoral dissertation). Retrieved from ProQuest. UMI 3414294. 
Barr, T. F. (2013). Utilizing student affairs professionals to enhance student and faculty experiences and mitigate risk in short-term, faculty-led study abroad programs. Journal of International Education in Business, 6(2), 136-147. doi. 10.1108/JIEB05-2013-0019

Becher, T. (1989). Academic tribes and territories: Intellectual enquiry and the culture of disciplines. Milton Keynes, UK: Open University Press.

Becher, T., \& Trowler, P. (2001). Academic tribes and territories (2 ${ }^{\text {nd }}$ ed.). Oxford, UK: Society for Research into Higher Education and Open University Press.

Bennett, S. (2007). Campus cultures fostering information literacy. Portal: Libraries and the Academy, 7(2), 147-167. doi: 10.1353/pla.2007.0013

Blimling, G. S., \& Whitt, E. J. (1999). Good student affairs practice: Principles to foster student learning. San Francisco, CA: Jossey-Bass.

Bolin, M. K. (2008). A typology of librarian status at land grant universities. Journal of Academic Librarianship, 34(3), 220-230.

Borst, A. J. (2011). Evaluating academic and student affairs partnerships: The impact of living-learning communities on the development of critical thinking skills in college freshman. (Doctoral dissertation). Retrieved from ir.iowa.edu/etd/927 (ETD 927).

Bowles-Terry, M. (2014). UNLV Libraries: Partners in student learning. Poster session presented at the meeting of the American Library Association, Las Vegas, NV. Retrieved from digitalscholarship.unlv.edu/lib_openhouse_ala/2

Calhoun, D.W., \& Taub, D. J. (2014). Exploring the gender-identity roles of men in student affairs. College Student Affairs Journal, 32(1), 35-51. 
Cossette, A. (2009). Humanism and libraries: An essay on the philosophy of librarianship. Sacramento, CA: Litwin Books.

Cownie, F. (2012). Law, research and the academy. In P. Trowler, M. Saunders, and V. Bamber (Eds.), Tribes and territories in the $21^{\text {st }}$ century: Rethinking the significance of disciplines in higher education (pp. 57-68). New York, NY: Routledge.

Creswell, J. W. (2009). Research design: Qualitative, quantitative, and mixed methods approaches $\left(3^{\text {rd }}\right.$ ed.). Thousand Oaks, CA: Sage.

Crowe, K. M., Hummel, M. L., Dale, J., \& Bazirjian, R. (2012). Living, learning, and libraries: A cross-campus approach. In L. J. Hinchliffe \& M. A. Wong (Eds.), Environments for student growth and development (pp. 113-129). Chicago, IL: Association of College and Research Libraries.

Crume, A. W. (2004). The historical development of the Student Government Association as a student sub-culture at Florida State University: 1946-1976. (Doctoral dissertation, Florida State University). Retrieved from http://diginole.lib.fsu.edu/etd/

Cummings, L. U. (2007). Bursting out of the box: Outreach to the millennial generation through student services programs. Reference Services Review, 35(2), 285-295. doi: $10.1108 / 009073207107$

Cutler, H. A. (2003). Identity development in student affairs professionals. The College Student Affairs Journal, 22(2), 167-179.

Davies, D. W. (1974). Libraries as culture and social centers: The origin of the concept. Metuchen, NJ: Scarecrow. 
Davis, D. M., \& Hall, T. D. (2012). Diversity counts. Chicago: American Library Association. Retrieved from http://www.ala.org/offices/sites/ala.org.offices/files/content/diversity/diversitycou nts/diversitycountstables2012.pdf

Dervin, B. (2003). Given a context by any other name: Methodological tools for taming the unruly beast. In B. Dervin, L. Foreman-Wernet, \& E. Lauterbach (Eds.), Sense-making methodology reader: Selected writings of Brenda Dervin (pp. 111132). Cresskill, NJ: Hampton.

Dungy, G. J. (2003). Organization and functions of student affairs. In S. R. Komives \& D. B. Woodward (Eds.), Student services: A handbook for the profession $\left(4^{\text {th }} \mathrm{ed}\right)$ (pp. 339-357). San Francisco, CA: Jossey-Bass.

Elguindi, A. C., \& Sandler, M. A. (2013). The ILS as outreach: Cataloging campus partner collections. Cataloging and Classification Quarterly, 51(1-3), 291-310. doi: 10.1080/0163937.2012.722589

Emmons, M., \& Wilkinson, F.C. (2011). The academic library impact on student persistence. College \& Research Libraries, 72(2), 128-142.

Flashmobs in libraries. (2010, February 15). Journal of the European Association for Health Information and Libraries. [Web log post]. Retrieved from http://jeahil/wordpress.com/2010/02/15/flashmobs-in-libraries/

Forrest, L. U. (2005). Academic librarians and student affairs professionals: An ethical collaboration for higher education. Education Libraries, 28(1), 11-15. 
Gatten, J. N. (2006). Student psychological and cognitive development: Theory to practice in academic libraries. Reference Services Review, 32(2), 157-163. doi: $10.1108 / 00907320410537676$

Gee, J. P. (2011). How to do discourse analysis: A toolkit. New York, NY: Routledge.

Gibson, H., Morris, A., Cleeve, M. (2008). Links between libraries and museums: Investigating museum-library collaborations in England and the USA. Libri, 57(2), 53-64. doi: 10.1515/LIBR.2007.53

Gilchrist, D. L. (2009). Academic libraries at the center of instructional change: Faculty and librarian experience of library leadership in the transformation of teaching and learning. (Unpublished doctoral dissertation). Oregon State University, Corvallis, Oregon.

Gordon, V. N., Habley, W. R., \& Giles, T. J. (2008). Academic advising: A comprehensive handbook ( $2^{\text {nd }}$ ed.). San Francisco, CA: Jossey-Bass.

Gorman, M. (2000). Our enduring values: Librarianship in the $21^{\text {st }}$ century. Chicago, IL: American Librarian Association.

Griffiths, J. M., \& King, D. W. (2009). A national study of the future of librarians in the workforce. Washington, DC: Institute of Museum and Library Services. Retrieved from libraryworkforce.org/tiki-index.php

Guba, E. G. (1981). Criteria for assessing the trustworthiness of naturalistic inquiries. Educational Communication and Technology Journal, 29, 75-91.

Hamrick, F. A., Evans, N. J., \& Schuh, J. H. (2002). Foundations of student affairs practice: How philosophy, theory, and research strengthen educational outcomes. San Francisco, CA: Jossey-Bass. 
Hinchliffe, L. J., \& Wong, M. A. (2012). The power of library and student affairs collaborations. In L. J. Hinchliffe \& M. A. Wong (Eds.), Environments for student growth and development (pp. 231-245). Chicago, IL: Association of College and Research Libraries.

Hollister, C. (2005). Bringing information literacy to career services. Reference Services Review, 33(1), 104-111.

John-Steiner, V. (1998). The challenge of studying collaboration. American Educational Research Journal, 35(4), 773-783.

Johnson, B. L. (1939). Vitalizing a college library. Urbana, IL: University of Illinois. Kahl, C., \& Paterson, J. (2012). In L. J. Hinchliffe \& M. A. Wong (Eds.), Environments for student growth and development (pp. 101-113). Chicago, IL: Association of College and Research Libraries.

Kezar, A. (2006). Redesigning for collaboration in learning initiatives: An examination of four highly collaborative campuses. Journal of Higher Education, 77(5), 804-838.

Kezar, A. J., \& Lester, J. (2009). Organizing higher education for collaboration. San Francisco, CA: Jossey-Bass.

Kitzinger, J., \& Barbour, R. S. (1999). The challenge and promise of focus groups. In R. S. Barbour \& J. Kitzinger (Eds.), Developing focus group research: Politics, theory and practice (p. 1-21). London, UK: Sage.

Kosygina, L. V. (2005). Doing gender in research: Reflection on experience in the field. The Qualitative Report, 10(1), 87-95.

Kuh, G. D. (1996). Guiding principles for creating seamless learning environments for undergraduates. Journal of College Student Development 37(2), 135-148. 
Krueger, R. A. (1998). Developing questions for focus groups: Focus group kit 3. San Francisco, CA: Jossey-Bass.

Lampert, L. D., Dabbour, K.S., \& Solis, J. (2007). When it's all Greek: The importance of collaborative information literacy outreach programming to Greek student organizations. Research Strategies, 20, 300-310. doi: 10.1016/j.resstr.2006.12.005

Lankes, R. D. (2011). The atlas of new librarianship. Cambridge, MA: MIT Press.

Laufgraben, J. L., \& Shapiro, N. S. (2004). Sustaining and improving learning communities. San Francisco, CA: Jossey-Bass.

Laosebikan-Buggs, M. O. (2006). The role of student government: Perceptions and expectations. In M. T. Miller \& D. P. Nadler, (Eds.), Student governance and institutional policy: Formation and implementation (pp. 1-8). Charlotte, NC: Information Age.

Leckie, G. J., \& Buschman, J. E. (2007). Space, place, and libraries: An introduction. In G. J. Leckie and J. E. Buschman (Eds.), The library as place: History, community, and culture (pp. 3-25). Westport, CT: Libraries Unlimited.

Ledwith, K. E. (2014). Academic advising and career services: A collaborative approach. In K. K. Smith (Ed.), Strategic directions for career services within the university setting: New directions for student services, No. 148. San Francisco, CA: JosseyBass.

LePeau, L. A. (2012). Academic affairs and student affairs partnerships promoting diversity initiatives on campus: A grounded theory. (Doctoral dissertation). Retrieved from ProQuest. UMI 3543589. 
Long. D. (2011). Embedded right where the students live: A librarian in the university residence halls. In C. Kvenild \& K. Calkins (Eds.), Embedded librarians: Moving beyond one-shot instruction (pp. 199-210). Chicago, IL: Association of College and Research Libraries.

Love, E., \& Edwards, M. B. (2009). Forging inroads between libraries and academic, multicultural, and student services. Reference Services Review, 37(1), 20-29. doi: $10.1108 / 00907320910934968$

Lozano, A. (2010). Providing a sense of belonging and promoting student success. In L. D. Patton (Ed.), Culture centers in higher education: Perspectives on identity, theory, and practice (p. 3-25). Sterling, VA: Stylus.

Maloney, M., Royce-Davis, J., \& Griego, E. (2012). The library and student life: Activist partnerships in first-year experience programs. In L. J. Hinchliffe \& M. A. Wong (Eds.), Environments for student growth and development (pp. 195-211). Chicago, IL: Association of College and Research Libraries.

Manning, K., Kinzie, J., \& Schuh, J. H. (2006). One size does not fit all: Traditional and innovative models of student affairs practice. New York, NY: Routledge.

Marines, A., \& Venegas, Y. (2012). Strategic partnerships across divisions: Aligning student affairs and the university library to increase diversity in an academic institution. In L. J. Hinchliffe \& M. A. Wong (Eds.), Environments for student growth and development (pp. 219-231). Chicago, IL: Association of College and Research Libraries.

Maxwell, N. K. (2006). Sacred stacks: The higher purpose of libraries and librarianship. Chicago, IL: American Library Association. 
Melling, M. (2013). Collaborative service provision through super-convergence. In M. Melling \& M. Weaver (Eds.), Collaboration in libraries and learning environments (pp. 149-156). London, UK: Facet.

Mezick, E. M. (2007). Return on investment: Libraries and student retention. Journal of Academic Librarianship, 33(5), 561-572.

Miller, L. (2012). The library and the campus visit: Communicating value to prospective students and parents. College and Research Libraries News, 73(10), 586-589.

Montiel-Overall, P. (2010). Toward a theory of collaboration for teachers and librarians. Chicago, IL: American Association of School Librarians.

Moore, E. L., \& Marsh, R. S. (2007). College teaching for student affairs professionals. New Directions for Student Services, no. 117. doi: 10.1002/ss.228

Morgan, D. L. (1998). Planning focus groups: Focus group kit 2. Thousand Oaks, CA: Sage.

Morgan, D. L. (2002). Focus group interviewing. In J. F. Gubrium \& J. A. Holstein (Eds.), Handbook of interview research: Context and method (pp. 141-159). Thousand Oaks, CA: Sage.

Myers, G., \& Macnaghten, P. (1999). Can focus groups be analysed as talk? In R. S. Barbour \& J. Kitzinger (Eds.), Developing focus group research: Politics, theory and practice (p. 173-185). London, UK: Sage.

Newbury, D. (2001). Diaries and fieldnotes in the research process. Research Issues in Art Design and Media, 1. Retrieved from biad.bcu.uk/research/rti/riadm/issue1/riadissue1.pdf 
Nilsen, C. (2012). Faculty perceptions of librarian-led information literacy instruction in postsecondary education. Paper presented at the meeting of the World Library and Information Congress: $78^{\text {th }}$ IFLA General Conference and Assembly, Helsinki, Finland. Retrieved from conference.ifla.org/past-wlic/2012/ifla78.htm

Oakleaf, M. (2010). The value of academic libraries: A comprehensive research review and report. Chicago, IL: Association of College and Research Libraries.

O'Connor, J. S. (2012). Factors that support or inhibit academic affairs and student affairs from working collaboratively to better support holistic students' experiences: A phenomenological study. (Doctoral dissertation). Retrieved from ProQuest. UMI 3535416.

Ortlipp, M. (2008). Keeping and using reflective journals in the qualitative research process. The qualitative report, 13(4), 695-705. Retrieved from http://www.nova.edu/ssss/QR/QR13-4/ortlipp.html

Onwuegbuzie, A. J., Leech, N. L., \& Collins, K. M. T. (2008). Interviewing the interpretive researcher: A method for addressing the crises of representation, legitimation, and praxis. International Journal of Qualitative Methods, 7(4), 1-17.

Pascarella, E., \& Terenzini, P. (2005). How college affects students: A third decade of research ( $2^{\text {nd }}$ ed.). San Francisco, CA: Jossey-Bass.

Peltier, M. S. (2014). The impact of faculty perception of student affairs personnel on collaborative initiatives: A case study. (Doctoral dissertation). Retrieved from digitalcommons.unl.edu/cehsedaddis/172. ETD 172. 
Piercy, F. P, \& Hertlein, K. M. (2005). Focus groups in family therapy research. In D. H. Sprenkle \& F. P. Piercy (Eds.), Research methods in family therapy (pp. 85-99). New York, NY: Guilford.

Raspa, D., \& Ward, D. (2000). Listening for collaboration: Faculty and librarians working together. In D. Raspa \& D. Ward (Eds.), The collaborative imperative: Librarians and faculty working together in the information universe (pp. 1-19). Chicago, IL: Association of College and Research Libraries.

Reason, R. D., \& Broido, E. M. (2011). Philosophies and values. In J. H. Schuh, S. R. Jones, \& S. R. Harper (Eds.), Student services: A handbook for the profession $\left(5^{\text {th }}\right.$ ed.) (pp. 80-95). San Francisco, CA: Jossey-Bass.

Reddick, G. T. (2014). Understanding the heart of the matter: Utilizing focus groups to better understand the participant experience in a marriage education program. (Doctoral dissertation). Retrieved from ProQuest. (UMI 3624110.)

Rentz, A. L. (1994). The emergence of student development. In A. L. Rentz (Ed.), Student affairs: A profession's heritage (2 ${ }^{\text {nd }}$ ed.) (pp. 257-268). Lanham, MD: American College Personnel Association.

Riehle, C. F., \& Witt, M. C. (2009). Librarians in the hall: Instructional outreach in campus residences. College \& Undergraduate Libraries, 16(1/2), 107-121.

Roberts, D. C. (2003). Community building and development. In S. R. Komives \& D. B. Woodward (Eds.), Student services: A handbook for the profession ( $\left.4^{\text {th }} \mathrm{ed}.\right)$ (pp. 539-554). San Francisco, CA: Jossey-Bass. 
Rodem, M. R. (2011). Collaborative relationships between faculty and student affairs professionals: A case study. (Doctoral dissertation). Retrieved from ProQuest. UMI 3493142.

Rubin, R. (2010). Foundations of library and information science ( $3^{\text {rd }}$ ed). Chicago, IL: Neal-Schuman.

Schulte, S. J., \& Sherwill-Navarro, P. J. (2009). Nursing educators' perceptions of collaborations with librarians. Journal of the Medical Library Association, 97(1), 57-66. doi: 10.3163/1536_5050.97.1.013

Shenton, A. K. (2004). Strategies for ensuring trustworthiness in qualitative research projects. Education for Information, 22, 63-75. Retrieved from www.credo.co.uk/docs/Trustworthypaper.pdf

Shera, J. H. (1967). The sociological foundations of librarianship. New York: Asia Publishing House.

Schrage, M. (1990). Shared minds. New York, NY: Random House.

Solis, J., \& Dabbour, K. S. (2006). Latino students and libraries: A US federal grant project report. New Library World, 107(1/2), 49-62.

Stewart, D. W., \& Shamdasani, P. N. (2015). Focus groups: Theory and practice (3 $3^{\text {rd }}$ ed.). Thousand Oaks, CA: Sage.

Stolz, K. A. (2010). Collaborative partnerships that promote seamless learning for students with disabilities. (Doctoral dissertation). Retrieved from ProQuest. UMI 3435112. 
Streit, M. R., Dalton, J. C., \& Crosby, P. C. (2009). A campus audit of student affairsfaculty collaborations: From contacts to compacts. Journal of College \& Character, 10(5), 1-4.

Strothman, M., \& Antell, K. (2010). The live-in librarian: Developing library outreach to university residence halls. Reference \& User Services Quarterly, 50(1), 48-58.

Suskie, L. (2009). Assessing student learning: A common sense guide. San Francisco, CA: Jossey-Bass.

Swartz, P. S., Carlisle, B. A., \& Uyeki, E. C. (2007). Libraries and student affairs: Partners for student success. Reference Services Review, 35(1), 109-122. doi: $10.1108 / 00907320710729409$

Tenofsky, D. (2007). Teaching to the whole student: Building best practices for collaboration between libraries and student services. Research Strategies, 20, 284299. doi: 10.1016/j.resstr.2006.12.023

Tinto, V. (1987). Leaving college: Rethinking the causes and cures of student attrition ( $2^{\text {nd }}$ ed.). Chicago, IL: University of Chicago.

Trowler, P. (2012). Disciplines and academic practices. In P. Trowler, M. Saunders, and V. Bamber (Eds.), Tribes and territories in the $21^{\text {st }}$ century: Rethinking the significance of disciplines in higher education (pp. 30-38). New York, NY: Routledge.

Walter, S. (2009). Building a "seamless environment" for assessment of information literacy: Libraries, student affairs, and learning outside the classroom. Communications in Information Literacy, 3(2), 91-98. 
Walter, S. (2007). Using cultural perspectives to foster information literacy instruction across the curriculum. In S. C. Curzon \& L. Lampert (Eds.), Proven strategies for building an information literacy program (pp. 55-75). New York, NY: NealSchuman.

Walter, S., \& Eodice, M. (2007). Meeting the student learning imperative: Supporting and sustaining collaboration between academic libraries and student services programs. Research Strategies, 20, 219-225. doi: 10.1016/j.resstr.2006.11.001

Weaver, M. (2013). Student journey work: A new review of academic library contributions to student transition and success. The New Review of Academic Librarianship, 19(2), 101-124. doi: 10.1080/13614533.2013.800754

Weiner, S. (2008). The contribution of the library to the reputation of a university. Journal of Academic Librarianship, 35(1), 3-13.

Whitchurch, C. (2008). Shifting identities and blurring boundaries: The emergence of third space professionals in UK higher education. Higher Education Quarterly, 62(4), 377-396. doi: 10.1111/j.1468-2273.2008.00387.x

Whitchurch, C. (2009). The rise of the blended professional in higher education: A comparison between the United Kingdom, Australia, and the United States. Higher Education, 58, 407-418. doi: 10.10007/s10734-009-9202-4

Whitchurch, C. (2010). Convergence and divergence in professional identities. In G. Gordon \& C. Whitchurch (Eds.), Academic and professional identities in higher education: The challenges of a diversifying workforce (pp. 167-184). London: Routledge. 
Whitchurch, C. (2013). Reconstructing identities in higher education: The rise of third space professionals. London, UK: Routledge.

Whitmire, E. (2004). Campus racial climate and undergraduates' perceptions of the academic library. Portal: Libraries and the Academy 4(3), 363-378.

Whitt, E. J. (2011). Academic and student affairs partnerships. In J. H. Schuh, S. R.

Jones, \& S. R. Harper (Eds.), Student services: A handbook for the profession $\left(5^{\text {th }}\right.$ ed.) (pp. 517-532). San Francisco, CA: Jossey-Bass.

Young, R. B. (1993). Identifying and implementing the essential values of the profession. New Directions for Student Services, no. 61. San Francisco, CA: Jossey-Bass.

Yousef, A. (2010). Faculty attitudes toward collaboration with librarians. Library Philosophy and Practice (e-journal). Retrieved from digitalcommons.unl.edu/libphilprac/512. Paper 512. 